\title{
THE HOKKAIDO-NANSEI-OKI EARTHQUAKE
}

\section{Final Report of the NZNSEE Reconnaissance Team}

\author{
G.W. Butcher', R.D. Beetham ${ }^{2}$, P.J. Millar ${ }^{3}$ \\ and H. Tanaka ${ }^{4}$
}

1

\section{INTRODUCTION}

At $10.17 \mathrm{pm}$ on the evening of 12 July 1993 , an earthquake with a magnitude of 7.8 occurred in the Sea of Japan off the south west coast of Hokkaido, the most northerly of the main Japanese Islands. The earthquake was located at a depth of 10 to $15 \mathrm{~km}$ with its epicentre about $55 \mathrm{~km}$ from the west coast of Hokkaido, and some $75 \mathrm{~km}$ north of the small offshore island of Okushiri. Indications are that the fault ruptured southwards, passing close to the west of Okushiri Island. Sea depth in the epicentral area is about $3,500 \mathrm{~m}$. The location of the epicentre is shown in Figure 1.

The earthquake produced some of the largest tsunamis recorded in Japan with run-up heights of between 10 to $30 \mathrm{~m}$ being measured on Okushiri Island, and almost $10 \mathrm{~m}$ on the west coast of Hokkaido. Most of the loss of life occurred on Okushiri Island as a result of the tsunami, but there was also loss of life due to tsunami on the coastal areas of western Hokkaido and on the Pacific Coast of Russia. The tsunamis caused extensive damage to housing and facilities on the coastal areas of Okushiri Island, Hokkaido and the Russian Pacific Coast. Hundreds of fishing boats were lost or swept out to sea along these coasts and the east coast of South Korea.

Only a small number of structures were damaged or destroyed as a result of ground shaking. Most damage to structures resulted from ground damage such as liquefaction, settlement, and landslides caused by the strong shaking. Substantial damage to port facilities at Hakodate and elsewhere in south-western Hokkaido, some 100 to $170 \mathrm{~km}$ from the epicentre, resulted from extensive liquefaction of deep soft sediments and reclaimed areas formed from harbour sands, silts, and muds.

After reviewing reports of damage received from Japan, and after seeking information from people in the region, the NZNSEE decided to despatch a reconnaissance team to investigate the earthquake, and to identify lessons of value to New Zealand. From the early reports it appeared that there would be particular interest in ground damage, damage to lifelines, fire following earthquake and tsunami, the performance of timber houses, and the effects of tsunami.

Consulting Engineer, Masterton, (Life Member)

Engineering Geologist, Institute of Geological and Nuclear Sciences (Member)

Geotechnical Manager, Tonkin and Taylor Ltd, Auckland (Member)

Senior Lecturer, Civil Engineering Department, University of Canterbury (Member)

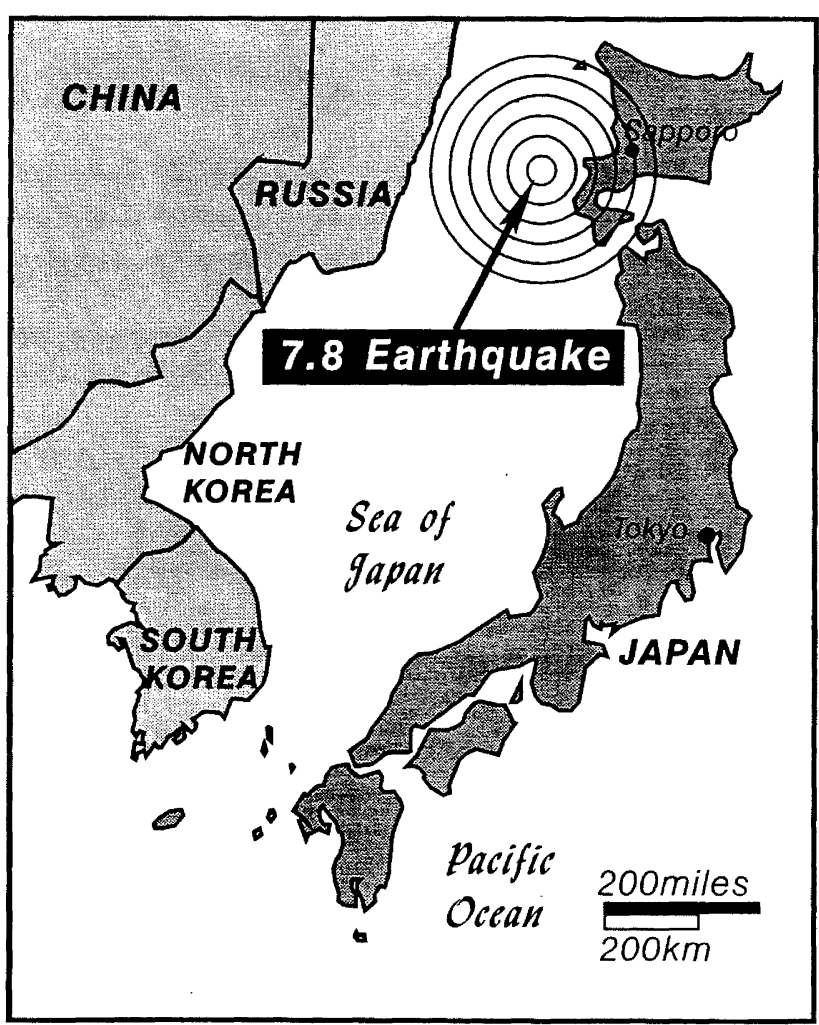

Figure 1 Map showing epicentre

Accordingly, a team of four members of the Society was selected, with emphasis given to the geotechnical, engineering geology, lifelines, and structural disciplines. The team spent 8 days in Japan investigating the effects of the earthquake. After arriving in Tokyo late on the evening of 25 July 1993, two days were taken up with briefings on the latest situation in the damage region, and in gathering information on the earthquake, at the University of Tokyo, the University of Hokkaido and the Hokkaido Development Bureau (HDB) in Sapporo and six days were spent in the field visiting damage areas in southern Hokkaido and Okushiri Island. Details of the reconnaissance programme are given in Appendix 1.

The aim of the reconnaissance was to observe and evaluate the effects of the earthquake; to gain from the Japanese experience of the event; and to assess the implications and lessons for seismic design and earthquake preparedness in New Zealand.

This report presents the observations and comments of the team on what they saw and learned during a brief visit. It 


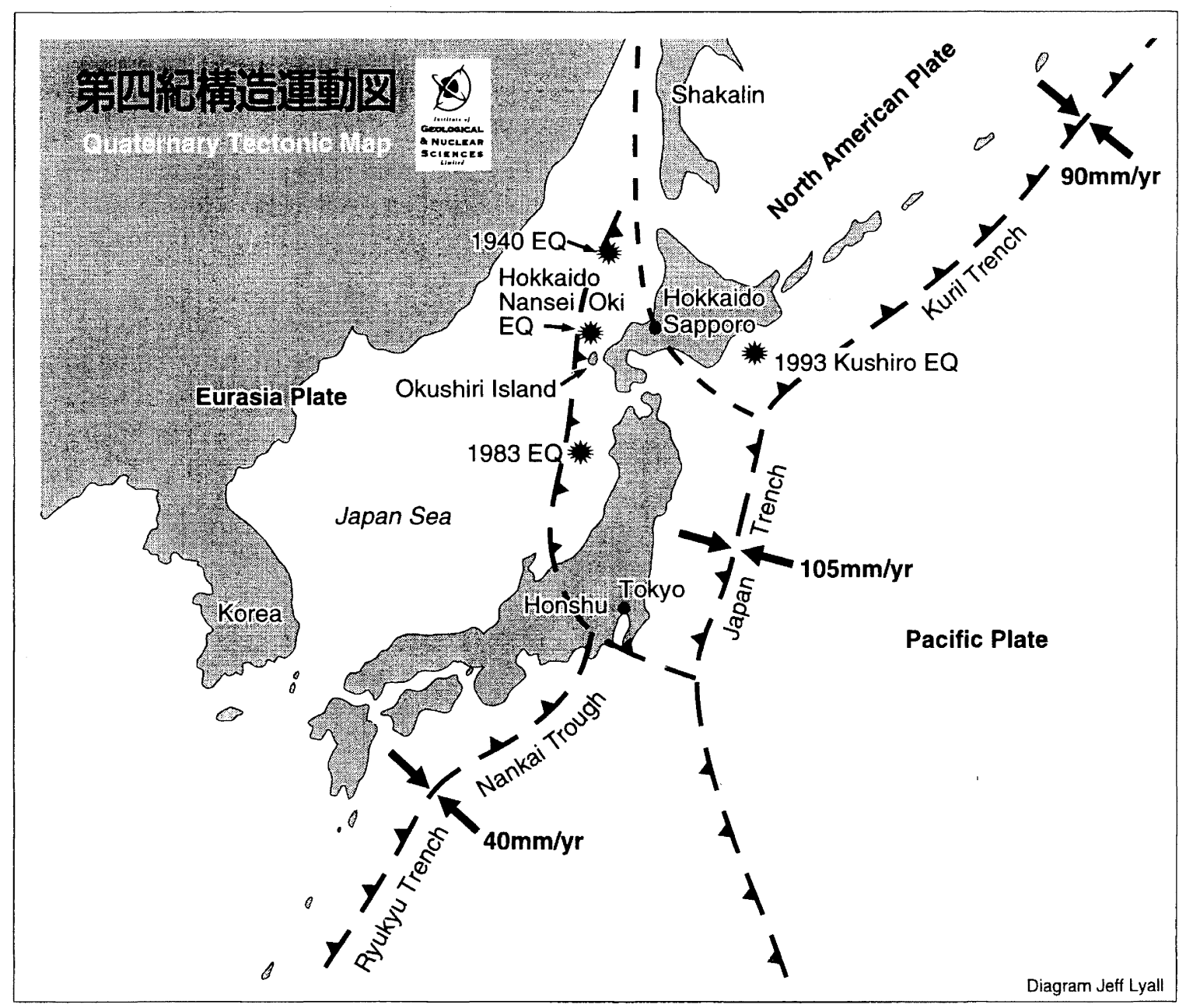

Figure 2 Map showing plate boundaries.

does not claim to be a complete coverage of an important event from which much data and many issues of international importance can be expected to be learned in the next few years.

According to an interim report as of 23 July 1993, the losses due to the Hokkaido-Nansei-Oki earthquake are estimated at 26.7 billion yen (about NZ\$612 million) including the losses in the main island of Honshu. The loss of fish processing facilities in Okushiro-Cho is not included in this estimate due to lack of information.

\section{GEOLOGICAL AND TECTONIC OVERVIEW}

The Japanese Islands are a chain of four mountainous island arc systems stretching along the eastern margin of the Asian continent. These are the Kuril, Northeast Japan, Southwest Japan, and Ryukyu arcs.

They face the Pacific Ocean on their convex (eastern) sides; on their concave sides, the Okhotsk, Japan, and East China seas lie between them and the Asian continent. A further island arc, the Izu-Marinas Arc, joins the main Japanese island of Honshu at the junction between the Northeast and Southwest Japan Arcs. It has the Pacific Ocean to the east and the Philippine Sea on its west. Along the eastern
(Pacific) side of the island arc systems stretch the Kuril and Japan deep sea trenches, the Sugami/Nankai troughs, and the Ryukyu and Marinas trenches (Figure 2).

The deep sea trenches on the eastern side of the Japanese islands form the boundary between the continental crust to the west and the oceanic crust of the Pacific Ocean and the Philippine Sea to the east. At these trenches, the oceanic crust from the east is being subducted beneath the continental crust, with the west dipping subduction interface well defined by small and medium magnitude earthquake hypocentres to a depth of about $600 \mathrm{~km}$. The shallower subduction zone interface is also the area where many of the large magnitude historical earthquakes have, and can be expected to occur (Figure 3). At northern Japan the rate of subduction is approximately $100 \mathrm{~mm} /$ year (Figure 2), about double the maximum rate of subduction of the Pacific Plate beneath the North Island of New Zealand.

Each arc of the Japanese Islands is a geologically complex mountainous chain some $1,000 \mathrm{~km}$ long, 200 to $300 \mathrm{~km}$ wide, forming a gently upwarped zone rising several kilometres above the adjacent, relatively flat sea floor. Where two or more island arcs join, the relative width and height of the islands increase, as is the case with Hokkaido, central Honshu, and Kyushu [1]. Owing to their location at a complex, actively subducting plate margin, the Japanese 


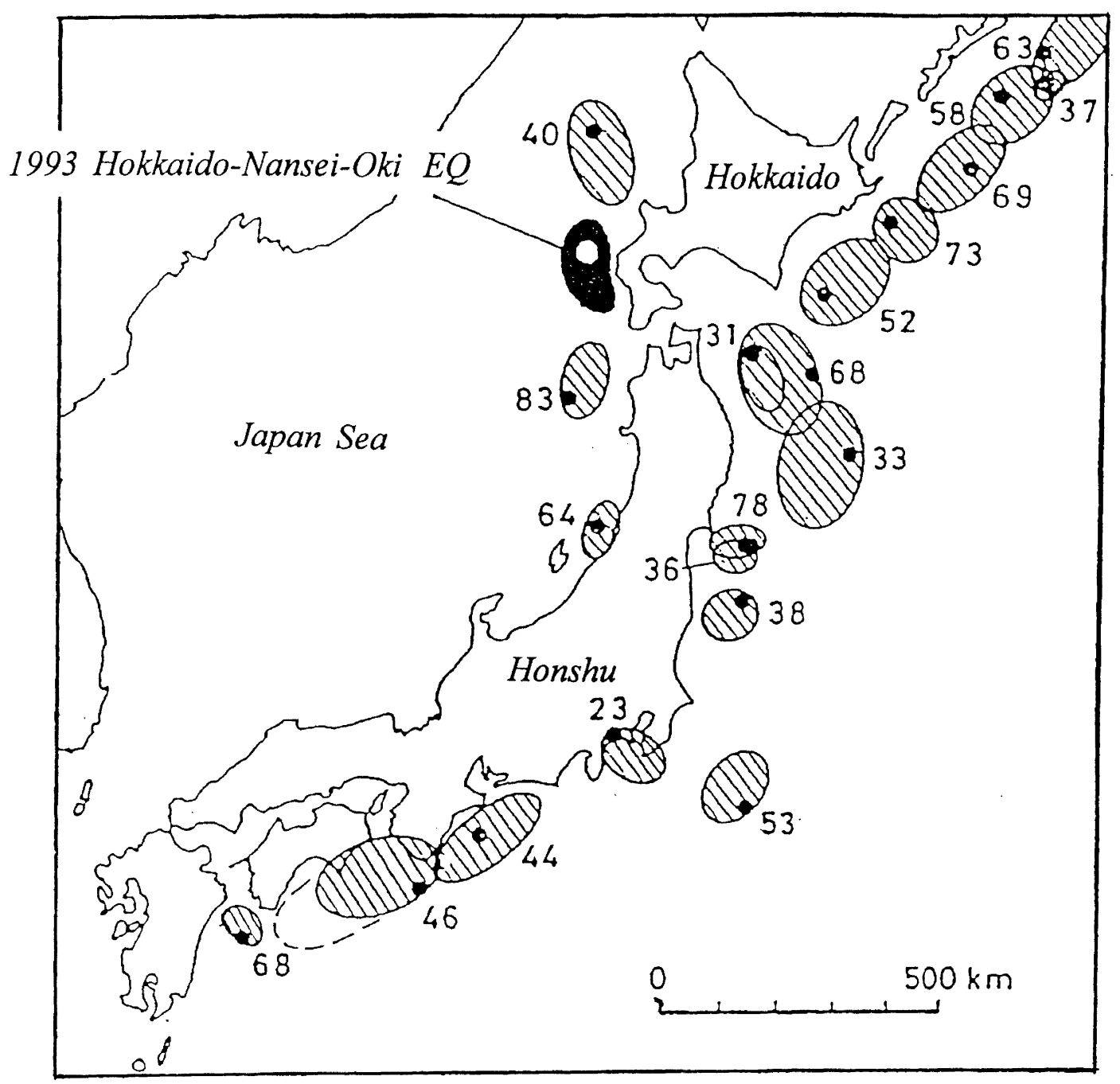

Figure 3 Map showing location of major offshore earthquake rupture zones (M $\geq 7.4)$ off the Japanese islands.

Islands have been tectonically active throughout recent geological times, with frequent dramatic morphological changes caused by earthquakes, volcanic activity, and heavy rainfall. The landforms of Japan are extraordinarily varied, and have a complicated mosaic structure. A large proportion of the landmass is mountainous; plains are scattered along the sea coasts and in basins, with their area forming only about a quarter of the total area of the country. The regional variety of the coastline reflects the complicated geological structure and diversity of landforms.

\section{EARTHOUAKE DESCRIPTION}

\subsection{Earthquake Tectonics}

Off the west coast of northern Japan, the region of the 12 July, Hokkaido-Nansei-Oki earthquake, a new tectonic picture is emerging as a result of the large earthquakes that have occurred beneath the Sea of Japan since 1940. These earthquakes, include the 1983 Nihon-Kai-Chubu event, located immediately to the south of the present epicentre, and the 1940 Shakotan-Oki located immediately to the north (Figure 4). They are considered to have similar magnitudes and mechanisms as the present earthquake, and have led to the suggestion that nascent subduction is occurring along the
Japan Sea coast off Hokkaido and northern Honshu [2 \& 3] The western side of this plate boundary is the Eurasian plate and the eastern side is the North American or newly proposed Okhotsk plate. However, at this stage, it is not clear whether either plate is starting to over-ride the other along a complex, low angle, east and west dipping thrust zone of reverse faulting. A series of uplifted marine terraces are a notable feature of southern Okushiri Island, indicating a regional tectonic model of geologically recent uplift and south-easterly tilting of the island [4]. Ota et al [5] present evidence for some 4.1 to $6.5 \mathrm{~m}$ of uplift of the island in the last 4,000 years. However, there is no bathymetric evidence yet of the development of a trench along the newly proposed plate margin. Rather, extensive marine seismic surveys carried out by the Japan Maritime Safety Agency following the earthquake [ $6 \& 7$ ], together with other recent work [8], reveals extensive imbricate thrust faulting of the sea floor and underlying sediments in the region.

The most recent earthquake has caused westwards lateral movement of Okushiri Island relative to Hokkaido mainland of over a metre, southwards tilting, and subsidence of Okushiri Island, locally measured to be as much as $790 \mathrm{~mm}$ near Aonae. However, detailed surveys of the seismic deformation are in the process of being carried out on both Hokkaido and Okushiri Island. Furthermore, it is possible 
that there has and could be some recovery of the initial tectonic deformation.

\subsection{Earthquake Mechanism and Faulting}

The earthquake occurred on July 12 at 22:17 local time (13:17 UT), at latitude $42.84^{\circ} \mathrm{N}$ and longitude $139.25^{\circ} \mathrm{E}$, and at 10 to $15 \mathrm{~km}$ depth [9]. Subsequent to the main shock, a large number of aftershocks have been recorded and accurately located. Based on studies of long and short wave records of the earthquake, the distribution of aftershocks, and detailed sea floor seismic refraction profiling in the fault rupture area, a complex two or three plane rupture surface has been derived. Variable low angle $\left(25-35^{\circ}\right)$, westwards dipping planes outlined by an area some $150 \mathrm{~km}$ long, northsouth, and $50 \mathrm{~km}$ wide, east-west, are defined by the aftershocks, with most of the aftershock hypocentres occurring at less than $20 \mathrm{~km}$ depth [7]. A seismic moment of $5.6 \times 10^{27}$ dyne cm corresponds to a moment magnitude (Mw) of 7.8. Based on the aftershock data, assuming a fault length of about $150 \mathrm{~km}$ and width $50 \mathrm{~km}$, the moment and fault geometry indicates an average slip on the fault planes of 2.5 $\mathrm{m}$. The most recently available focal mechanism derived in Japan [7] has a complex, west dipping rupture surface with dominant propagation of the rupture southwards past Okushiri Island. This interpretation is consistent with the accurately located aftershock distribution (Figure 5), and the attitude of the faults located in the sea bed by the seismic refraction profiling carried out in the mesoseismic area of the Sea of Japan immediately after the earthquake. A shallow focal depth for the main shock, and significant displacement of a large area of sea floor, is required to generate the devastating tsunamis that afflicted the region following the earthquake.

\subsection{Strong Ground Motion}

Strong ground motions from the earthquake were recorded by numerous agencies (the Hokkaido Development Agency, the Japan Meteorological Agency, the Ports and Harbours Research Institute, Japan Rail, the Ministry of Construction, and others). Although there were no strong motion recorders located in the epicentral area of Okushiri Island or on the immediately adjacent western coast of Hokkaido, there appear to be many records available from more distant stations. An example from Hakodate, some $170 \mathrm{~km}$ from the epicentre, is presented (Figure 6). At Hakodate the strong motion recorder is located near the port wharves on $70 \mathrm{~m}$ of soft soils above bedrock, and the strong motion record, with a peak horizontal acceleration of $0.2 \mathrm{~g}$, appears to reflect this. The duration of strong shaking is more than $60 \mathrm{~s}$, the peak acceleration appears to coincide at $47 \mathrm{~s}$ for all three components, and the natural period of the soft site is about $3 \mathrm{~s}$.

The recorded duration of strong shaking at sites within 100 $\mathrm{km}$ of the rupture surface was approximately $1-2$ minutes. The highest peak horizontal acceleration of $0.5 \mathrm{~g}$ was recorded at Kuromatsunai, midway between Suttsu and Oshamanbe, some $80 \mathrm{~km}$ from the nearest point on the fault. This recording apparently had an unusually large ratio of peak horizontal to vertical accelerations (by a factor of about 5)[6]. Suttsu which is a similar distance from the fault, had a peak horizontal acceleration of about $0.2 \mathrm{~g}$ and a higher intensity of shaking.

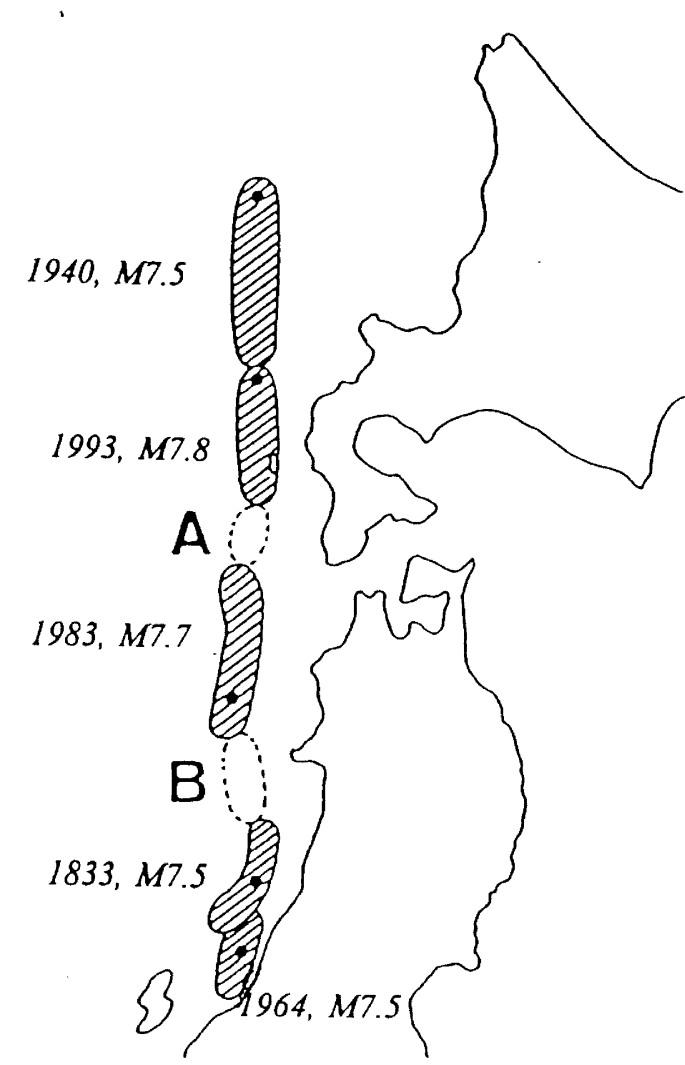

Figure 4 Map showing earthquake nupture zones in the Sea of Japan.

Okushiri Island lies close to the south eastern margin of the main rupture surface outlined by the aftershocks, and this surface appears to lie some 10 to $20 \mathrm{~km}$ to the west of the island. At Aonae cemetery at the south end of the island, some $80 \%$ of the tombstones were overturned, and in houses, furniture was overturned. According to investigators at Tokyo and Hokkaido Universities, the overturned tombstones indicate peak horizontal accelerations greater than $0.2 \mathrm{~g}$ and possibly reaching $0.4-0.5 \mathrm{~g}$. At the Aonae concrete batching plant located near to the cemetery, the main batching plant tower structure was damaged (Section 4.2 .4 following), and recent stockpiles of dumped crushed aggregate chip that were initially at their static angle of repose had been flattened into more gently inclined heaps by the strong shaking during the earthquake. Measurement of the flattened slope angle compared to the static angle of repose allows an estimate of peak ground acceleration to be derived. In this case the slope angle measurements indicated a peak horizontal acceleration of $0.26 \mathrm{~g}$, a value that fits well on Campbell's curves [10] for a magnitude 7.8 earthquake (Figure 7) and the acceleration values estimated by similar methods for the Edgecumbe earthquake [11] assuming a fault distance of 25 $\mathrm{km}$ (the distance from the site to the rupture surface).

On the main island of Hokkaido, in the area closest to the fault zone between Esashi and Iwanai, there was no major structural damage, few gravestones were overturned, and few household furniture items were displaced, indicating that ground motions were significantly less severe than at Okushiri. 

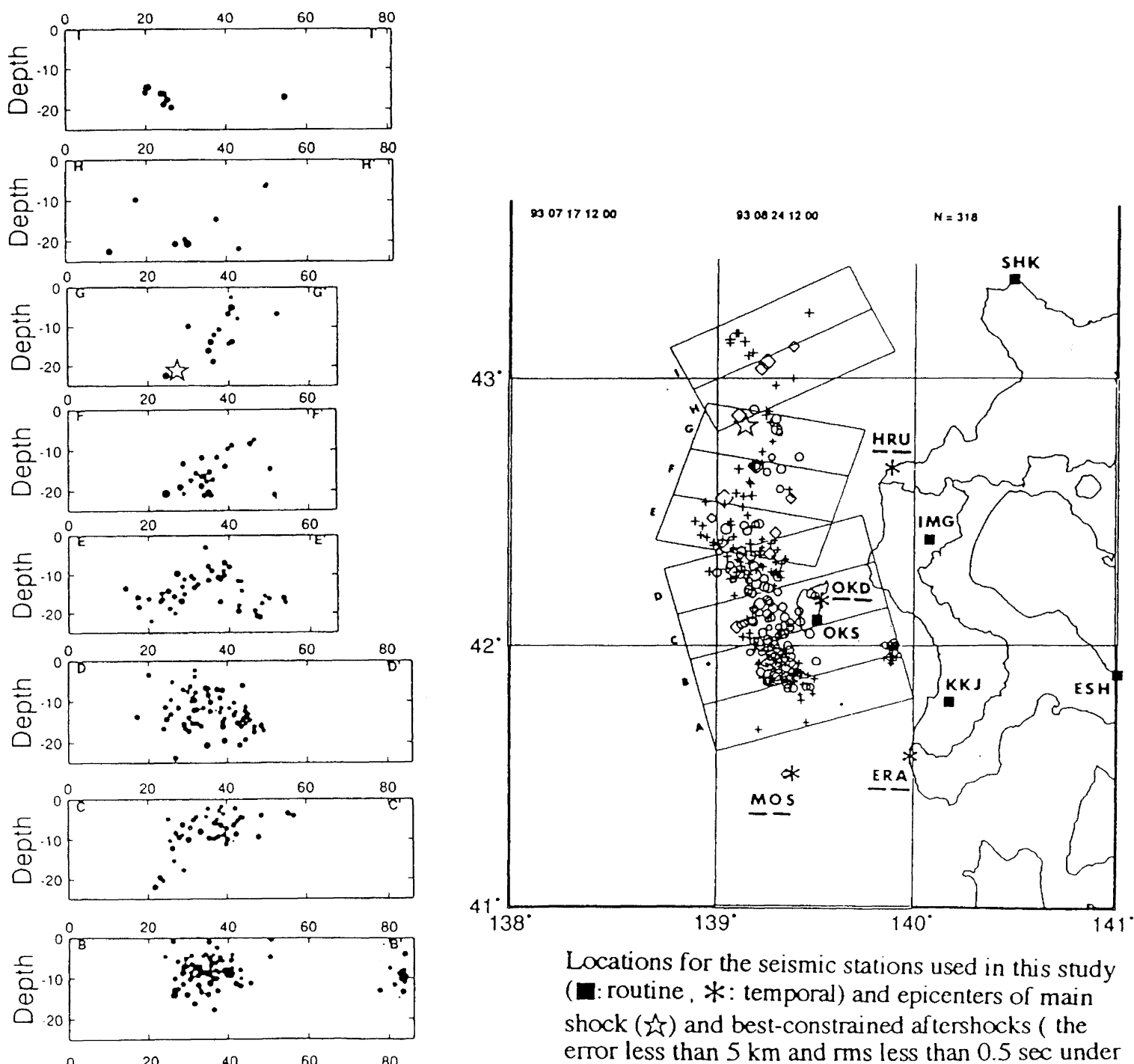

Locations for the seismic stations used in this study

(范 routine, *: temporal) and epicenters of main shock ( $\hat{2} \overrightarrow{5}$ ) and best-constrained af tershocks ( the error less than $5 \mathrm{~km}$ and rms less than $0.5 \mathrm{sec}$ under the homogenious station conbination) from July 17 . August 24, 1993.

Figure 5 Plan showing locations of seismic stations and best constrained aftershocks. The vertical cross-sections show hypocentres for each rectangular area shown on the plan (source [7]).

\subsection{Intensity}

Earthquake shaking intensities in Japan are traditionally recorded in the seven level JMA scale (see Appendix 4 for JMA scale descriptions and their assessed correlation with the Modified Mercalli (MM) Intensity scale). The greatest intensities recorded on Hokkaido due to the Hokkaido Nansei - Oki earthquake were JMA 5 on the western coast of southern Hokkaido and northern Honshu (Figure 8), the land areas closest to the rupture zone. For some reason there is no record of a JMA intensity for Okushiri Island, the land area which is closest to the rupture zone, and obviously the inhabited area that received the highest intensity shaking. However, using published $\mathrm{MM}$ intensity attenuation relationships, and the JMA intensities recorded for the earthquake, approximate MM intensities for the earthquake can be constructed (Figure 8). It is estimated that MM 10 intensity could be felt up to $30 \mathrm{~km}$ from the rupture plane (in this case taken as $30 \mathrm{~km}$ from the north - south projection of the centre line of the area of aftershocks), MM 9 intensity 45 to $60 \mathrm{~km}$, MM8 intensity 65 to $95 \mathrm{~km}, \mathrm{MM} 7$ intensity 105 to $155 \mathrm{~km}$, and MM 6 intensity 195 to $235 \mathrm{~km}$. Using the average of these ranges modified by the recorded JMA intensities converted to the MM scale, it can be seen that the intensity on Okushiri Island may have reached MM 10, while the intensity on the main islands was not greater than MM 8 , and the MM 7 isoseismal did not extend much to the east of Hakodate and Lake Toya (Figure 8). It is noted that all ground failures (landslides, liquefaction and subsidence) attributed to the earthquake occurred at intensities of MM 7 or greater.

\subsection{Seismology}

Both seismographs and strong motions of earthquakes in Japan are recorded by many agencies. The predominant 
22:17 1993/07/12 M=7.8 SMAC-MD HKD:Construction Office
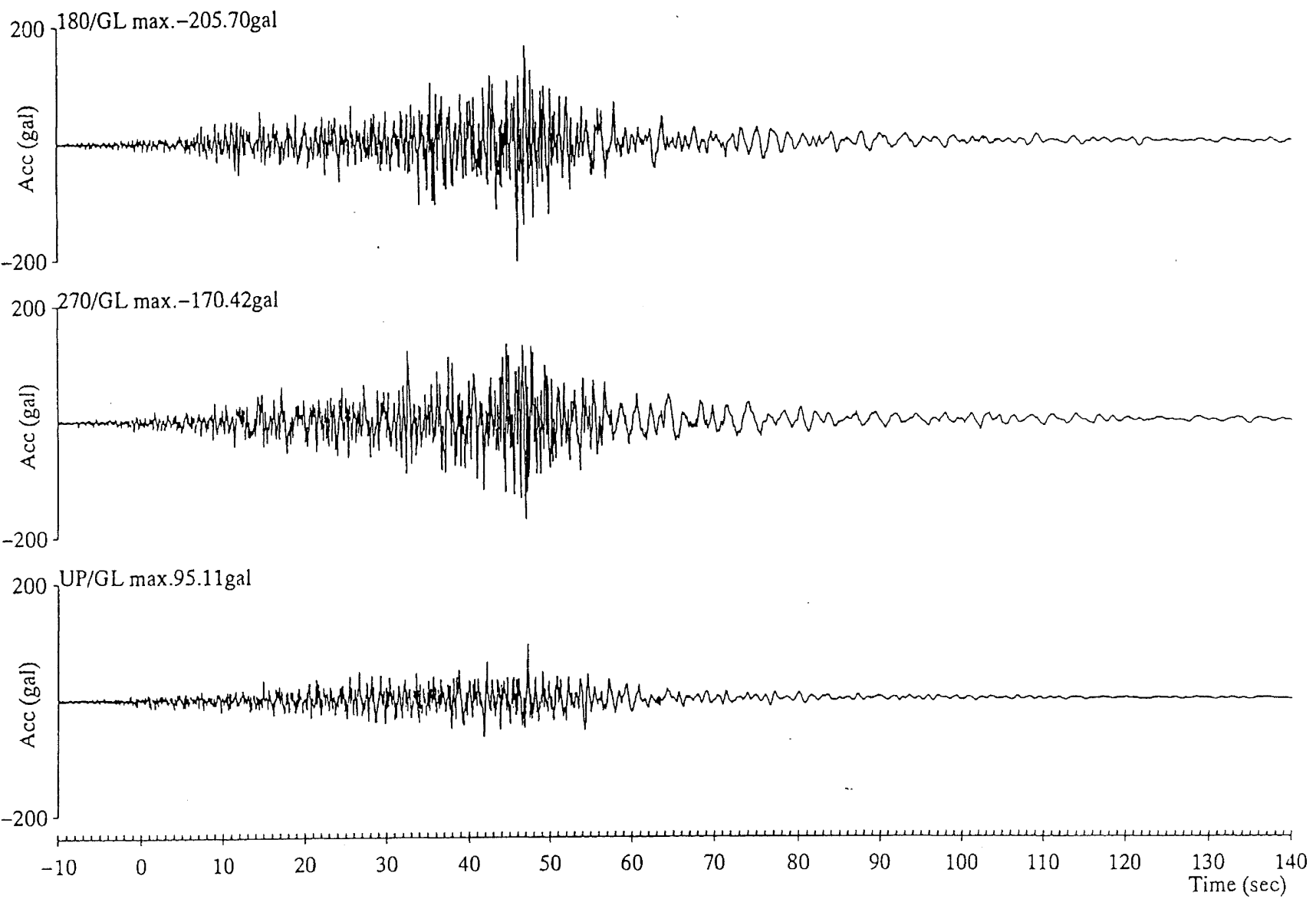

Figure 6 Strong motion record of the Hokkaido-Nansei-Oki earthquake recorded at Hakodate Port.

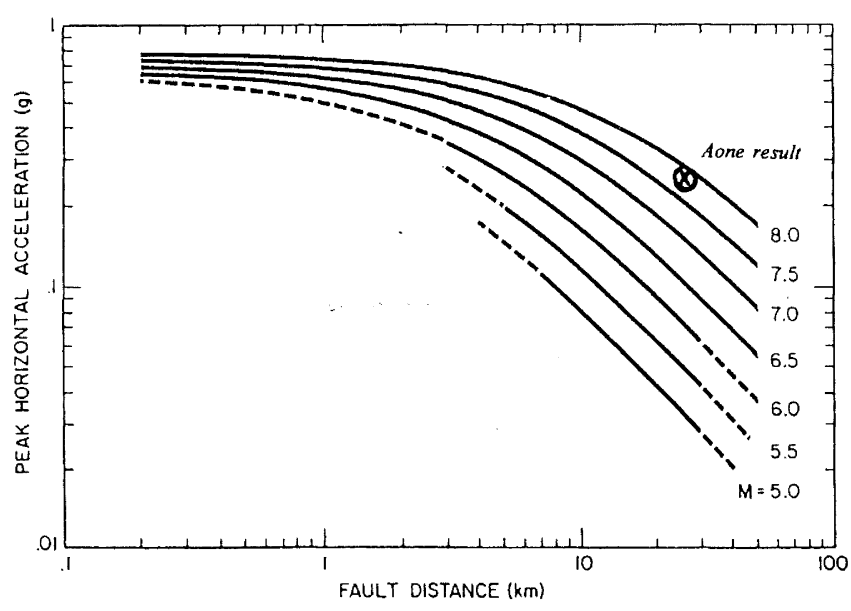

Figure 7 Fit of Aonae result to Campbells attenuation curve. agency operating a seismograph network throughout the country is the Japan Meteorological Agency (JMA). Strong ground motions are recorded by a wider group (Section 3.3 above), however there appears to be a good system in operation for data sharing between these organisations and the universities, who were playing an important active role as a data receiving and transfer stations after the earthquake, and helping to co-ordinate reconnaissance activities. Since the earthquake there has been much work carried out on the source mechanism of the main shock, and the accurate locations of the aftershocks (Section 3.2 above \& [7]).

\section{OBSERVED EFFECTS}

\subsection{Geotechnical}

While there were only infrequent cases of structural damage directly attributable to strong earthquake shaking, there was a considerable amount of ground damage and ground induced damage to structures.

Ground damage can generally be characterised as the following types:

- $\quad$ landslide

- liquefaction

- $\quad$ subsidence (often in association with liquefaction). 


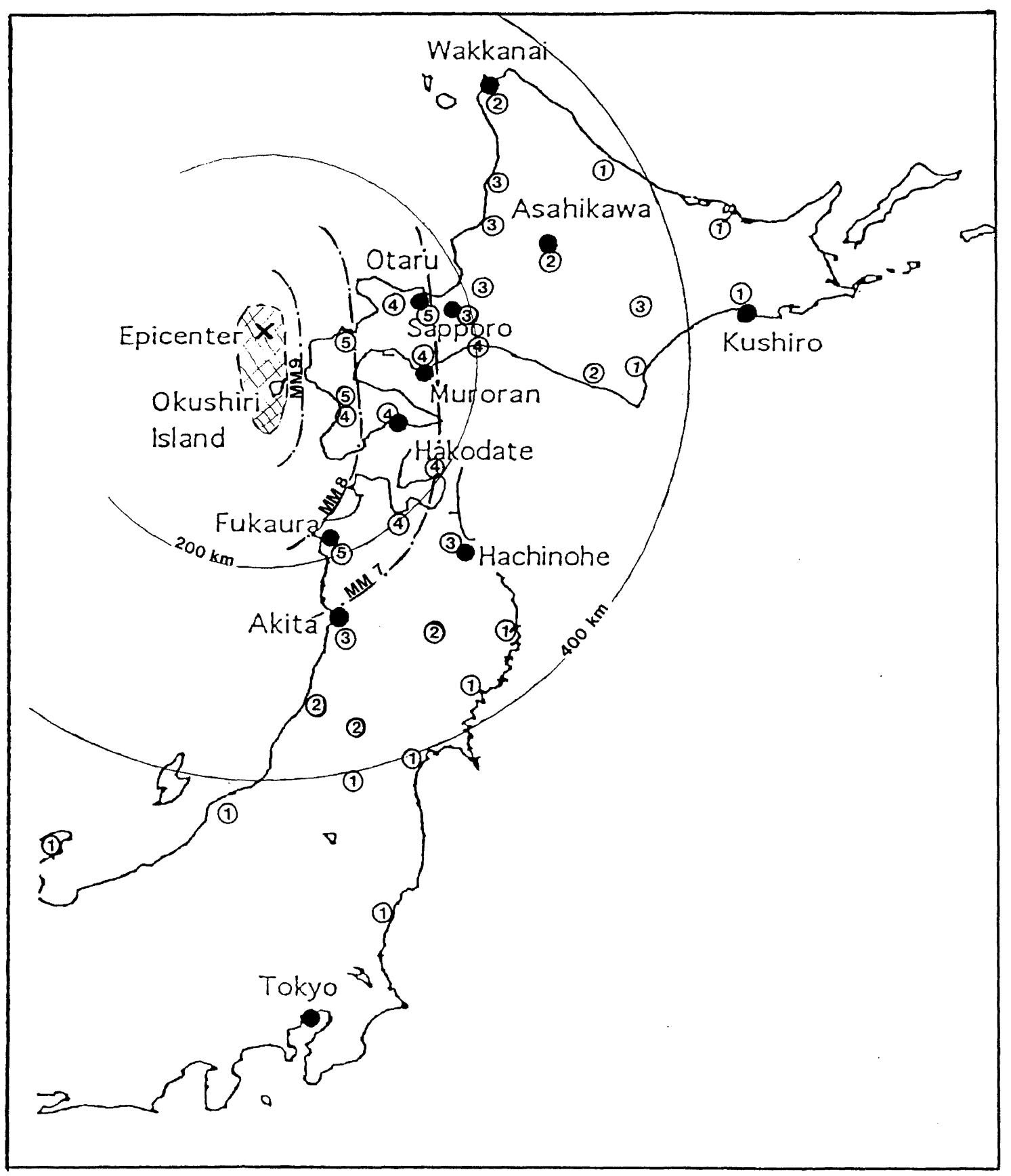

Figure 8 JMA intensities (circled numbers) and estimated MM intensities for the Hokkaido-Nansei-Oki earthquake.

\subsubsection{Landslides}

The majority of landslides that were triggered by the earthquakes were rock falls and slides on the steep coastal slopes of Okushiri Island and the west coast of the south western peninsula of Hokkaido. These slopes comprised volcanic breccia, tuffaceous sandstone, andesite lava and granodiorite from which large joint controlled blocks of rock were loosened by the shaking. The affected slopes generally exceeded $60^{\circ}$ and were typically about $100 \mathrm{~m}$ in height. It is likely that the stability of many of these slopes was marginal and that the earthquake triggered slides of previously loosened rock.

Talus shelters, concrete gravity walls and wire meshing have been constructed to provide protection to traffic along lengthy sections of roadways constructed at the foot of the steep slopes. The scale of these works reflects the regular occurrence of very high intensity rainfall during typhoons, the hazards of ice and snow and freeze-thaw, and the high commitment to protect life. However, the performance of the systems was variable and in some places inadequate due mainly to the size of the rock debris caused by the earthquake. The mesh provided little effective containment and was readily torn by the larger rock falls. The benefits of the light mesh system is questionable for earthquakes, but may have been more effective if an increased number of reinforcing cables were included. Its effectiveness is currently limited to stopping smaller pieces of fretting rock debris.

The gravity walls are unreinforced and were occasionally overturned or shattered by the rock falls. Their performance 


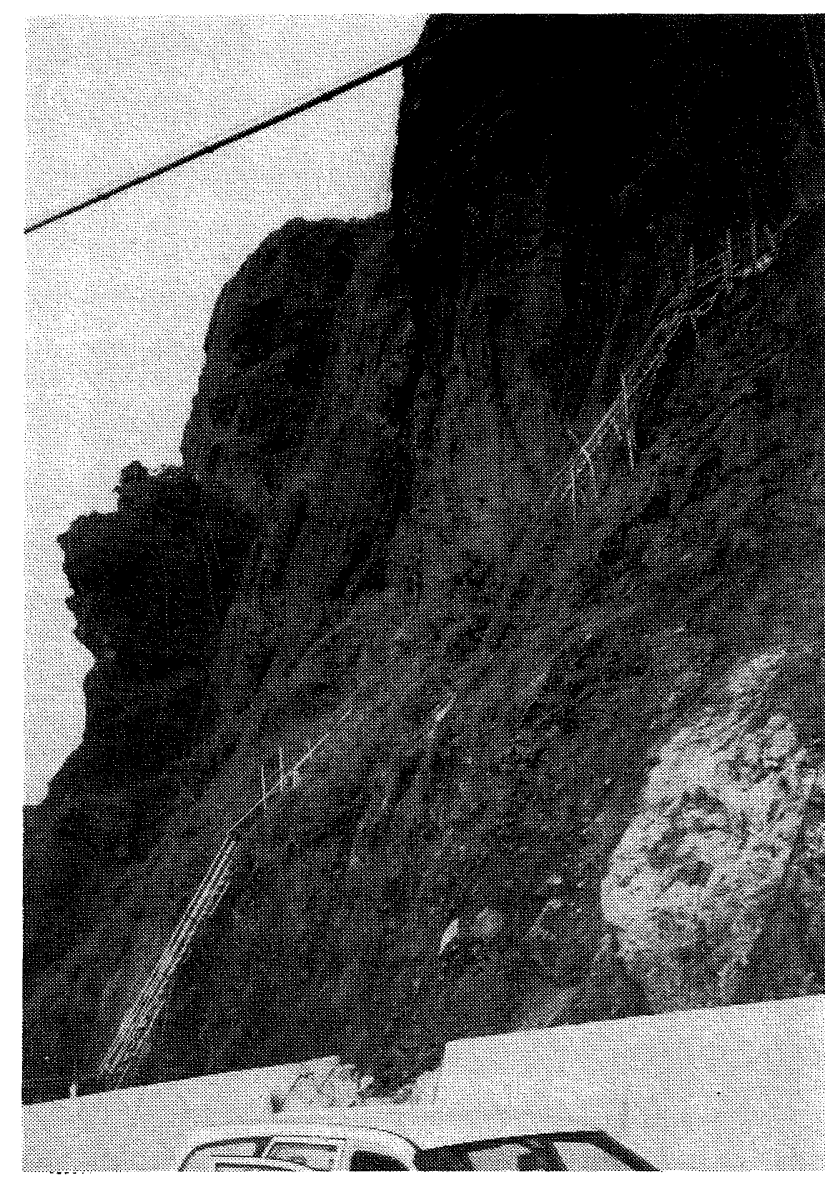

Figure 9 Okushiri West Coast Road Slope protection meshing. Access scaffolding and wall damaged by debris

could be significantly improved if they were reinforced and a holding down system was included (Figure 9).

The talus shelters are more substantial engineering structures and provided a much higher level of protection. When damaged by large blocks, as occurred at the Shiraito tunnel on Highway 229 north of Setana, access for repair may be difficult. This section of the road was still closed to normal traffic four weeks after the earthquake (Figure 10).

The above comments indicate that the cost effectiveness of rock slope protection works need to be carefully considered. Low cost options may only offer very limited protection and the risks involved in installation and delays in reinstatement need to be evaluated, particularly on lowly trafficked roads.

The largest landslide caused by the earthquake occurred at Okushiri Port, an area of MM 9 intensity shaking, where an $100 \mathrm{~m}$ high, $800 \mathrm{~m}$ wide translational slide of tuffaceous sandstone with an estimated volume of $800,000 \mathrm{~m}^{3}$ [6] occurred in a $60^{\circ}$ slope (Figure 11). The slide buried the Yoyoso Hotel killing 26 of the 37 guests. An $800 \mathrm{~m}^{3}$ kerosene oil tank which was half full was also destroyed but the kerosene was contained by a concrete bund. The slope had previously been steepened by cuts at its base and the remains of retention walls could still be observed at the edge of the slide. Yamazaki F et al [12] report that the slope was previously identified as a stability hazard.

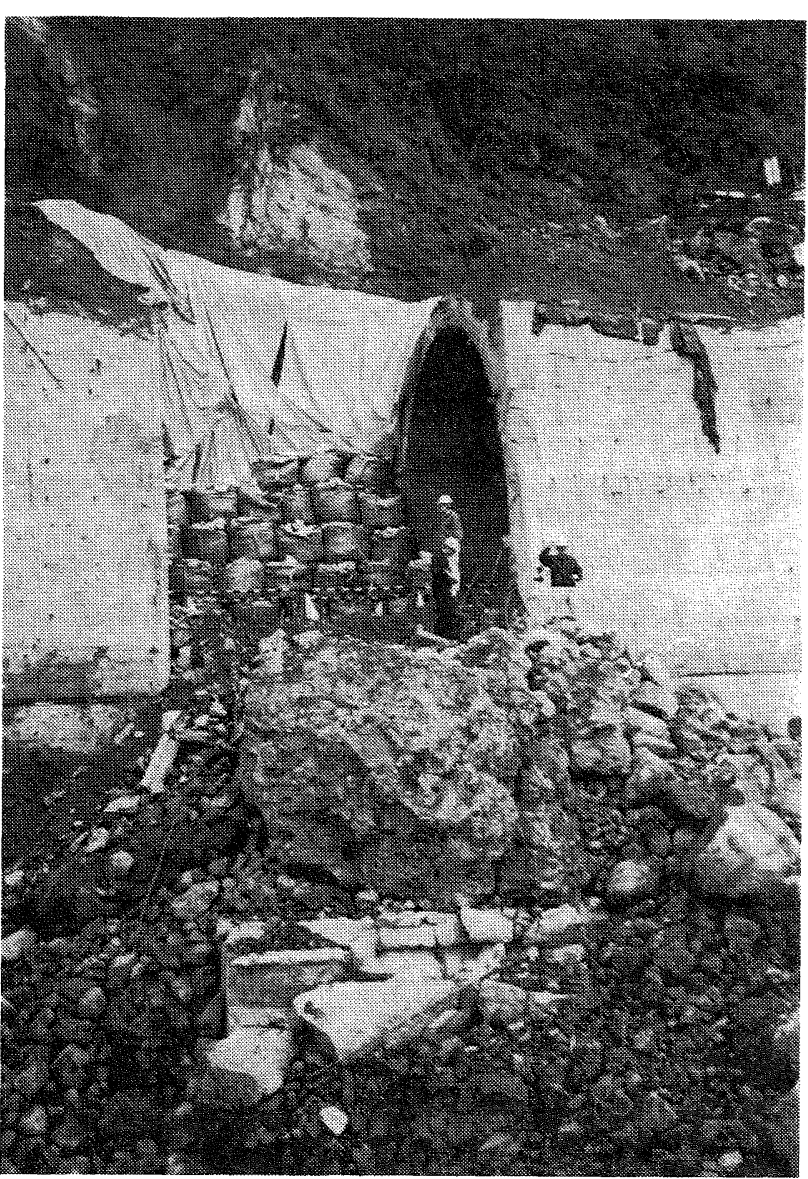

Figure 10 Shiraito No. 2 Tunnel, Shimamaki-Mura. Collapsed section.

In southern Hokkaido a slump developed on a road embankment on Highway 5, $10 \mathrm{~km}$ north-west of Oshamanbe in an area of MM 8 intensity shaking. The nearby railway embankment was also affected by the slump failure. The mechanism of failure has been identified as a rotational failure with the head of the failure at the road while the railway was close to the toe. The underlying soils are wet, marshy deposits accumulated near the toe of the slope. These materials appear to have been softened during the earthquake. During inspection of the site, evidence of progressive creep movements was noted with rotation of tree trunks and shape correction works of the road surface. It is apparent that the earthquake caused a rapid failure of an area undergoing incipient creep failure.

Also in Hokkaido within the MM 7 isoseismal near Lake Toya, a landslide failure of a very steep, $5 \mathrm{~m}$ high stream bank was inspected on the edge of a sandy tephra deposit. This area had been planted in celery and was subject to heavy irrigation which may have resulted in saturation of the soil prior to failure during the earthquake. The wet, mobile debris exhibited a lengthy runout distance along the edge of the stream.

Other minor slumping was observed in highway cuts, often where previous stabilizing works had been undertaken, suggesting that ground conditions were only marginally stable prior to the earthquake. 


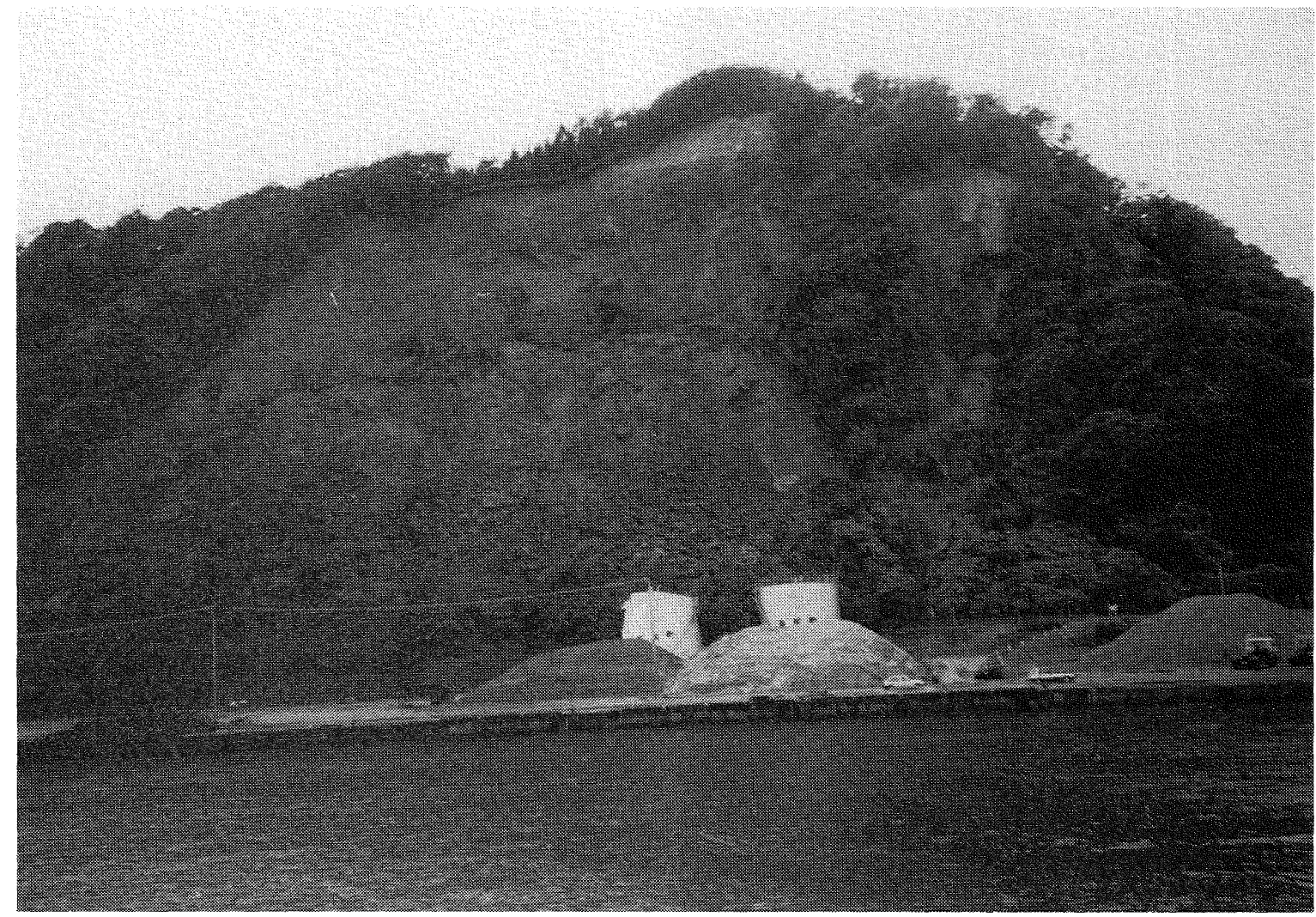

Figure 11 Okushiri Feny Port. The earthquake induced landslide that buried the Yoyaso Hotel and damaged kerasine tanks.

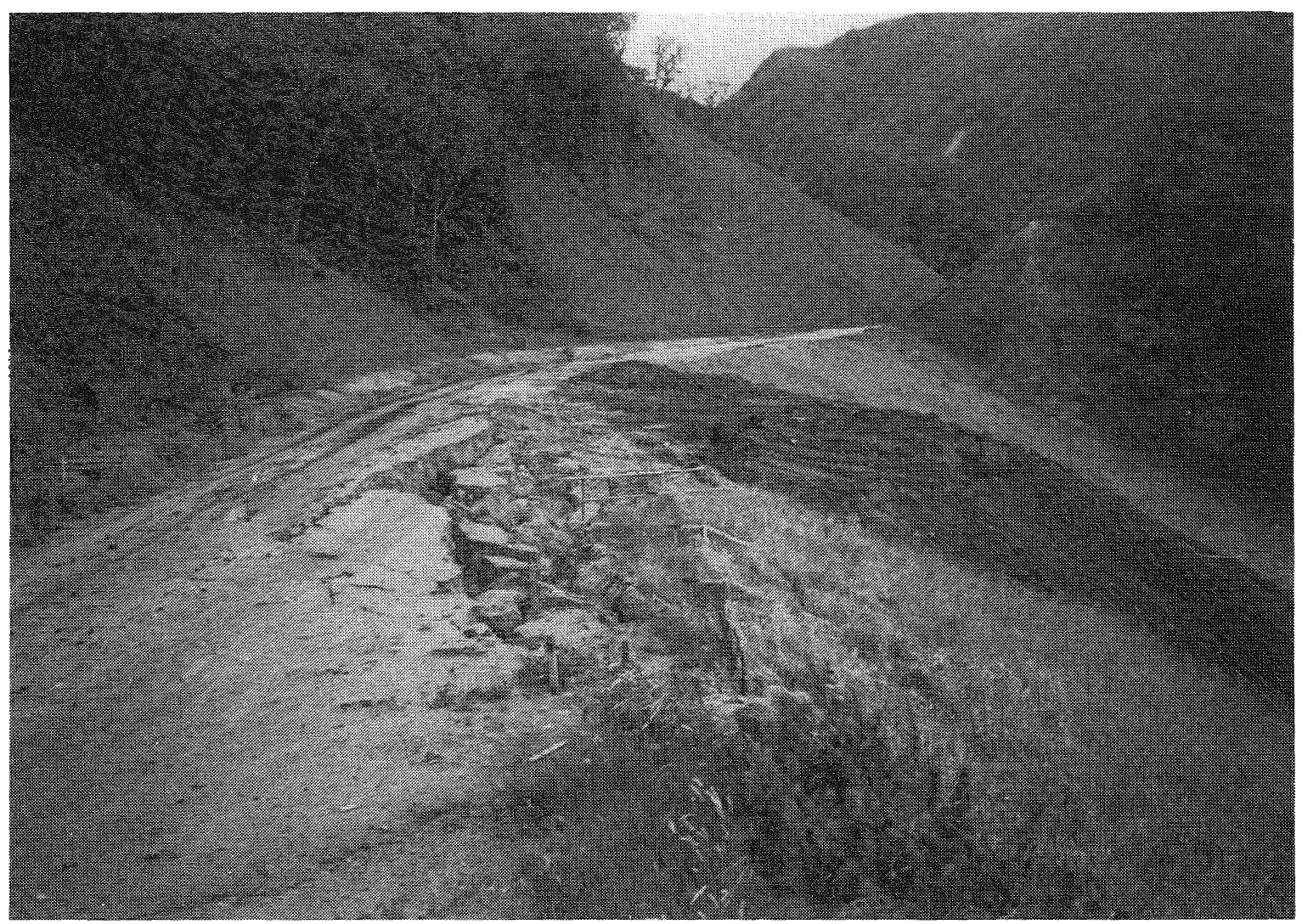

Figure 12 Horonai, Okushiri Island. Shumped sidling fill 
In general, few significant landslides were observed in areas of cut slopes in residual soils. Extensive revetments have been constructed, and steel framed debris traps installed on road cuts and behind at-risk properties, but these were not tested. An exception to this occurred at Horonai on the west coast of Okushiri Island, an area where MM 10 intensity shaking may have been reached. A number of large rotational landslides in steep forested land were observed in the residual granodiorite soils on the north (shady) facing slopes of the valley in which a newly constructed bridge is being completed. A sidling approach embankment constructed using the residual soils had also slumped (Figure 12) and the shallow founded face walls to the bridge approach at the north end had failed (Figure 13). Surficial landslips had occurred in a scarp of a previous failure where the surface drainage collection systems were overwhelmed by small mudflows. These soils were observed to have a high water content and are likely to be very sensitive.

\subsubsection{Liquefaction and Ground Softening}

Liquefaction ground damage was widespread on the alluvial plains of south west Hokkaido and in areas of reclamation at several ports causing substantial damage to services, flood control stopbanks, bridge approaches and to quay walls. Liquefaction induced damage to buildings was uncommon, with most well built structures suffering no significant effects. However there were some notable exceptions which are discussed in more detail later.

On Okushiri Island, isolated areas of liquefaction induced damage were observed at Okushiri port and evidence of sand boils that caused minor subsidence was seen in the oil storage tank compound. Depressions in the concrete slabs and rotation of a bulkhead to the south of the ferry terminal were also thought to be the result of liquefaction.

The snow shelter north of Aonae is constructed on a raised beach terrace where loss of strength of subsoils and lateral spreading of road embankment fills inside the shelter, resulted in rotation and overturning of the shelter arch support walls.

At Horonai, "liquefaction" (cyclic mobility) of the alluvial soils in the river valley caused lateral spreading and cracking of the road embankment.

Extensive areas of liquefaction occurred in the fine grained soils in the Shiribetsu and Shiribeshi-Toshibetsu River valleys on the south west coast of Hokkaido. The Shiribetsu River has a 100 year return period flood flow of 3,000 cumecs and the Shiribeshi-Toshibetsu River 1,200 cumecs. The flood protection stopbanks on the rivers were extensively damaged, with lengths of $2.3 \mathrm{~km}$ and $6.5 \mathrm{~km}$ respectively severely affected by loss of support in the liquefied foundation soils. This caused longitudinal cracking at the crest, slumping of the side slopes, settlement of the embankments (up to $2 \mathrm{~m}$ ) and cracking and heaving at the toe. Some cracking of the riverbanks was also observed. Discussions with the River Planning Section of the HDB determined that the stopbanks had been progressively constructed and developed, and that a programme of upgrading works was being undertaken. However the quality of some sections remained poor and planned toe blankets in areas of sand filled oxbows had not yet been constructed. The foundation soils in these areas typically exhibit SPT 'N' values of $2-3$ in the sands and up to 10 in the gravels. Temporary repairs involving

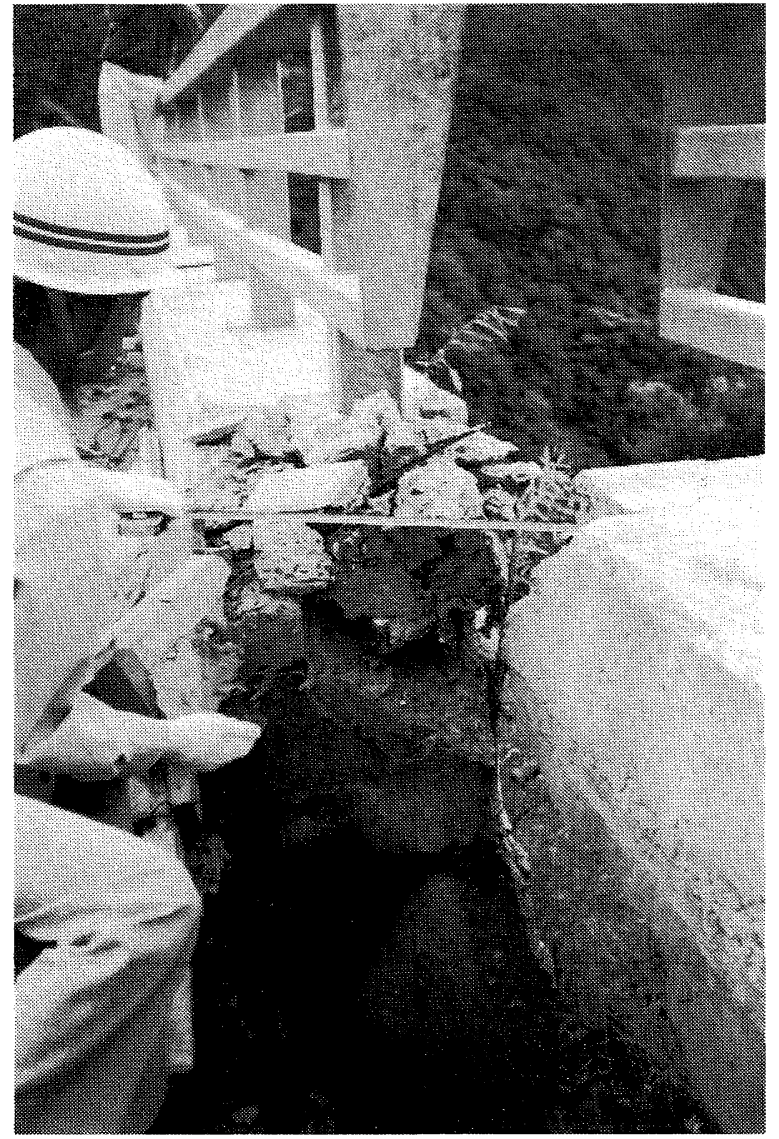

Figure 13 Horonai No 2 Bridge, Okushiri Island Slump failure of shallow founded face wall to northern bridge approach

impermeable surface cover membranes had been installed within two to three days of the earthquake, and a comprehensive 6 month repair programme was in progress (Figure 14). This includes the construction of temporary sheet pile walls over much of the length of the repairs (Figure 15).

The three year old Pirika Dam located within the MM 7 isoseismal on the Shiribeshi-Toshibetsu River was undamaged. The dam is a combined, irrigation storage and power generation (capacity $4 \mathrm{MW}$ ) facility and is of earth and concrete construction.

Elsewhere in the flatter gradient, coastal sections of river valleys, ground fissuring and lateral spreading of rice fields were observed with up to $2 \mathrm{~m}$ wide rifts developed. Translational movements of the ground could also be seen in displacements of the road where sand filled ox-bows passed beneath the pavement. The extent of damage to the services in these valleys has been relatively light, with some water and sewer lines fractured. A number of manholes were also observed to have floated relative to the ground surface.

Many bridge abutments also showed evidence of settlement and slumping of the approaches. However these had quickly been repaired. Minor damage to bridge bearings occurred due to the large cyclic displacement movements of the abutments relative to the spans during the earthquake. For example at the Yanagizaki Bridge, located close to the MM 7 - MM 8 intensity change North of Esashi, where the bridge 


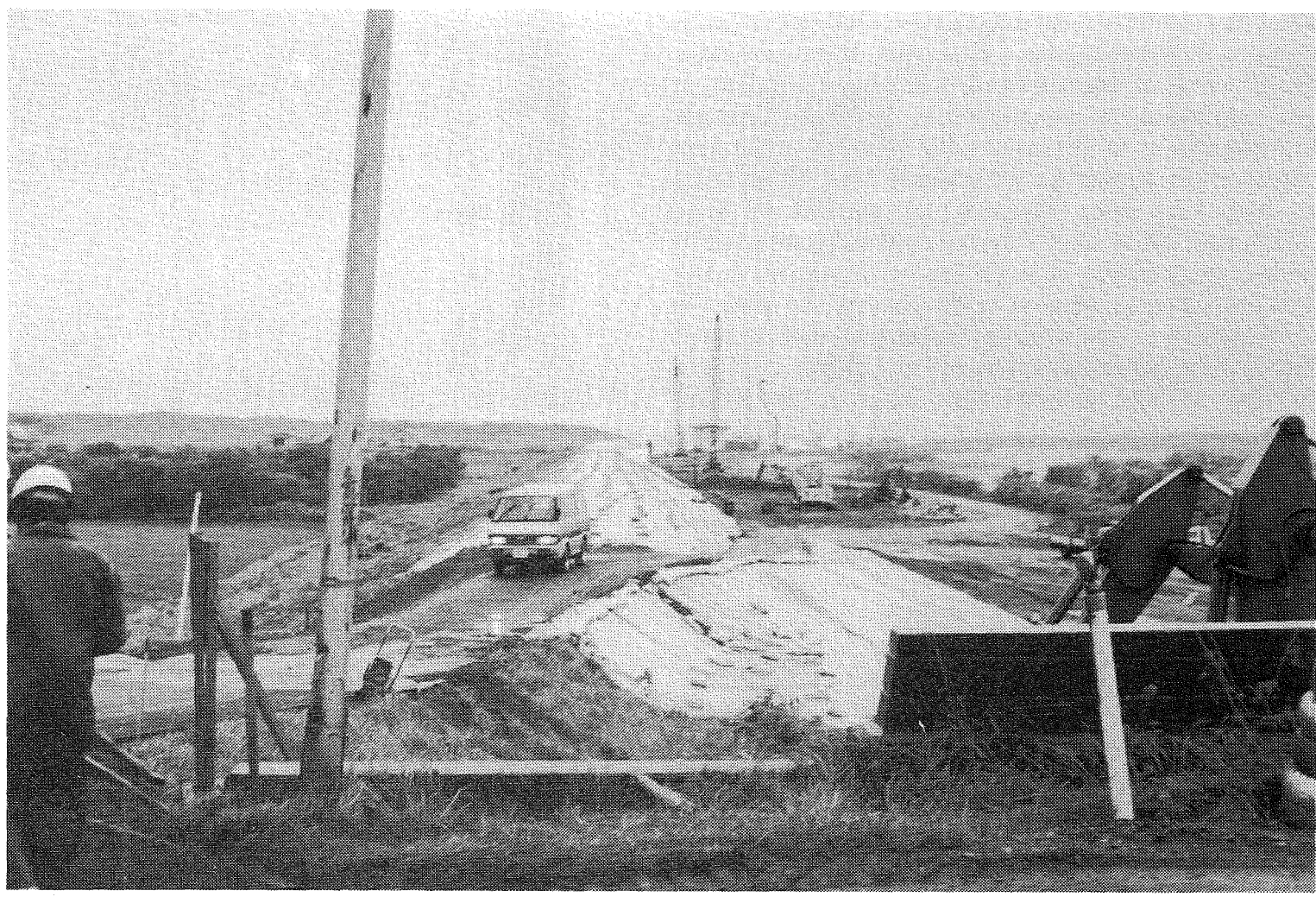

Figure 14 Shiribeshi-Toshibetsu River. Stopbank temporary repairs showing surface protection, and sheetpiling works in progress in the background.

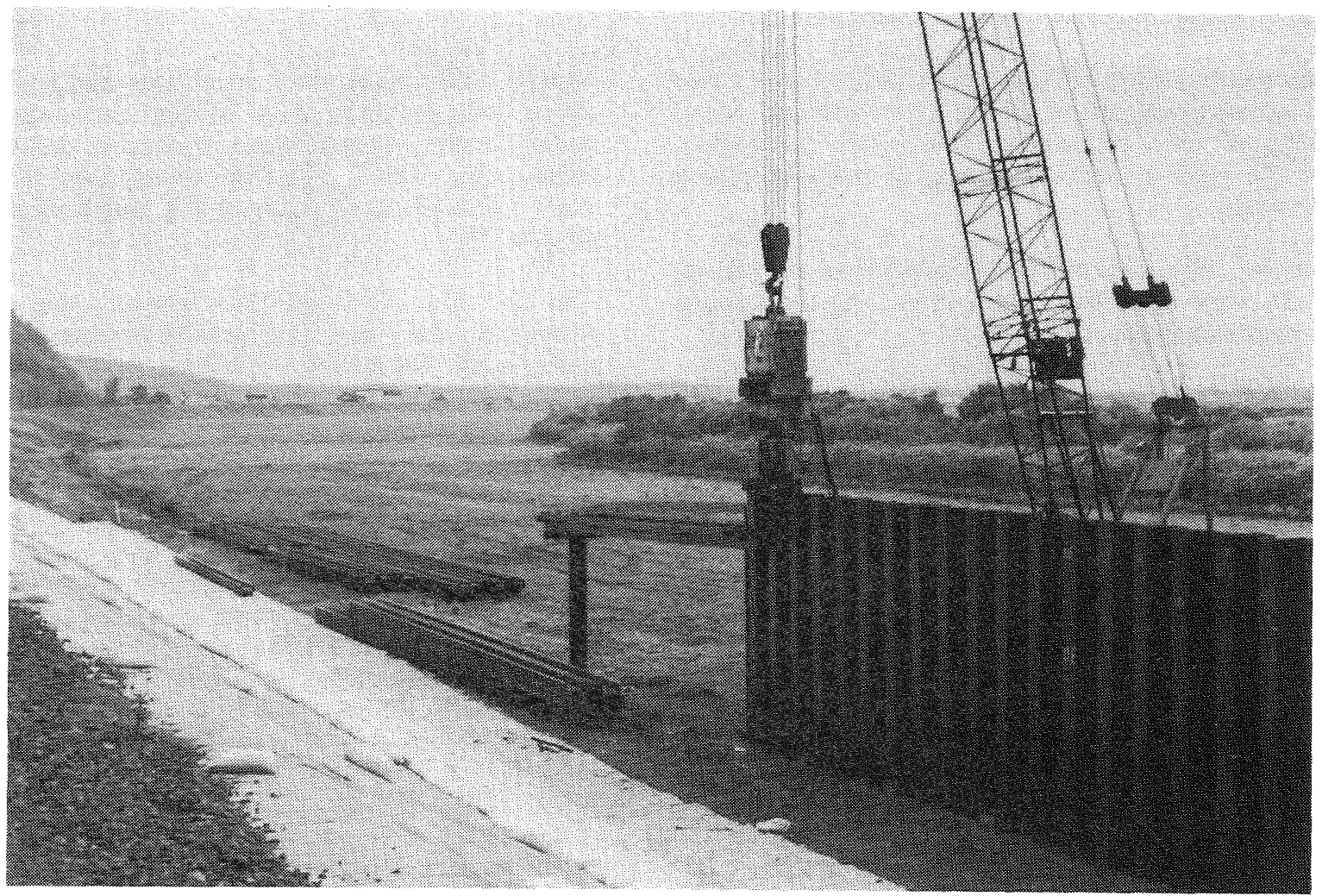

Figure 15 Shiribeshi-Tashibetsu River. Stopbank repairs. Temporary sheetpiling being driven. 
bearing stops were sheared off. Nearby an $8 \mathrm{~m}$ long, 20,000 1 underground fuel tank to a polystyrene board factory floated out of the ground lifting bearing piles with it (Figure 16). At the time of the earthquake it contained 7,000 l of fuel (Figure 16).

At Oshamanbe on the east coast of the south west Peninsula, and located within the MM 8 isoseismal area some $110 \mathrm{~km}$ from the epicentre, there was extensive liquefaction of saturated, near-coastal, aeolian sands. The contrasting effects of buoyancy of the petrol tanks and ground settlements due to liquefaction in a service station, resulted in major damage to the forecourt and considerable damage to the station buildings (Figure 17). Other buildings nearby were also affected and damaged by differential settlements and lateral spreading. Liquefaction damage in the low lying back-dune area several hundred metres from the sea at Oshamanbe was extensive with large areas of highly susceptible loose sand having very low SPT ' $N$ ' values being affected. Of particular interest was the Nakanosawa School near Oshamanbe (Section 4.2 .9 following) where some of the concrete piles were sheared to the point of failure by the over $500 \mathrm{~mm}$ of settlement and translational displacements of the foundation soils. The school grounds were badly damaged by liquefaction and the walls lining a nearby stream collapsed. SPT ' $N$ ' values measured in the soils at the school site before construction were in the range of 1 to 5 between $2 \mathrm{~m}$ and 8 $m$ deep. This data, in conjunction with the high (near surface) ground water table, suggests that liquefaction (and a high level of associated ground damage) was inevitable during strong shaking.

Hakodate port located within the MM 7 intensity isoseismal some $170 \mathrm{~km}$ from the epicentre, has been developed by major reclamation works constructed on $70 \mathrm{~m}$ deep alluvial soils. Amplification of the earthquake ground motions is thought to have caused peak ground accelerations of about $0.2 \mathrm{~g}$, and extended the duration of strong shaking, resulting in extensive liquefaction damage of susceptible soils.

At the Hakodate docks ground fissuring with extensive ejection of large quantities of uniform fine sands occurred over a wide area (Figure 18) and settlements of up to $1.5 \mathrm{~m}$ were measured (Figure 19). Some bulkheads or quay walls rotated seaward about $1 \mathrm{~m}$ and associated tie back anchor points had moved in the liquefied soils leaving an open fissure $10 \mathrm{~m}$ back from the walls (Figure 20). Piled crane beams and buildings were largely undamaged, but the underground services were badly disrupted. Individual floating floor slabs within adjacent buildings were displaced by differential settlements of up to $500 \mathrm{~mm}$.

Similar but less extensive damage was observed elsewhere at the port. At the grain unloading facility, $300 \mathrm{~mm}$ differential settlements of concrete slabs were observed together with upwards floatation of subsurface concrete conveyor ductings. At the nearby Nittetsu Cement Company yard in an area of widespread sand ejection, a $25 \mathrm{~m}$ high silo tilted $1 \mathrm{~m}$ at the top and displaced $200 \mathrm{~mm}$ horizontally at ground level (Figure 21). The silo is believed to have been founded on piles. A similar sized silo immediately adjacent was unaffected, as were the main oil and chemical storage tanks in the port area. Surrounding the cement silo was extensive evidence of liquefaction, with up to $150 \mathrm{~mm}$ thickness of uniform fine sands deposited on the ground surface, differential settlements and lateral ground movements relative to more fixed objects, such as concrete drainage sumps.

Work to upgrade the old Honshu ferry terminal (now closed due to the opening of the tunnel link between Hokkaido and Honshu) and convert it into a shopping and leisure plaza has been severely affected by liquefaction damage and rotation of the quay walls.

\subsection{Performance of Structures}

\subsubsection{General}

In general, all types of civil engineering and building structures performed well in the earthquake which caused maximum intensities possibly reaching MM 10 on Okushiri Island. Most structural failures were the result of ground damage and foundation instability, and particularly the failures of breast work wharves. However, there were some examples of failure due to inadequate structural concepts, workmanship and supervision.

\subsubsection{Snow Shelter Okushiri Island}

One structure which suffered severe damage from ground shaking and loss of strength of subsoils was the snow shelter covering a section of road between Aonae and Monai at the southern end of the Island. At this point, the road is exposed on an elevated marine terrace where it passes through a dairy farming area, and is subject to snow drifts in winter. The snow shelter was officially opened only a few days before the earthquake.

The structure was designed as a three pin arch, with the thrusts at the lower springing, resisted by retaining walls up to $4.5 \mathrm{~m}$ high, and supported on single and double rows of piles depending on the height of the wall (Figure 22). The shelter was $230 \mathrm{~m}$ long and was constructed of $2 \mathrm{~m}$ wide precast arch segments, bolted at the apex and at the springing. The arch segments were not connected longitudinally. The retaining walls, cast in $10 \mathrm{~m}$ lengths, were also not connected longitudinally, and were supported on a single row of piles for walls up to $3 \mathrm{~m}$ high, and a double row of piles for walls with greater heights. A total of 518 piles were specified with diameters of $500 \mathrm{~mm}$ and lengths of 5.5 to $10.5 \mathrm{~m}$. The stability of the arches would have been significantly improved if ties between the walls had been included in the design.

As a result of ground shaking, the central $120 \mathrm{~m}$ of tunnel collapsed completely (Figure 23), with $60 \mathrm{~m}$ at the northern end, and $50 \mathrm{~m}$ at the southern end remaining standing (Figure 24). As can be seen by the longitudinal crack in the pavement of the portion still standing, the retaining walls have spread by up to $100 \mathrm{~mm}$. In some cases, the arches moved relative to the walls splitting off the cast in situ upstand on the inside, which formed the U-shaped groove for the arch seatings. Schmidt hammer readings showed that the upstand concrete was of poor quality with cylinder strengths much less than the $30 \mathrm{MPa}$ for the walls proper. The reinforcing details to this upstand were also inadequate, and in some areas short lengths of bar had been dowelled into the wall to replace missing starters. There was no longitudinal steel in the upstand. Examination of the footing to the overturned retaining wall (Figure 25), showed that if piles were provided to this section, they were not connected to the footing. Without moment resisting pile connections, the retaining walls were unstable, and unable to resist the 

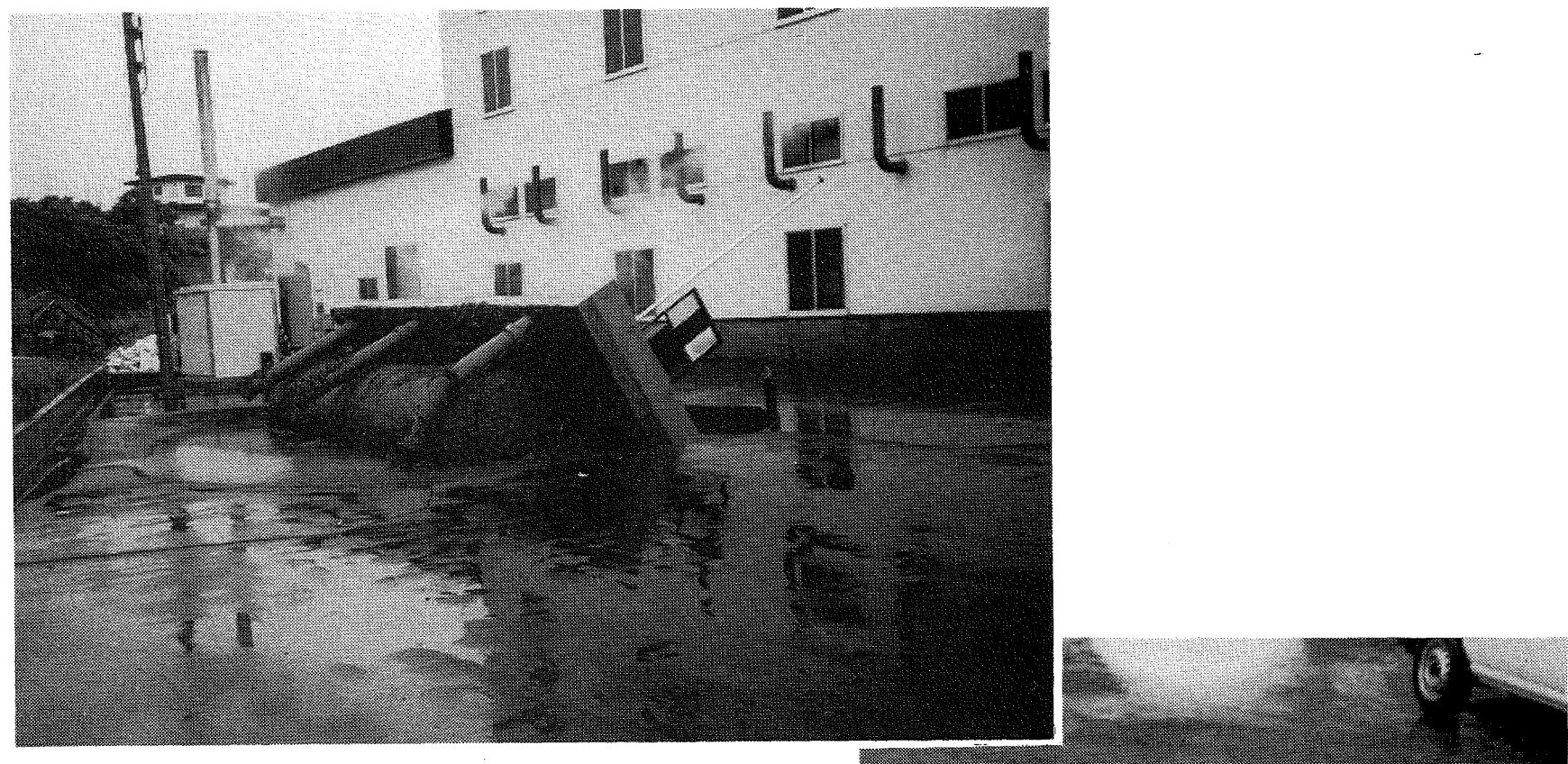

Figure 16 Yanagizaki Liquefaction and flotation of 20,000l storage tank.

Figure 17 Oshamanbe. Damage to service station forecourt and structures due to liquefaction causing ground settlement and buoyancy of underground tanks.

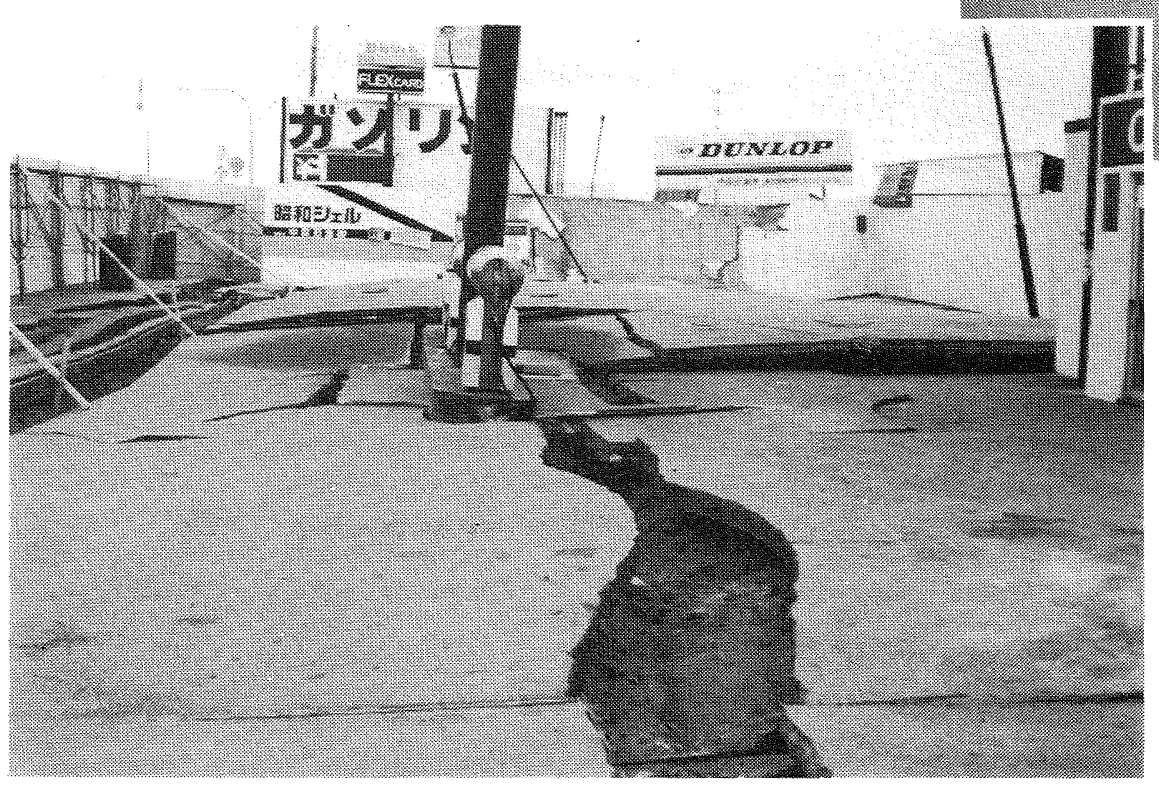

Figure 18 Hakodate Port. Sand boil 


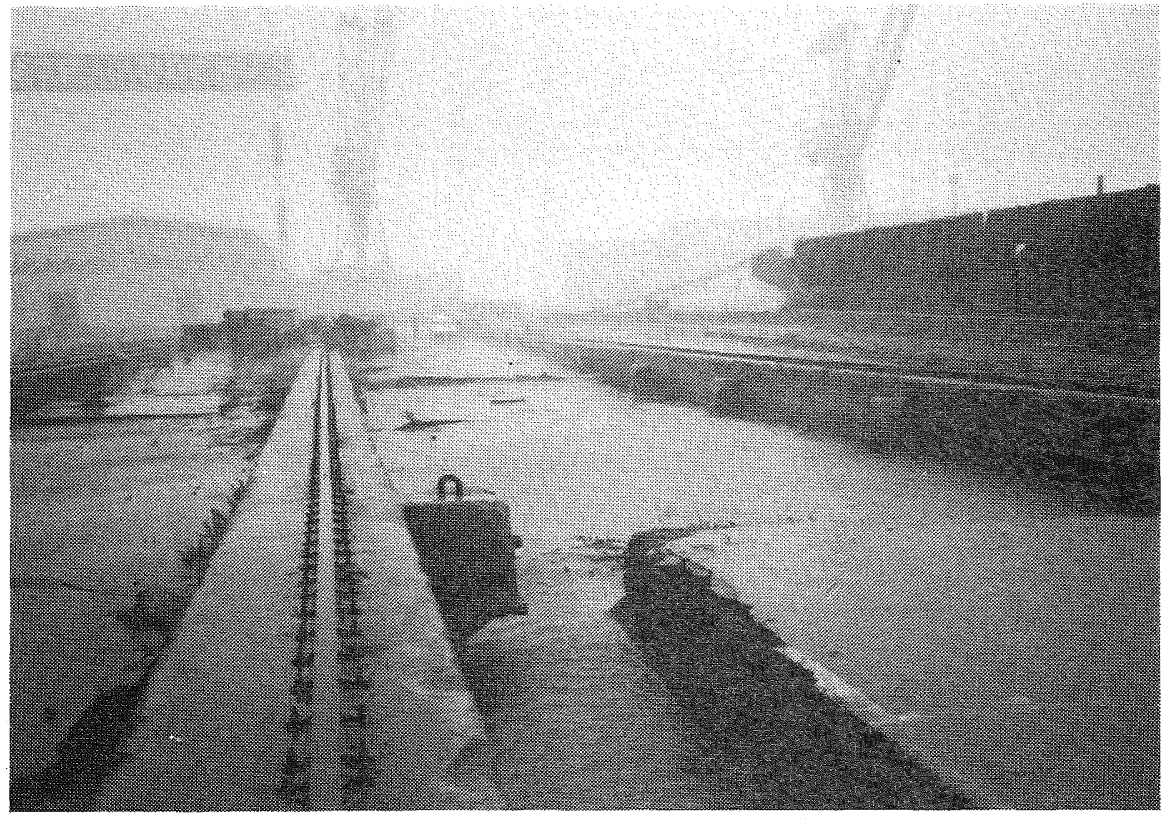

Figure 19 Hakodate Dock. Subsidence of reclamation.

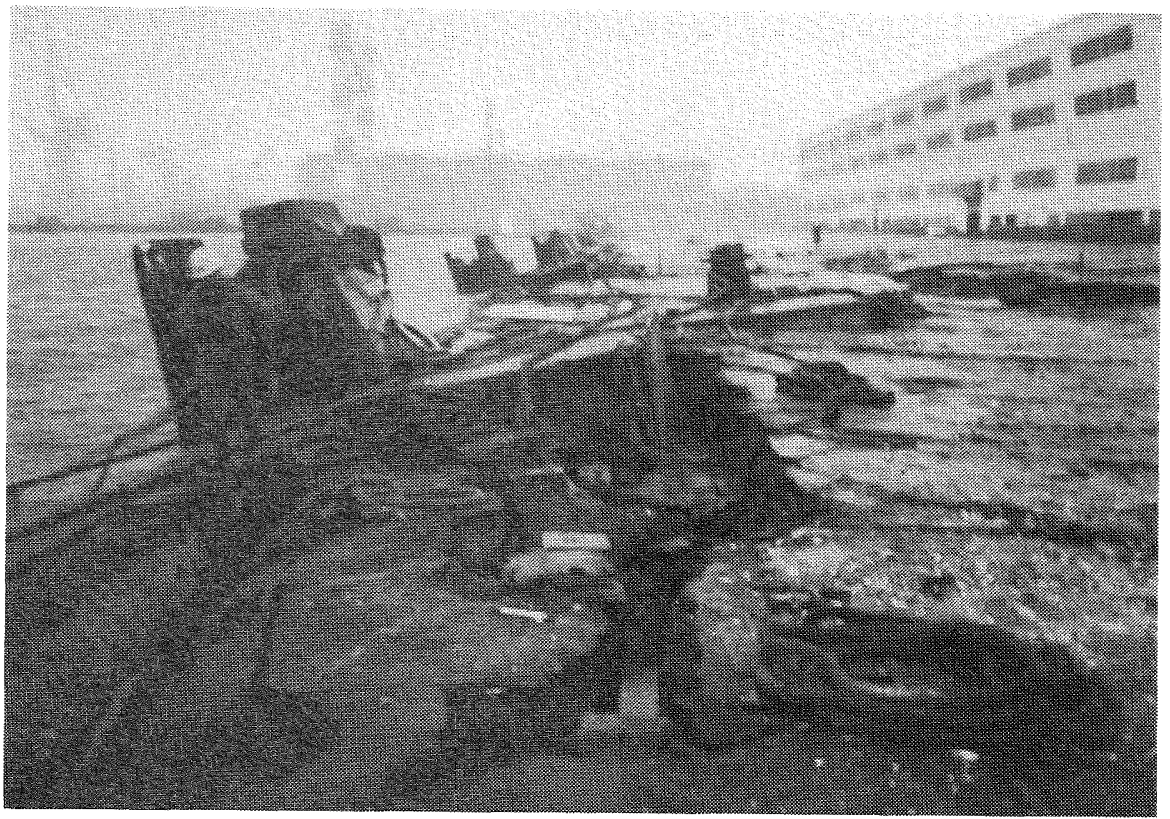

Figure 20 Hakodate Dock. Liquefaction damage to quay wall.

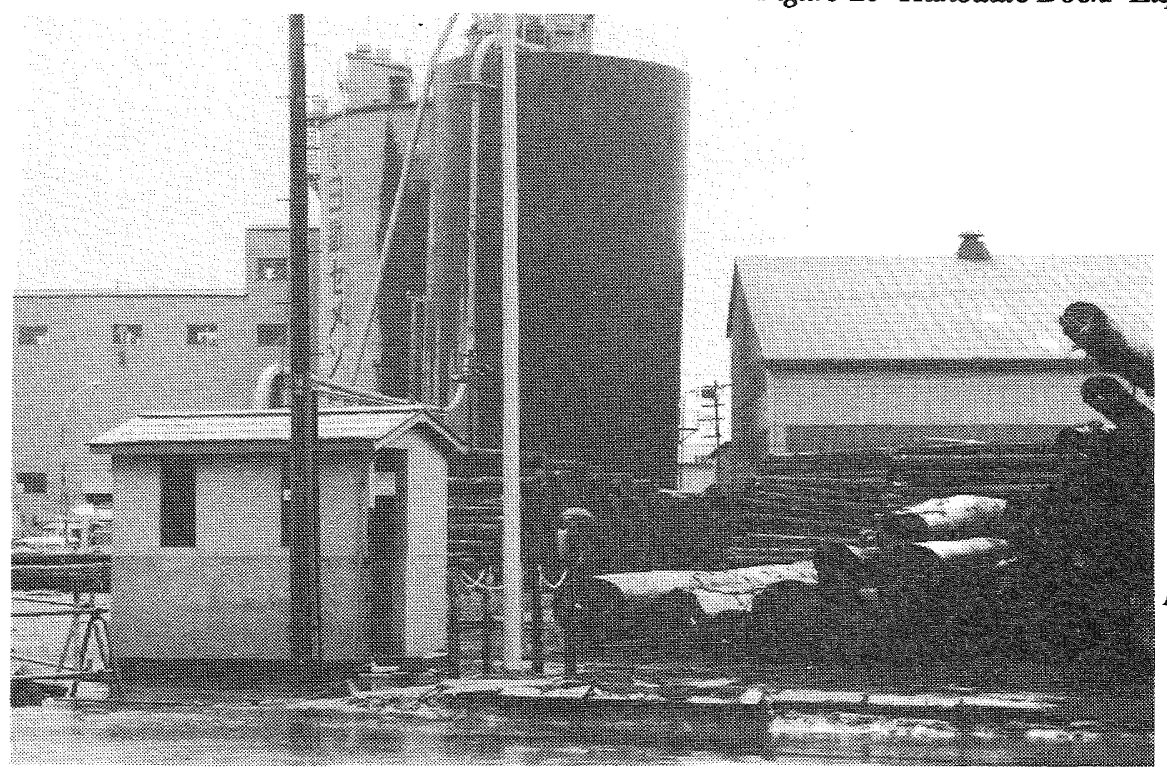

Figure 21 Hakodate Nittetsu Cement Company. Cement silo is leaning due to differential foundation settlement. 


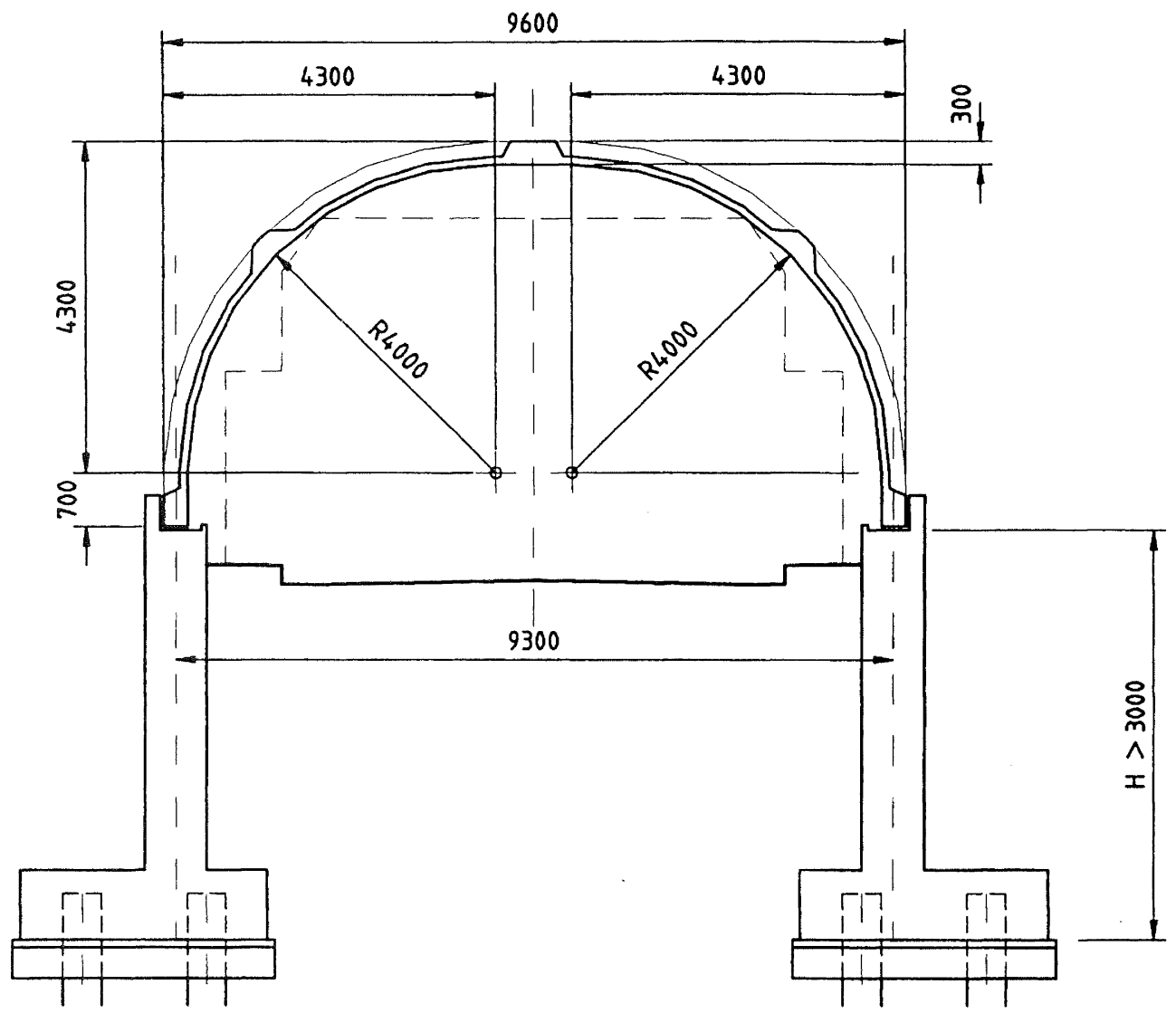

Cross-Section Through Twin Pile Section

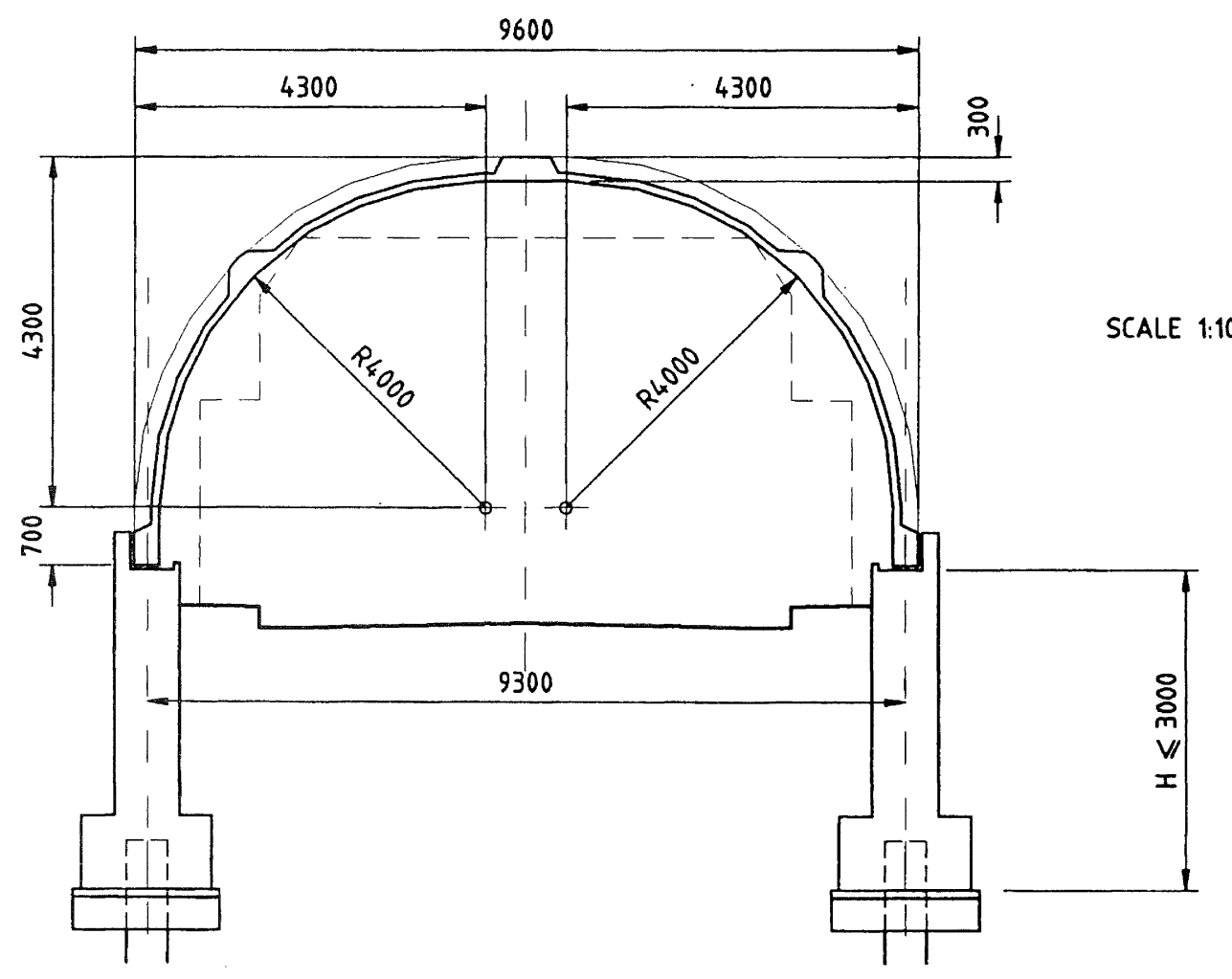

Cross-Section Through Single Pile Section

Figure 22 Aonae, Okushiri Island. Crass-sections through snow shelter structure (source HDB). 

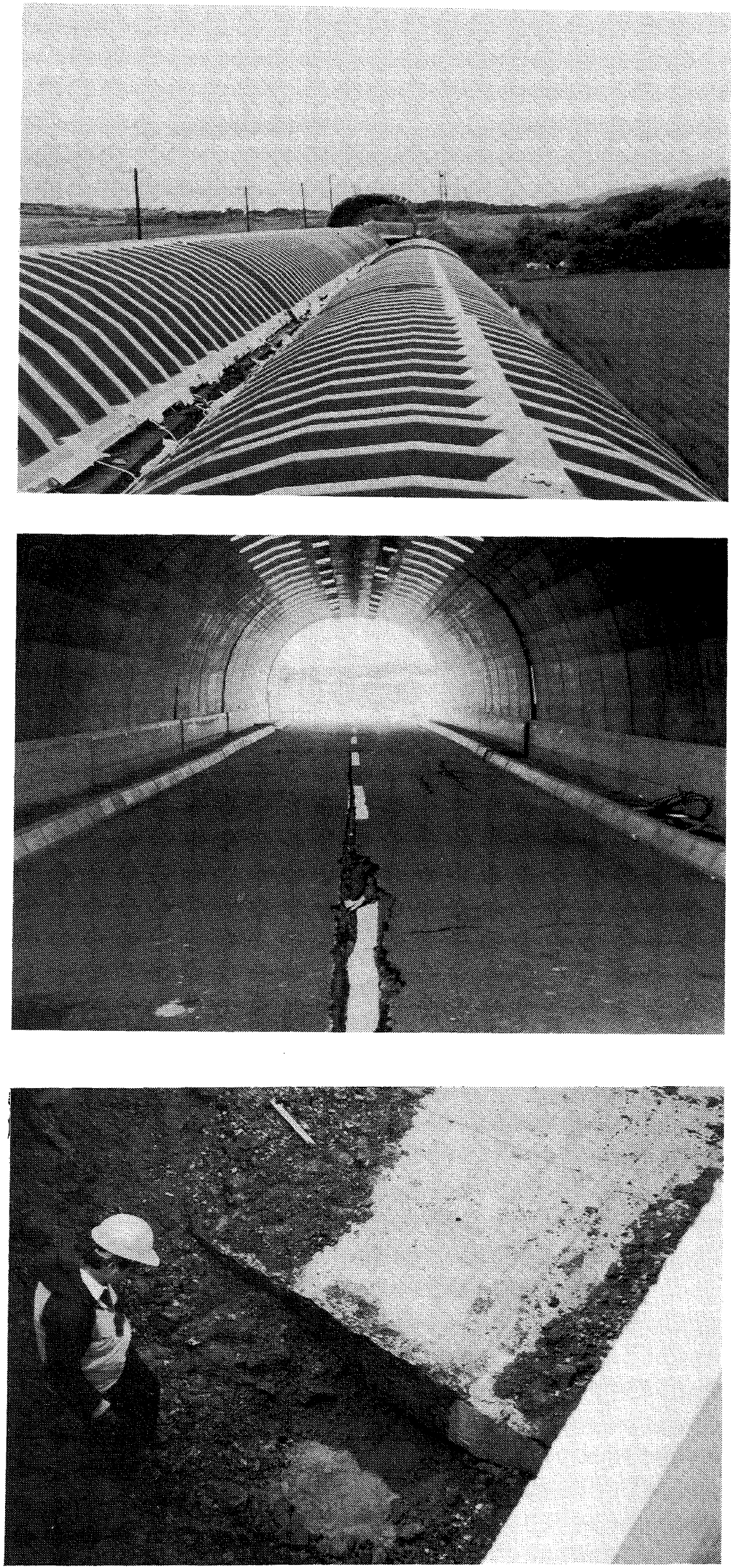

Figure 23 Aonae, Okushiri Island. Collapsed centre section of snow shelter.

Figure 24 Aonae, Okushiri Island. Southern portion of snow shelter which did not collapse. Note the longitudinal crack in the pavement caused by lateral spreading, and the displacement at a transverse joint.

Figure 25 Aonae, Okushiri Island. Overtumed retaining wall for the snow shelter showing lack of pile connection. 
lateral (dynamic) soil pressures developed during the earthquake.

\subsubsection{Horonai No 2 Bridge - Okushiri Island}

The bridge is on a new section of highway under construction on the west coast of Okushiri Island (Figure 26), and survived the earthquake without damage. The bridge consists of a continuous partially prestressed concrete box girder of three spans, 40, 70, and $40 \mathrm{~m}$ (Figure 27). The width of the deck is $8 \mathrm{~m}$. The bridge superstructure is mounted on two leadrubber bearings at each abutment. The bridge is founded on deep piles down to granites shown in the cross section. The only indication of movement is that the width of the expansion joint at the south abutment, which was $40 \mathrm{~mm}$, has reduced to $10 \mathrm{~mm}$, and the upper surfaces of the rubber bearings have been displaced in opposite directions, relative to each other by $10 \mathrm{~mm}$.

The shallow founded facing wall on the northern filled approach to the bridge moved outwards as a result of foundation instability in the weathered granite soils (Figure 14).

\subsubsection{Concrete Batching Plant - Aona}

The readymix concrete plant situated on the coast about 2 $\mathrm{km}$ from Aonae suffered damage as a result of ground shaking. Based upon flattening of slope angles of aggregate stock piles (see Section 3.3), the peak horizontal acceleration at the site was calculated to be $0.26 \mathrm{~g}$. The plant was located high enough above mean sea level so as not to be effected by the tsunamis. The major plant components were the concrete batching tower with its associated sloping belt conveyor for aggregates, and two steel cement silos (Figure 28). The silos appeared to be undamaged, but according to an EERI report [6], one of the silos buckled near the base. The quantity of cement in the silos at the time of the earthquake was not determined.

The concrete batching tower was about $24 \mathrm{~m}$ high and was constructed of structural steel. The lower storey was a moment resisting frame to allow access for concrete trucks, and the upper storeys supporting the aggregate bins were eccentrically or $\mathrm{K}$ braced frames. The main corner columns were cold formed steel angles with very large outstand to thickness ratios. Damage to the tower consisted of buckling of the angle corner columns including the gussets for the bracing (Figure 29) to the bottom node at the junction of the first and second storeys. The tower was being dismantled at the time of the visit and it was not possible to carry-out a detailed inspection. It is believed that the instability of the cold formed angles with their outstand to thickness ratios, and the high load demands from the bracing, caused the failure. The tower did not collapse but the upper stories were tilted about $5^{\circ}$ from vertical.

\subsubsection{Green Village Resort, Horonai - Okushiri Island}

The Green Village Resort on the west coast of Okushiri Island near Horonai is a recently completed tourist hotelrecreation complex of modern design. At the time of the earthquake it had not been opened to the public. The site is about $10 \mathrm{~km}$ east of the earthquake rupture zone and the shaking intensity may have reached MM 10.
However, damage to the complex was minor and consisted of shear cracking of a part of the single storey $150 \mathrm{~mm}$ reinforced masonry wall to a restaurant, resulting in the shattering of a fixed window (Figure 30 ) and the cracking and failure of the brick veneer (Figure 31), tension cracking in the asphalt pavement at the main entrance, the opening up of a joint in the marble flooring in reception, and damage to a free standing concrete feature motif.

\subsubsection{Motoei Bridge - Esashi-Cho}

The Motoei bridge is located north of Esashi-Cho on the west coast of Hokkaido about $110 \mathrm{~km}$ from the epicentre. The bridge crosses the Assabu river in seven $20.7 \mathrm{~m}$ and 24.0 $\mathrm{m}$ spans and has a total length of $165.7 \mathrm{~m}$ (Figure 32). The superstructure is a continuous composite design with three steel girders $1138 \mathrm{~mm}$ deep and a reinforced concrete deck $190 \mathrm{~mm}$ thick and $8 \mathrm{~m}$ wide. The single stem reinforced concrete cylindrical piers are $1,800 \mathrm{~mm}$ in diameter and are each founded on five steel pipe piles $500 \mathrm{~mm}$ in diameter and $9 \mathrm{~m}$ or $12 \mathrm{~m}$ long. The piers have clear heights of 7.2 to $7.8 \mathrm{~m}$.

Three piers on the north end or right bank were damaged just above the junction with the steel piles. The second pier suffered spalling of the $100 \mathrm{~mm}$ thick concrete cover. In the third and fourth piers several longitudinal bars buckled and there was fracture of the spiral hoops. The reinforcing in this region consists of $36 \times 22 \mathrm{~mm}$ diameter longitudinal bars and $13 \mathrm{~mm}$ diameter spiral hoops with a spacing of $125 \mathrm{~mm}$. Ground failure with several wide cracks could be seen around the embankment. Damage to the piers may have been due to liquefaction as well as ground shaking. The bridge was closed to vehicle traffic three weeks after the earthquake.

\subsubsection{Yanagizaki Bridge - Esashi}

The bridge is located about $10 \mathrm{~km}$ north of Esashi and suffered only minor damage. The area around the bridge suffered considerable ground failure, due to liquefaction, and settlements of $1.2 \mathrm{~m}$ to $1.3 \mathrm{~m}$ were evident on the approaches to the bridge. The bridge has six spans and is of composite construction with steel beams and reinforced concrete deck (Figure 33). At some stage, the bridge was widened and movement at the construction joint was evident.

Damage to the bridge consisted of the shearing off of the 60 x $30 \mathrm{~mm}$ thick mild steel restraining lugs to the bearings (Figure 34). Teflon pads were used on the bearing faces but insufficient clearance was provided to allow for more than temperature movement. The bridge was opened for traffic soon after the earthquake by backfilling against the abutments and providing an asphalt smoothing coat (Figure 35).

\subsubsection{Shiraito No 2 Tunnel - Shimamaki-Mura}

The tunnel is located on National Highway Route 229, on the west coast of Hokkaido. The distance from the epicentre is $57 \mathrm{~km}$. The total length of the tunnel is $741 \mathrm{~m}$ and damage due to a rock fall is apparent over a length of $46 \mathrm{~m}$ where the tunnel portal daylights at the foot of the coastal cliff and effectively acts as a talus shelter. The tunnel lining was cast in $6 \mathrm{~m}$ segments with no connection between adjacent segments. The internal height was $5.9 \mathrm{~m}$ and the width 8.4 $\mathrm{m}$. One of the exposed segments of the tunnel collapsed under the impact of the rock fall (Figure 10), and the 


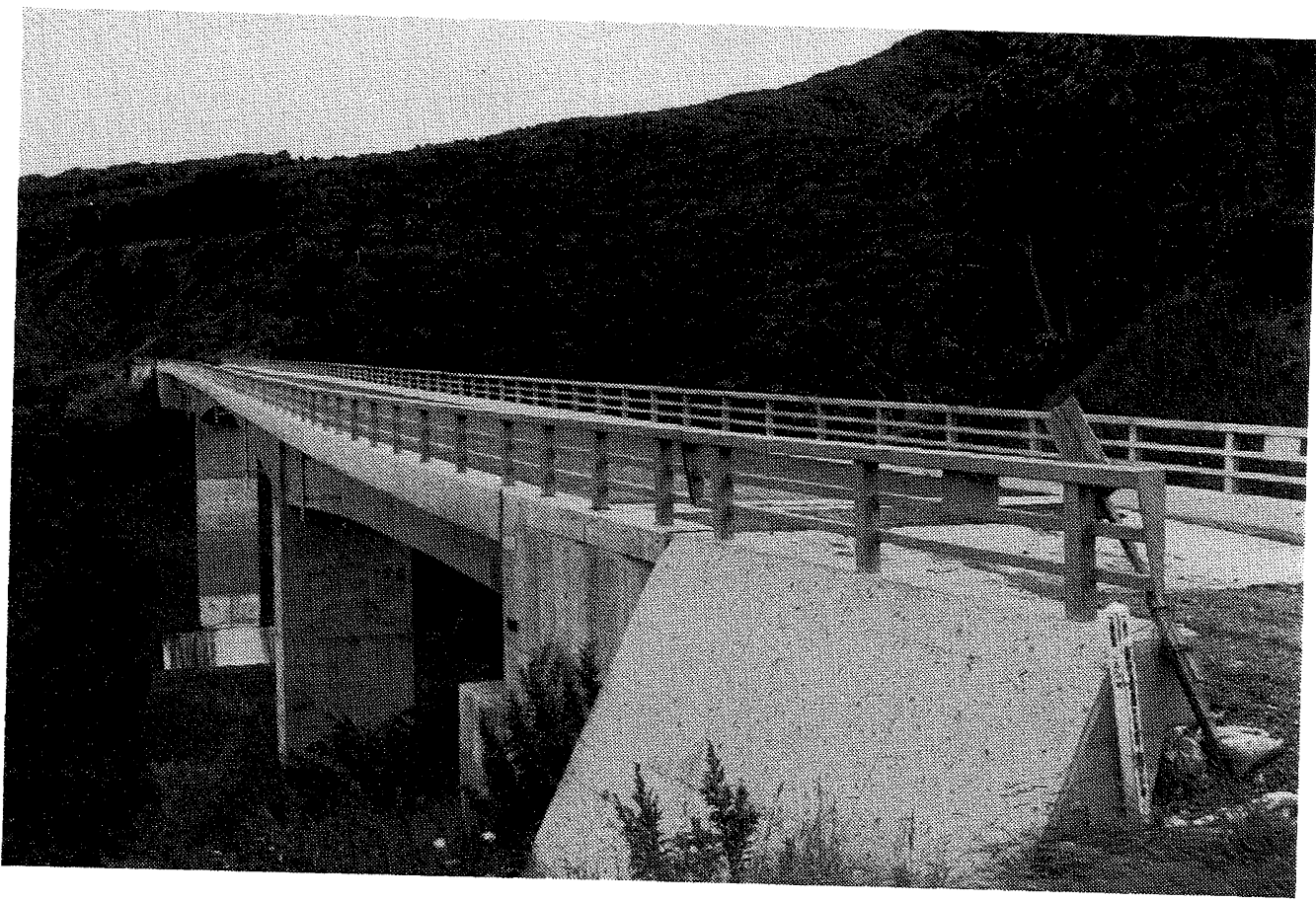

Figure 26 Horonai, Okushiri Island. General view of Horonai No 2 bridge.

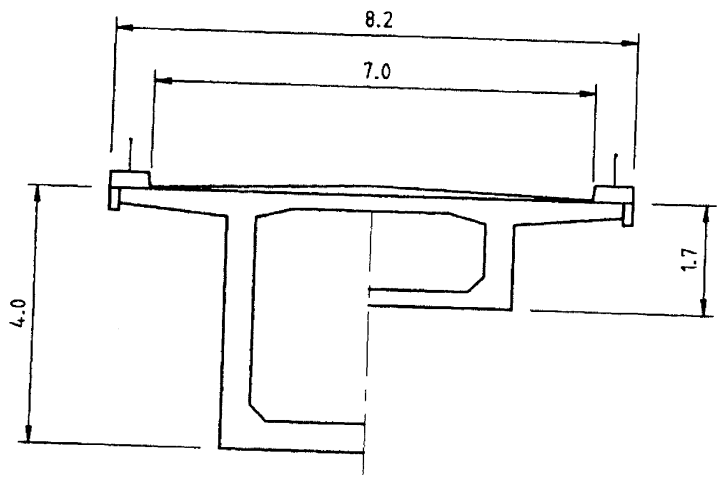

Section Through Prestressed box Girder

At Piers And Centre of Span

Scale 1:100

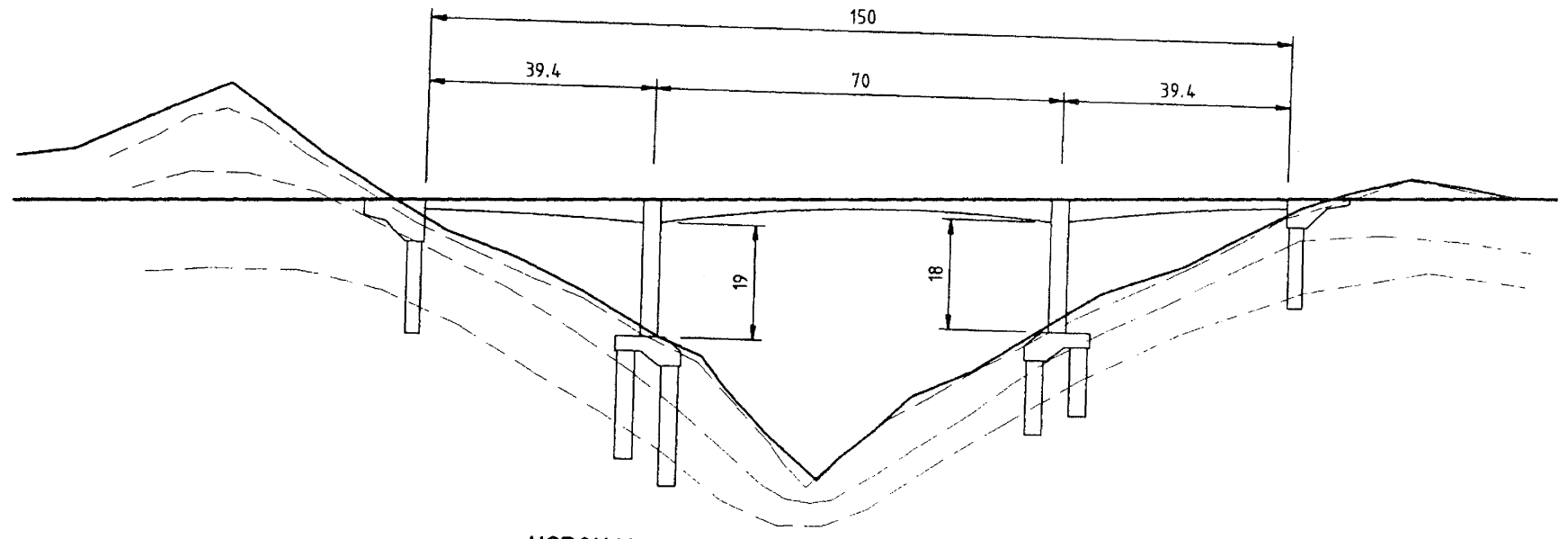

HORONAI No.2 BRIDGE OKUSHIRI ISLAND Scale 1:1000

Figure 27 Horonai, Okushiri Island. General details of Horonai No 2 bridge (source HDB). 
Figure 28 Concrete Batching Plant, Aonae, Okushiri Island. View of plant. Note that the conveyor and cement slide have been removed from the concrete batching tower.

Figure 29 Concrete Batching Plant, Aonae, Okushiri Island Typical buckling of cold formed angle comer columns and gussets.
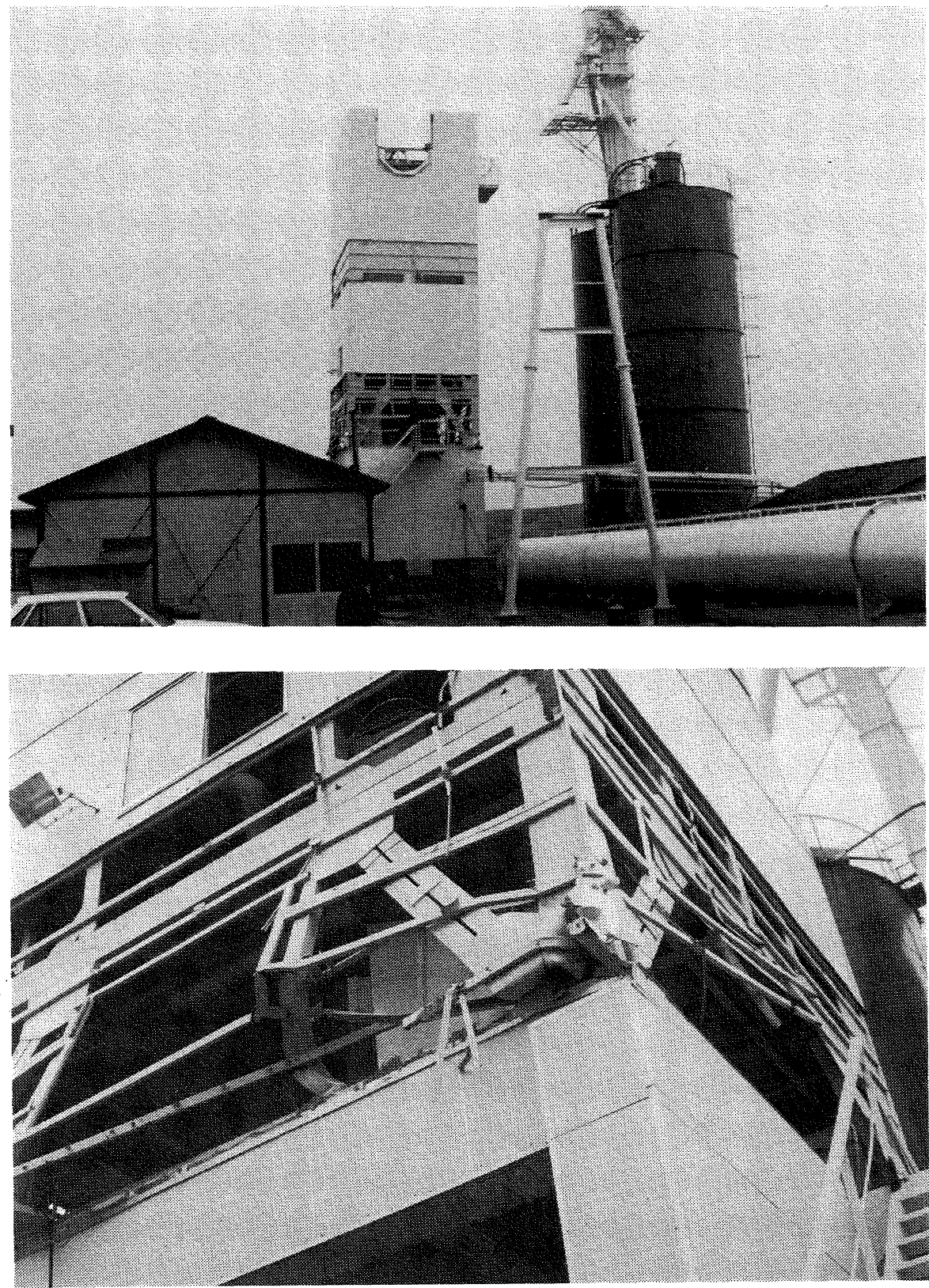

Figure 30 Green Village Resort, Horonai, Okushiri Island. View of damage to brick veneer reinforced masonry wall and window which shattered. Note the tension cracks in the pavement.

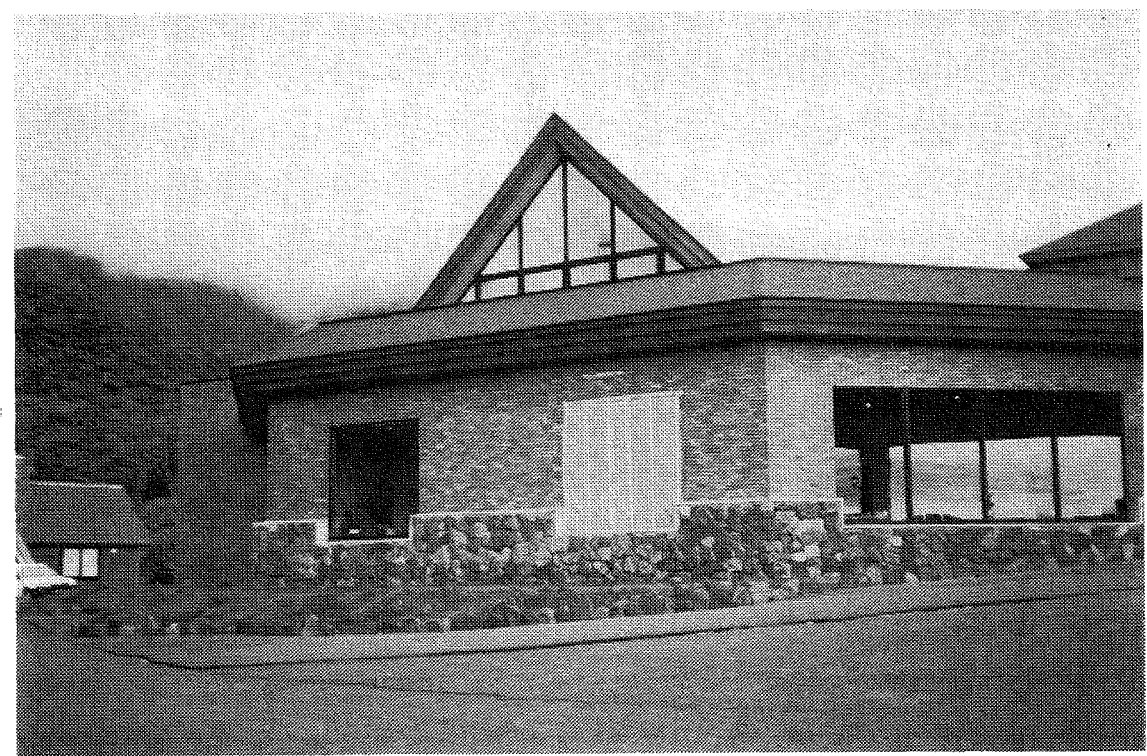



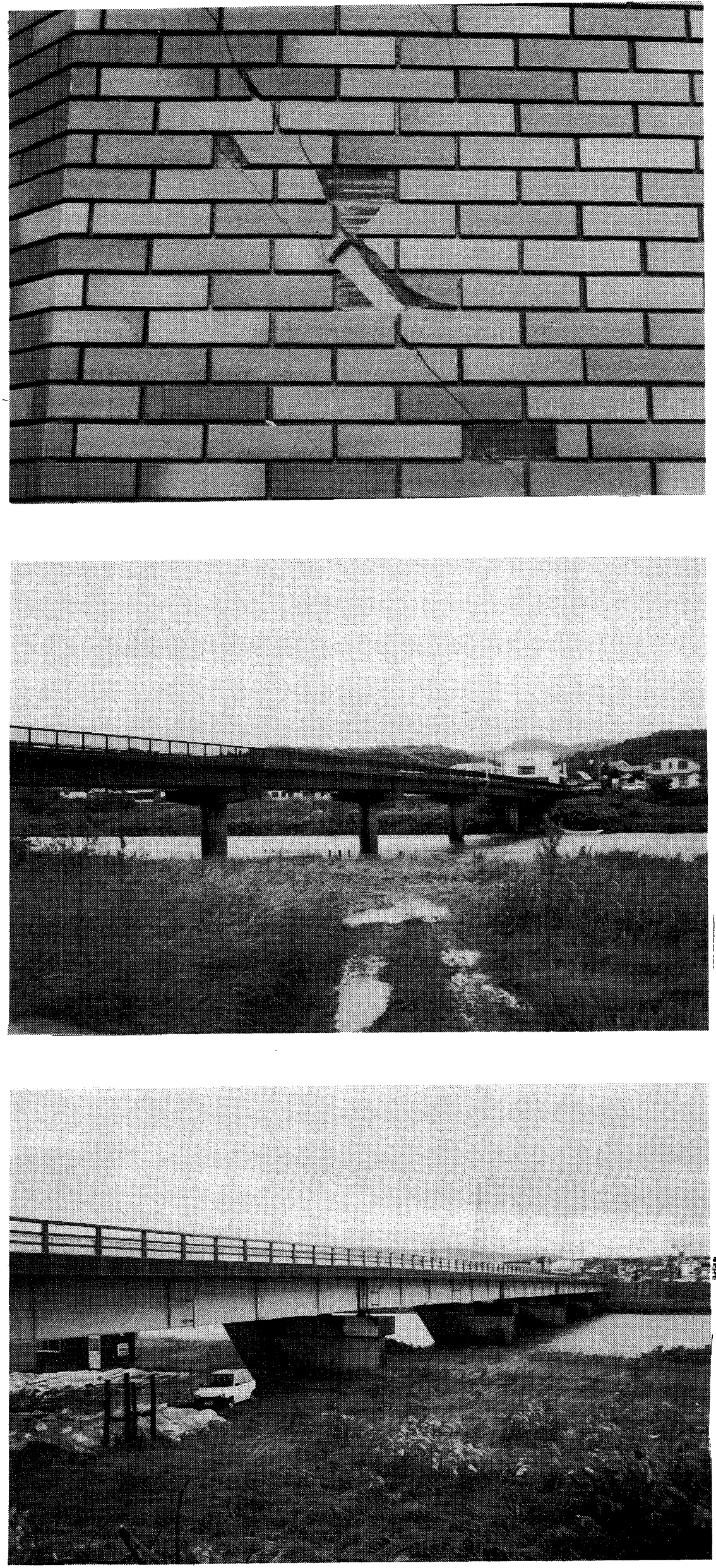

Figure 31 Green Village Resort. Horonai, Okushiri Island. Smear cracking of brick veneer and reinforced masonry wall.

Figure 32 Esashi General view of Motoei bridge.
Figure 33 Esashi General view of
Yanagizaki bridge. 
Figure 34 Esashi View showing sheared bearing lug of the Yanagizaki bridge. Note the small amount of clearance provided.

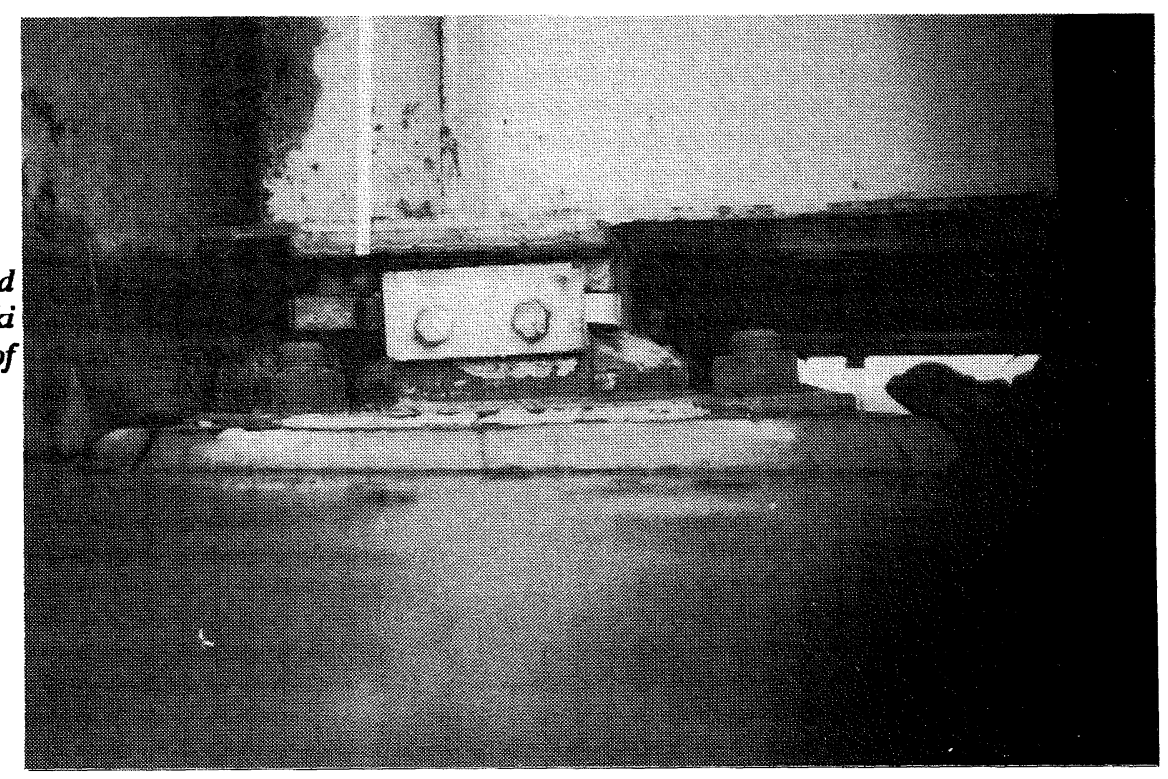

Figure 35 Esashi View showing settlement of the approach fill at the north abutment and the backfilling and asphalt smoothing coat at the Yanagizaki bridge.

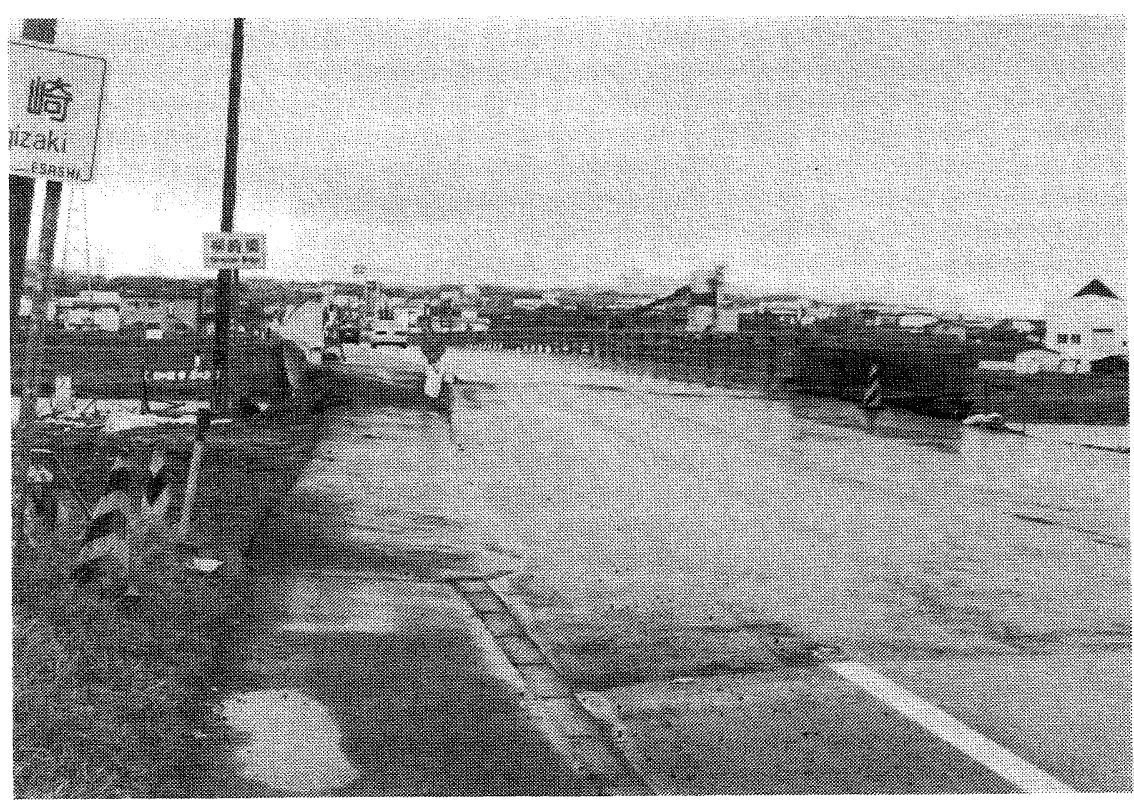

Figure 36 Shimamika-Mura Spalling of concrete cover and exposure of reinforcing steel due to impact of rock fall on the portal section of the Shiraito No 2 tunnel. Note the displacement at the transverse joint of the tunnel segments.

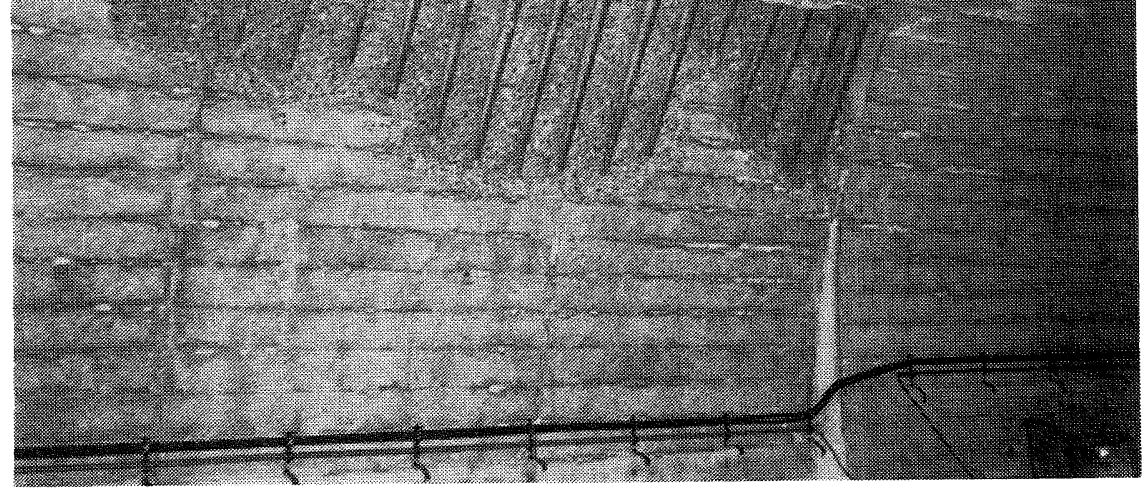


segments on either side were deformed and had concrete spalled from the soffit exposing the main reinforcing steel (Figure 36). The total amount of material in the rock fall is estimated at about $2,500 \mathrm{~m}^{3}$ with a maximum single rock size of 6 by 5 by $5 \mathrm{~m}$. This material fell from the top of the overhanging cliff face about $100 \mathrm{~m}$ above the tunnel.

\subsubsection{Nakanosawa Primary School - Oshamanbe-Cho}

Oshamanbe-Cho is located about $107 \mathrm{~km}$ east of the epicentre. The school was built in 1990 and cost about NZ\$5 million. Construction of the school buildings is in timber with knee bracing and diaphragms of timber sarking (Figure 37), although structural steel frames are used in the attached gymnasium building. The buildings are founded on $12 \mathrm{~m}$ long piles with single piles used under the single storey section and two pile groups used under the columns in the gymnasium and multistorey section. There are two sizes of prestressed concrete piles to Japanese Industrial Standard (JIS) A5337 which have diameters of $300 \mathrm{~mm}$ and $350 \mathrm{~mm}$ and allowable vertical load capacities of 34 and 45 tons respectively. The piles are hollow core with a wall thickness of $60 \mathrm{~mm}$ and are stressed longitudinally with 6 deformed prestressing bars of $6 \mathrm{~mm}$ diameter. Transverse steel consists of $3 \mathrm{~mm}$ diameter spirals. Concrete strength is more than 50 MPa.

Liquefaction resulted in some $500 \mathrm{~mm}$ or more of settlement and translation displacements of the foundation soils (Figure 38) which caused shear failures at the tops of some of the single piles in the single storey section where the piles joined the foundations (Figure 39). There was no evidence of damage to the two pile groups. The problem with hollow core prestressed concrete piles is that they cannot be effectively confined to ensure ductility when subject to transverse loading in this manner.

It was significant that the school was otherwise structurally undamaged; freestanding bookshelves did not overturn, and glassware in cupboards and on benches in the laboratory was not disturbed. Several timber framed staff houses with shallow foundations adjacent to the school did not suffer structural damage but were tilted off level due to differential settlement of the underlying soils.

\subsubsection{Local Authority Offices and Fire Station - Iwanai-Cho}

These structures highlight the problems involved in the progressive development of a complex of buildings where no consideration is given to the provision of seismic separation to allow for differing earthquake response characteristics. The complex consists of two and three storey administrative buildings built at different times on the left (Figure 40) and the fire station, meeting rooms and public assembly areas built later on the right.

During the earthquake there was considerable secondary damage due to pounding at the vertical joints between buildings (Figure 40) and at the construction joint to the shear wall of the fire station (Figure 41). Fortunately the floors coincided. In addition considerable damage to interior finishes occurred, particularly around the stairwells.

There were also two examples of building services failures which were not attributable to the building response performance. In the first instance a main supplying water to a toilet block in an upper storey fractured, flooding the lower offices, resulting in a loss of files and clean up costs.

In the second instance a weld to a bolted flange in a hot water line fractured in the building services section of the basement, adding to the flooding.

\subsubsection{Nittetsu Cement Company - Hakodate Port}

The tilting of the $25 \mathrm{~m}$ high cement silo due to ground damage is discussed in Section 4.1.2 (Figure 21). The effect of the tilt of the silo was to distort the cement line and its support structure which crosses an adjacent road (Figure 42). The structure was rigidly attached to the silo.

The failure of the stiff, end column of the structure at a weld was due to lack of fusion of the single $\mathrm{V}$ butt weld (Figure 43). The prepared face of the weld can be clearly seen in the upper pipe section. Bracing and cleats to the column at the weld fracture were necessary to prevent collapse of the structure and provide temporary support, although the cement line itself did not fail. This is an example of an earthquake searching out the weak points of a structure.

\subsubsection{Timber Framed Housing}

Although some 1500 houses were destroyed or severely damaged, mainly as a result of tsunami and fire, modern timber framed houses are soundly built and generally performed well.

Ground shaking did cause some damage but this was the result of rotting of the framing caused by poor detailing and construction practices allowing the weather to enter the external cladding (Figure 44). Inadequate holding down connections to foundations were a problem in some older houses which were floated off by the tsunami (Figure 45).

Japanese practice in the construction of timber framed domestic housing follows the same general principles as those used in New Zealand. However there are significant departures in detail. The framing of a house near Inaho (Figure 46) at the northern end of Okushiri Island which was under construction at the time of the earthquake, was subjected to tsunamis 3-4 m high with only minor resulting damage. This house is regarded as typical of current Japanese practice.

Studs are 100 by $100 \mathrm{~mm}$ rather than the 100 by $50 \mathrm{~mm}$ more usually used in New Zealand, but are spaced at $900 \mathrm{~mm}$ centres and up to a maximum of $1800 \mathrm{~mm}$ (to suit the tatami floor/sleeping mat module), rather than the $450-500 \mathrm{~mm}$ used here. Stud height is also greater by about $400 \mathrm{~mm}$. Plates are 100 by $100 \mathrm{~mm}$ or two 100 by $50 \mathrm{~mm}$ timbers side by side, with the studs often connected to the plates by mortice and tenon joints (Figure 47). With the wider spacing of studs, girts are provided for fixing the internal linings and external claddings. These are 100 by $30 \mathrm{~mm}$ with a maximum spacing of $450 \mathrm{~mm}$. Wall bracing consists of continuous let-in 100 by $40 \mathrm{~mm}$ timber at steep angles (about $60^{\circ}$ ) used in compression, as the nailing provided is not adequate for developing the strength of the brace in tension (Figure 48iv). Bearers and floor joists are also 100 by $100 \mathrm{~mm}$, with joists at $900 \mathrm{~mm}$ centres. Secondary floor joists are 45 by $45 \mathrm{~mm}$ spaced at 150 to $300 \mathrm{~mm}$ centres for netting and insulation which is placed below the tatami mats (Figure 48). 

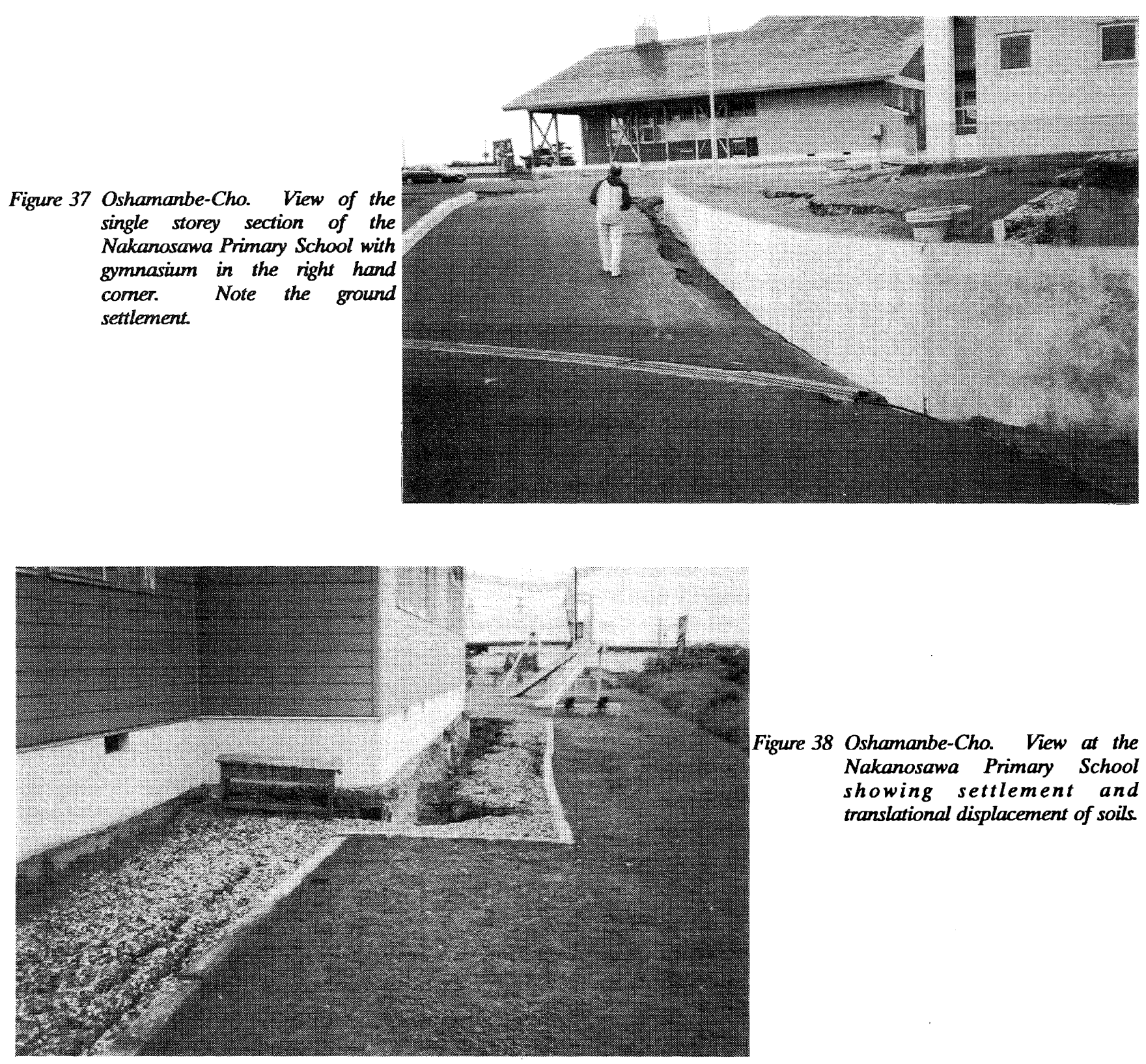

Figure 38 Oshamanbe-Cho. View at the Nakanosawa Primary School showing settlement and translational displacement of soils.

Figure 39 Oshamanbe-Cho. Shear failure of tops of prestressed piles supporting the Nakanosawa Primary School Note inadequate confunement.

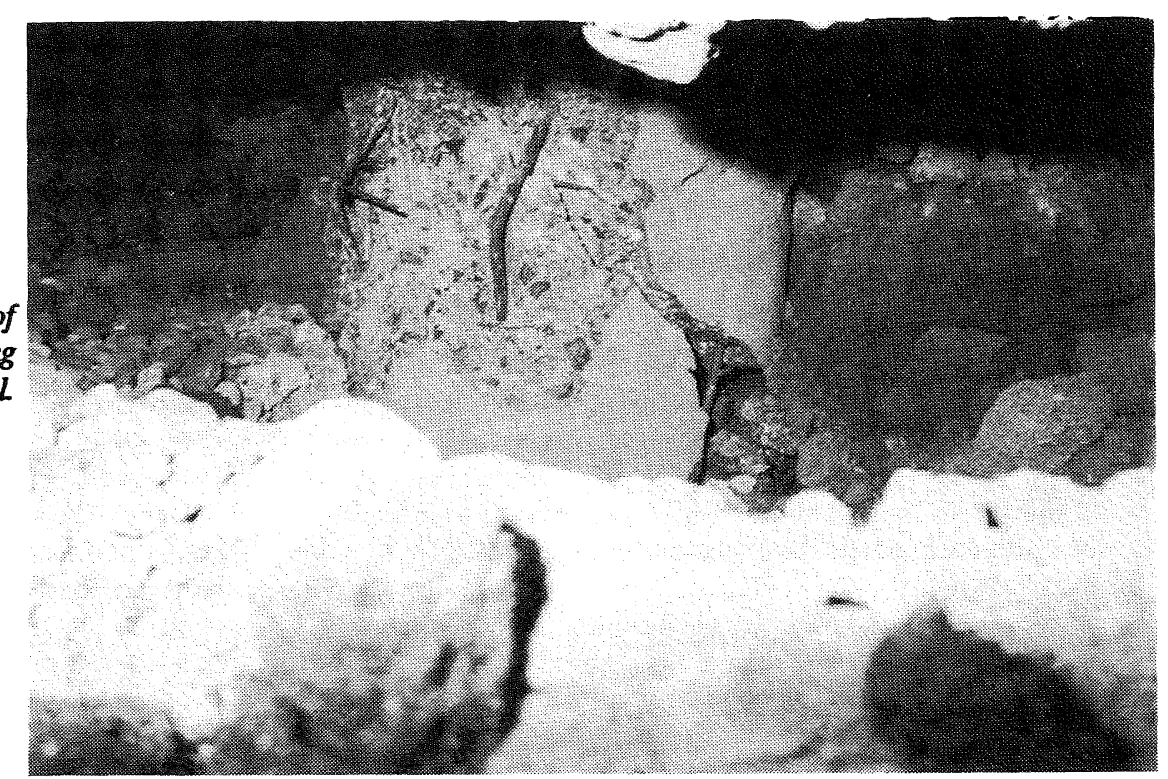




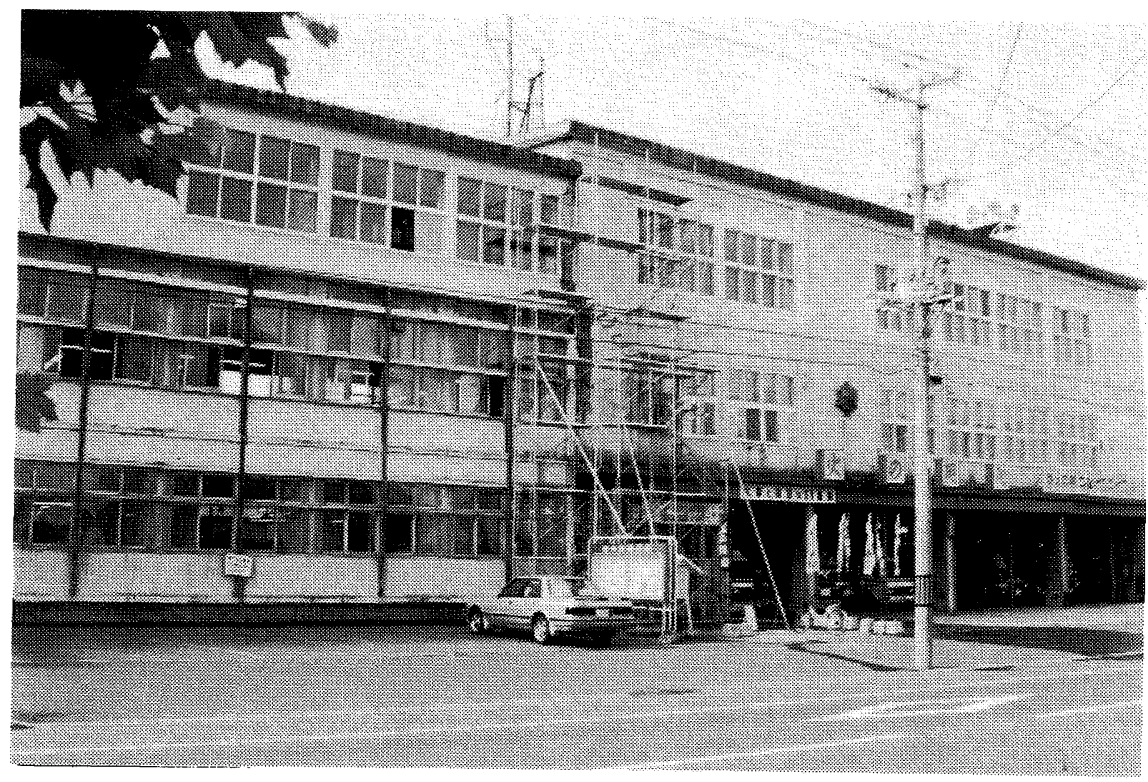

Figure 40 Repairs being carried out to pounding damage area at the junction between the local authority administrative offices on the left, and the fire station, meeting rooms and hall on the right.

Figure 41 Movement on the construction joint between the administrative offices and the fire station at storey mid height.
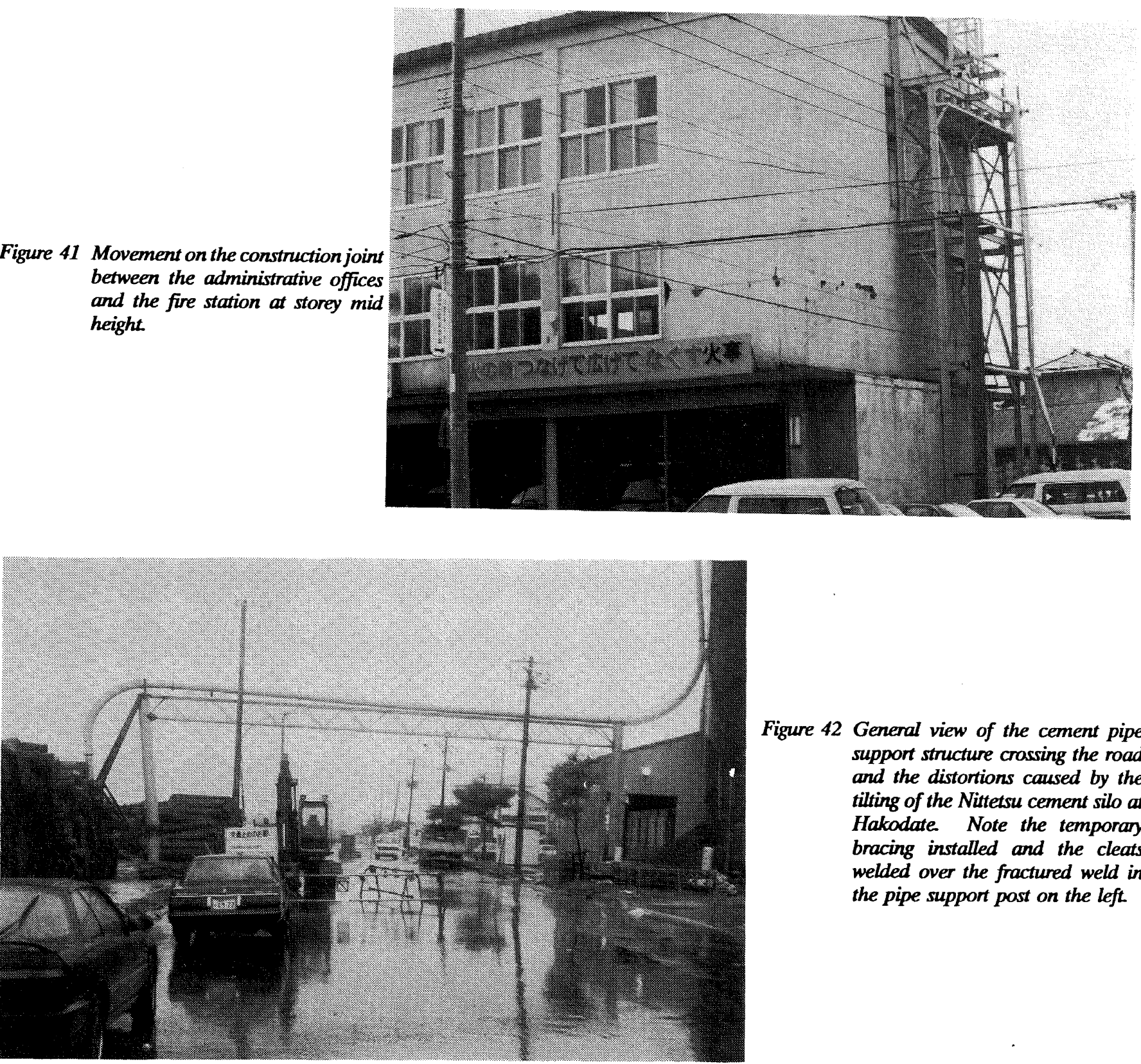

Figure 42 General view of the cement pipe support structure crassing the road and the distortions caused by the tilting of the Nittetsu cement silo at Hakodate Note the temporary bracing installed and the cleats welded over the fractured weld in the pipe support post on the left. 
Figure 43 Failure of welded joint in the pipe

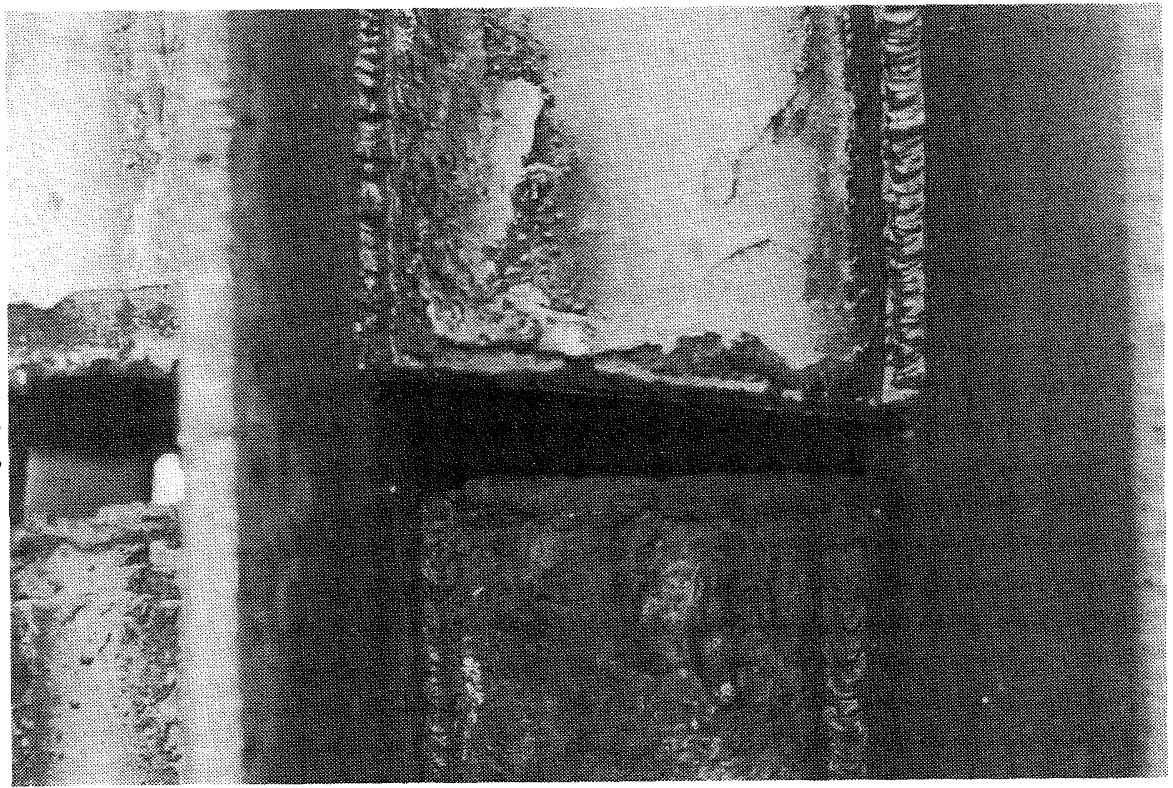

support past shown in Figure 43.

Note the lack of fusion to the prepared face of the upper pipe section.

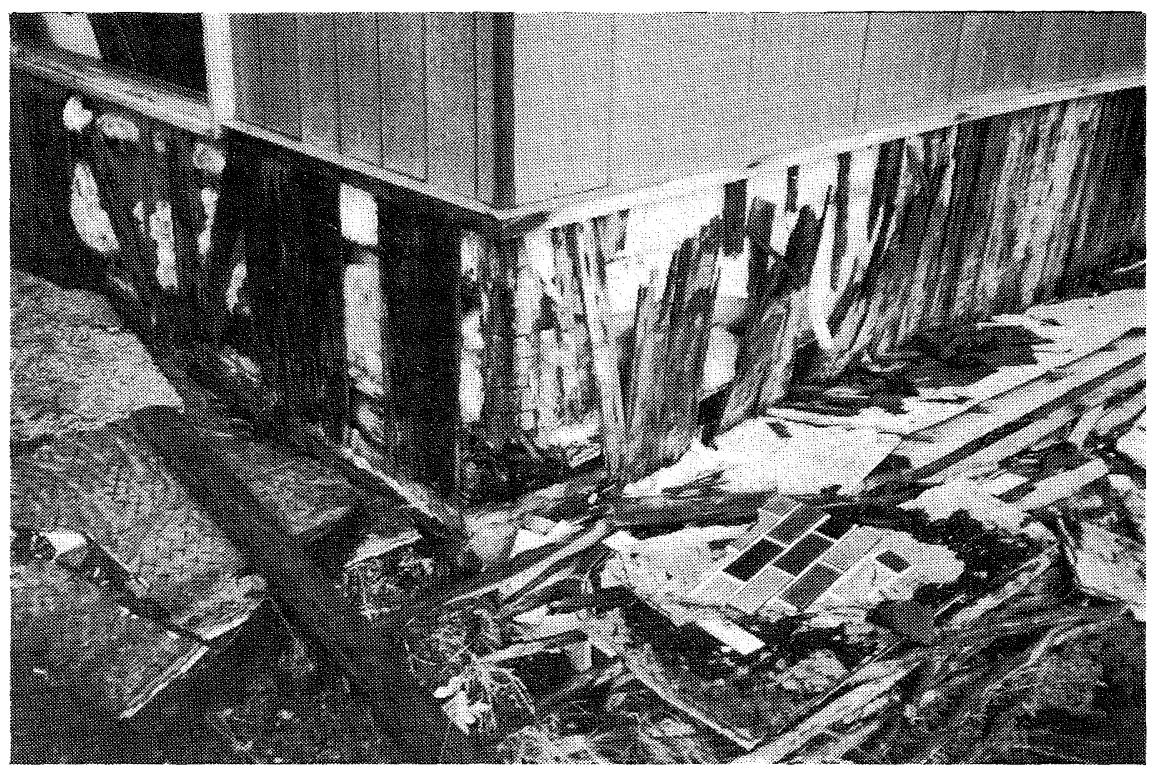

Figure 44 Aonae, Okushiri Island. House which suffered damage due to ground shaking showing rotting frame and sarking due to poor weathering details to lower cladding

Figure 45 Hokkaido. Houses with inadequate anchorage to foundations which were floated off by the tsunami (Source Asahigraph)

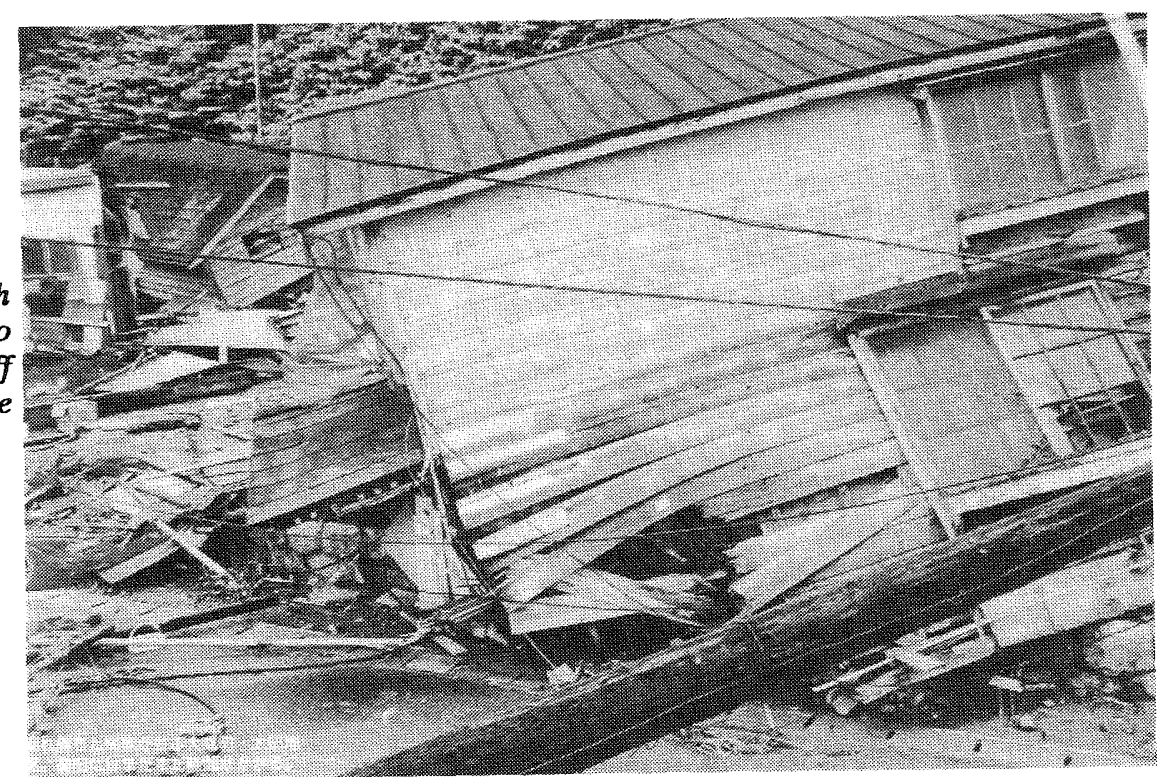




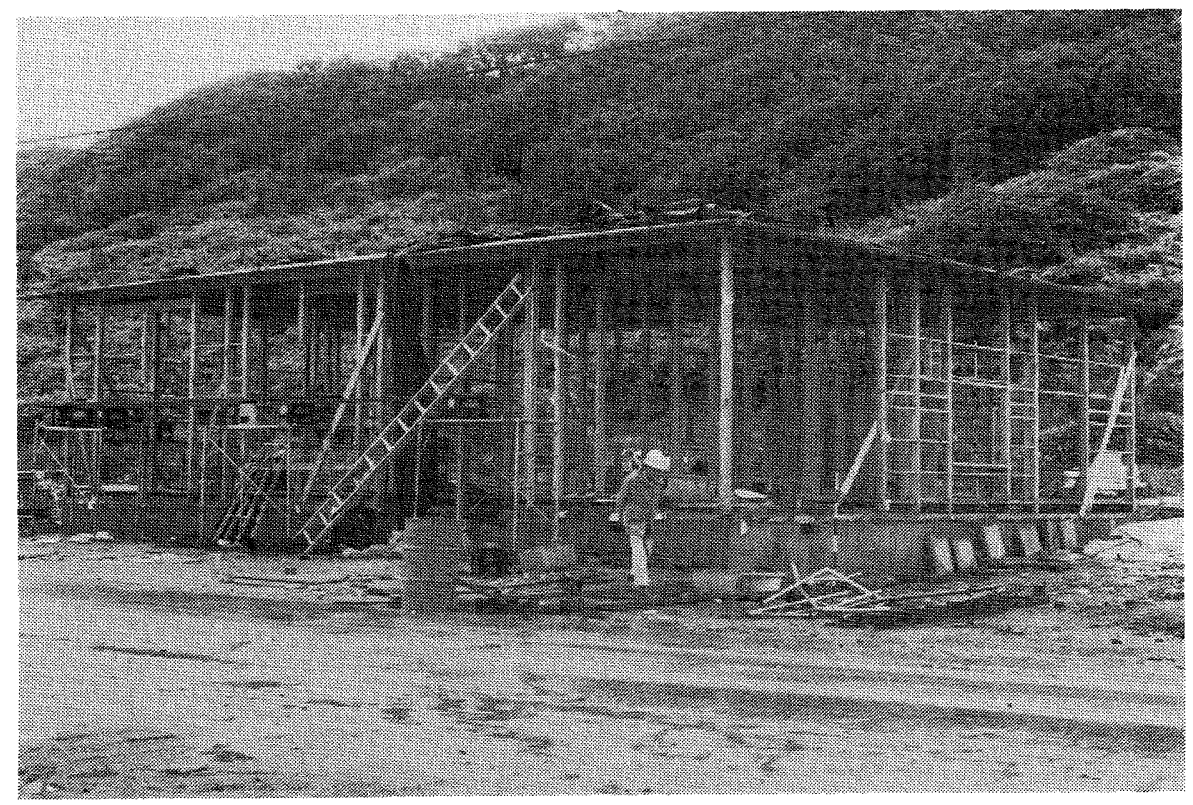

Figure 46 Inaho, Okushiri Island Well built timber framed house under construction at the time of the earthquake and typical of current Japanese housing practice.

Figure 47 Hatsumatsumae, Okushiri Island Wall construction showing mortice and tenon joints to top and bottom plates. Note the failure of the nailed brace connection in tension
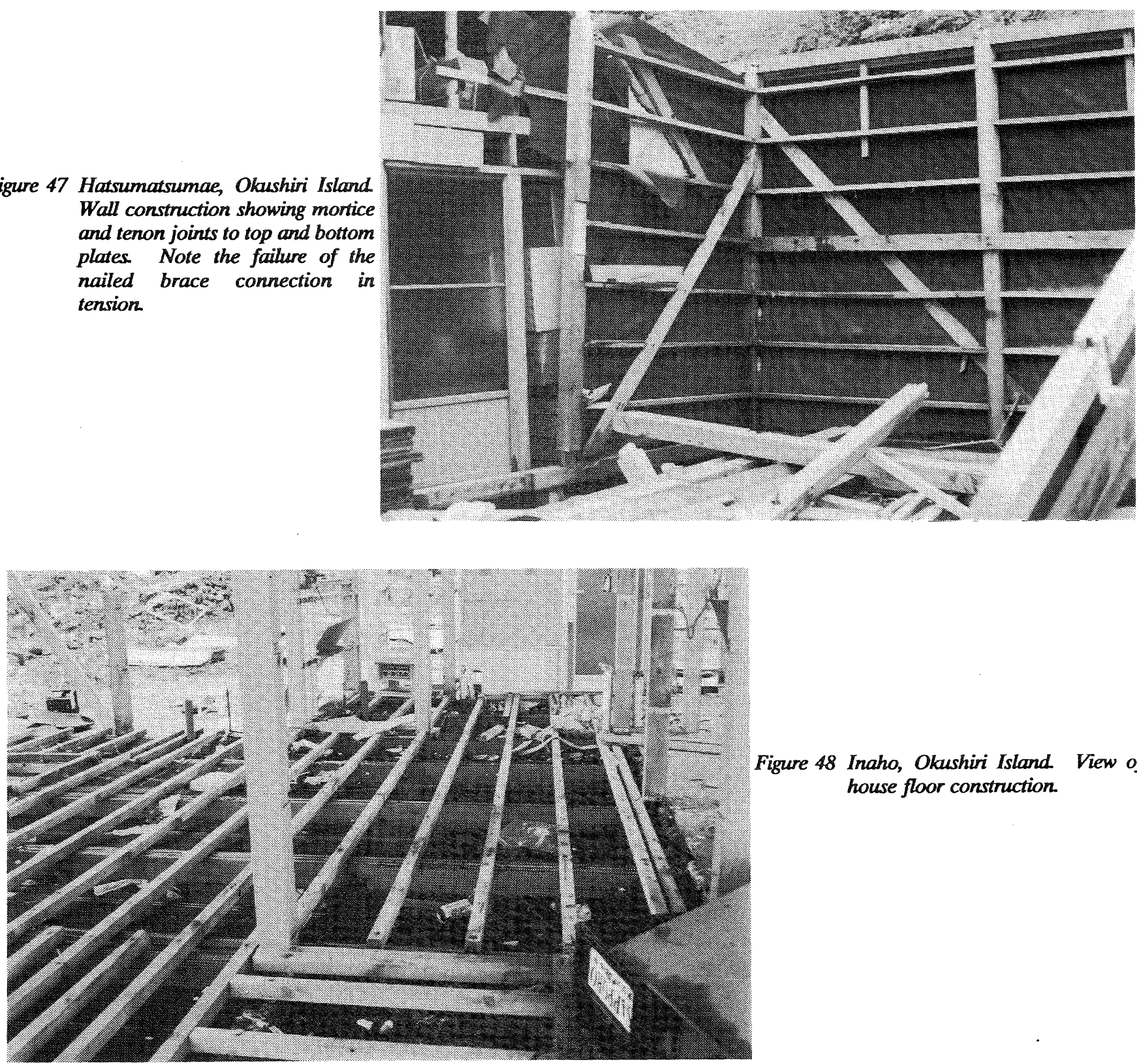

Figure 48 Inaho, Okushiri Island. View of house floor construction. 
Foundations are usually continuous $100 \mathrm{~mm}$ thick reinforced concrete with cross walls. Holding down bolts to the bottom plate are $12 \mathrm{~mm}$ diameter spaced at $1800 \mathrm{~mm}$ centres with a maximum of $500 \mathrm{~mm}$ from the corners (Figure 49). Precast concrete piles are internally spaced at a maximum of 1200 $\mathrm{mm}$, and $270 \mathrm{~mm}$ jack studs without ties or connections to the bearer, joist or pile (Figure 50).

Exterior cladding is usually 9 to $12 \mathrm{~mm}$ thick fibre-cement sheet material (Figure 51), but may in older houses be solid plaster, with or without backing. Interior linings are gypsumbased sheet material (similar to gib-board) about $9 \mathrm{~mm}$ thick. Nails used in frame construction are coated spiral shank flatheads, 80 by $3.8 \mathrm{~mm}$. There appeared to be no use made of nail plates of the types used in New Zealand (or similar) for connections or jointing. Specialised connections and braces are used in some positions (Figure $52 \& 53$ ). Roofs are usually sarked (Figure 53) with continuous metal roofing of various profiles used.

Timber houses of this type situated 4 to $5 \mathrm{~m}$ above sea level performed well even when subjected to complete inundation by tsunami with run up heights of up to $10 \mathrm{~m}$ (Figure 54). Primary damage to such structures, consisted of broken windows and punctures of the external cladding caused by floating debris. Secondary damage to house interiors, finishes and contents was considerable.

Ground shaking caused some damage to precast and cast in situ chimneys attached to timber framed houses. A typical chimney is $600 \mathrm{~mm}$ square with a $150 \mathrm{~mm}$ diameter salt glazed earthenware flue, and four $8 \mathrm{~mm}$ longitudinal reinforcing bars. In Iwanai-Cho alone 67 domestic chimneys collapsed.

The recommendations by some Japanese Authorities (Section 4.3.5) requiring reinforced concrete or masonry structures and houses to be placed in front of timber houses on coasts exposed to the risk of tsunami, could reduce the incidence of damage from floating houses and house debris. Nevertheless such structures, particularly the smaller ones, need to be designed to resist overturning by the tsunami (Figure 55). However, such planning measures could lead to higher local water velocities and the introduction of other problems such as scour and higher water pressures. The option of zoning to require rebuilding on higher ground does not appear to be a practical or acceptable solution in many cases.

\subsubsection{Breast Work Wharves}

The breastwork wharves at Hakodate and Mori ports were typically anchored steel sheet piling structures composed of arch-web interlocking piles, a reinforced concrete capping beam and an anchor rod to a deadman in the fill about $10 \mathrm{~m}$ behind the breastwork wall. A section through the wharf at Port Mori on the east coast of the south west peninsular of Hokkaido is shown in Figure 56.

At Port Mori which is about $130 \mathrm{~km}$ south east of the epicentre, the effect of the earthquake was to cause liquefaction and settlement of the fill materials behind the walls It is apparent that deadman anchors are rendered ineffective when the surrounding soil liquefies and the breastwork as a result moved outwards $600 \mathrm{~mm}$, with a tilt of 4 to $5^{\circ}$ and the pavement slabs behind settled $100 \mathrm{~mm}$ (Figure 57).
At Hakodate similar walls moved out more than $1 \mathrm{~m}$ at some points (Figure 20).

\subsubsection{Examples of Structures Which Were Undamaged}

A number of substantial structures in areas close to the epicentre performed well and were undamaged by the earthquake.

The nuclear power station at Tomari on the west coast of Hokkaido near Iwanai-Cho (Figure 58), about $90 \mathrm{~km}$ from the epicentre, is estimated to have been subjected to MM 7 to 8 intensity ground shaking, and the coast at the station was attacked by a tsunami with a runup height of $4-5 \mathrm{~m}$. The station was reported to be undamaged. On the day following the earthquake the Ministry of International Trade and Industry reported that all the nuclear power stations on Hokkaido and northern Honshu were functioning normally. It was not possible for the team to obtain permission to carry out an inspection of the plant.

There were a number of major buildings on Okushiri Island which were apartments, barracks and command centres for the Japan Self-Defence Forces. Typical of these is the five storey building shown in Figure 59. This building is located in Okushiri-Cho on the east coast of the island, about $60 \mathrm{~km}$ from the epicentre and about $25 \mathrm{~km}$ from the rupture zone, and is likely to have been subjected to at least MM 9 intensity shaking.

The building is a solid looking reinforced concrete structure that appears to be well built and conservatively designed. The team was unable to inspect the building which was reported to be undamaged.

\subsection{Tsunami}

\subsubsection{General Aspects}

A series of tsunamis generated by the earthquake battered Okushiri Island (Figure 60) and the south western coast of Hokkaido, and killed at least 120 people, which is about $65 \%$ of the confirmed death toll, as of 21 July. According to the Mainichi newspaper of 14 July [13], in the Aonae area of Okushiri Island, the tsunamis destroyed about 550 homes (Figures $61 \& 62$ ), and about 200 homes on the southern shores of Hokkaido. Nearly 270 vessels along the Japan Sea coast were sunk or swept away. In Hokkaido, about 110 of 140 fishing boats at Suttsu port capsized or were swept away, while about 60 boats were sunk at Setana.

In Japan, significant loss of life and property damage has been recorded over hundreds years due to tsunamis. For example, an earthquake which occurred near Ohshima, an island off the coast of Ojima peninsula, Hokkaido, caused a large tsunami in 1741 . The record for the last six decades is as follows. On 3 March 1933, a tsunami as high as $27.8 \mathrm{~m}$ killed 3,064 people on the coast of Miyagi prefecture. On 7 December 1944, a tsunami and shaking due to a magnitude 7.9 earthquake killed 998 people in Wakayama prefecture. On 4 March 1952, 33 people died, 815 buildings collapsed and 91 were washed away by a tsunami after a magnitude 8.2 earthquake struck off Hokkaido. On 23 May 1960, a tsunami triggered by a magnitude 8.5 earthquake off Chile killed 142 people and destroyed 1,599 buildings in north eastern Japan, after travelling about 17,000km from Chile. On 26 May 1983 , a magnitude 7.7 earthquake under the Sea of Japan, 


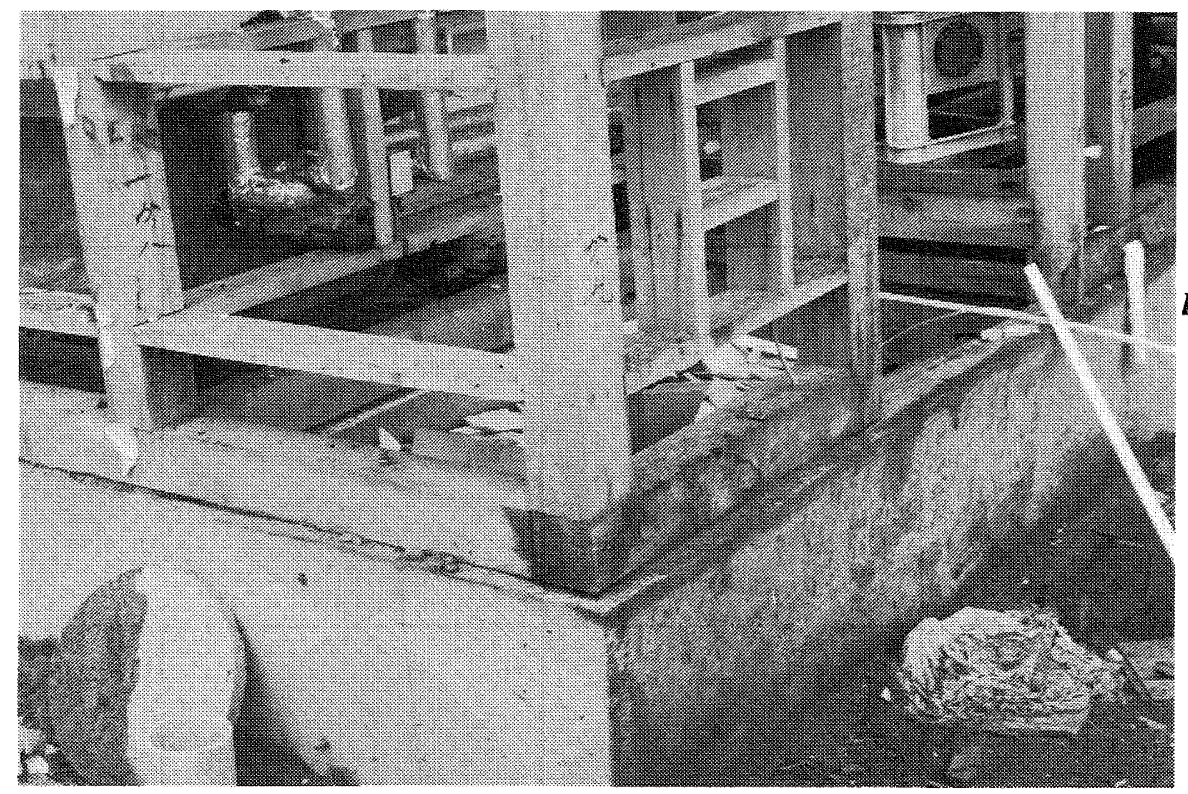

Figure 49 Inaho, Okushiri Island. View of comer of house showing holding down bolts to bottom plate. Note the comer stud sitting on the bottom plate does not appear to be connected to the plate.

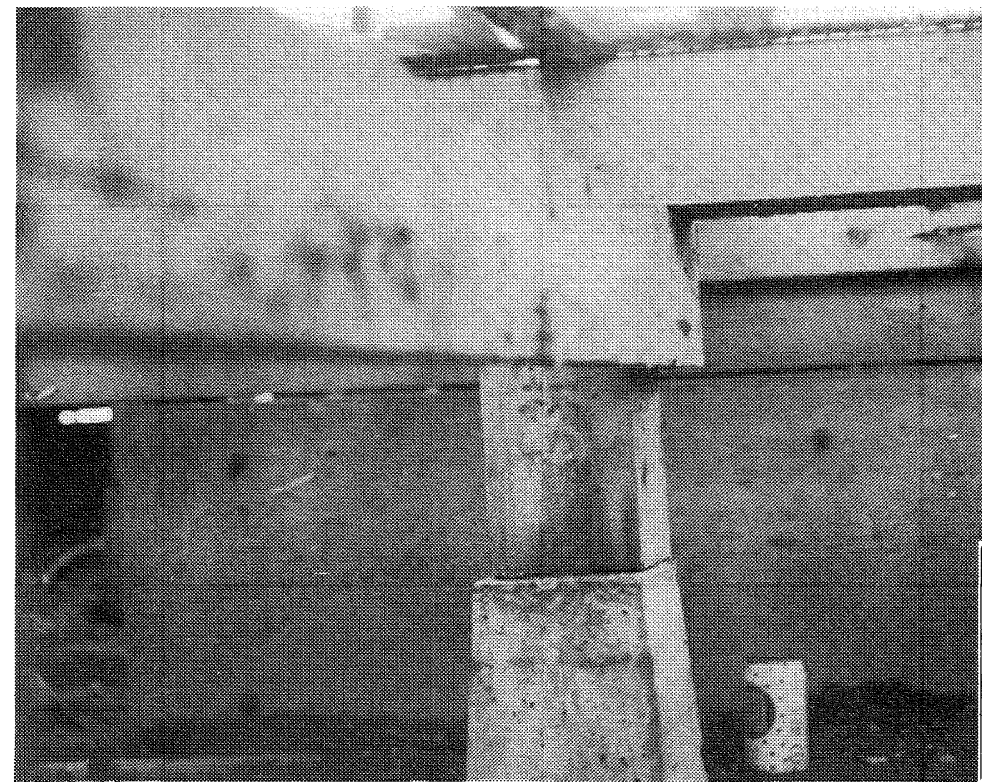

Figure 50 Inano, Okushiri Island View of intemal precast concrete pile and jack stud. Note the lack of connections jack stud to pile.

Figure 51 Hatsumatsumae, Okushiri Island. Fibre-cement sheet cladding to house Note the impact damage from floating debris at the comer.

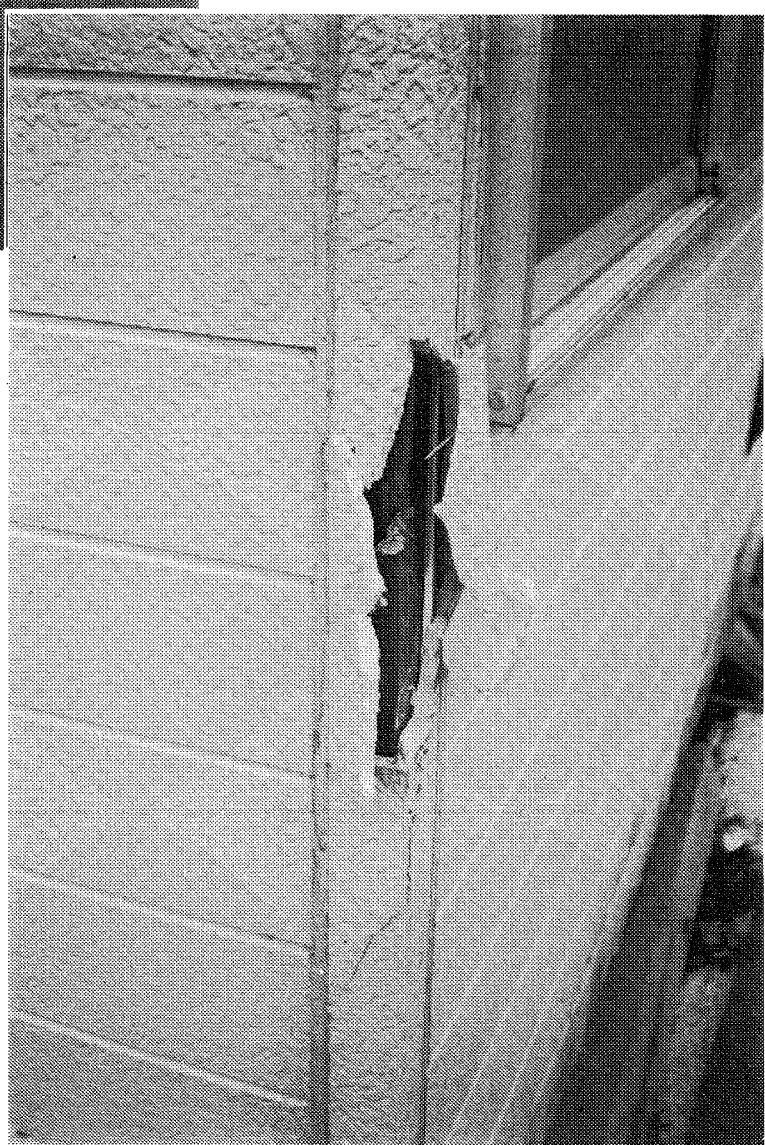


Figure 52 Inaho, Okushivi Island Corner detail showing specialised connector for cormer stud.
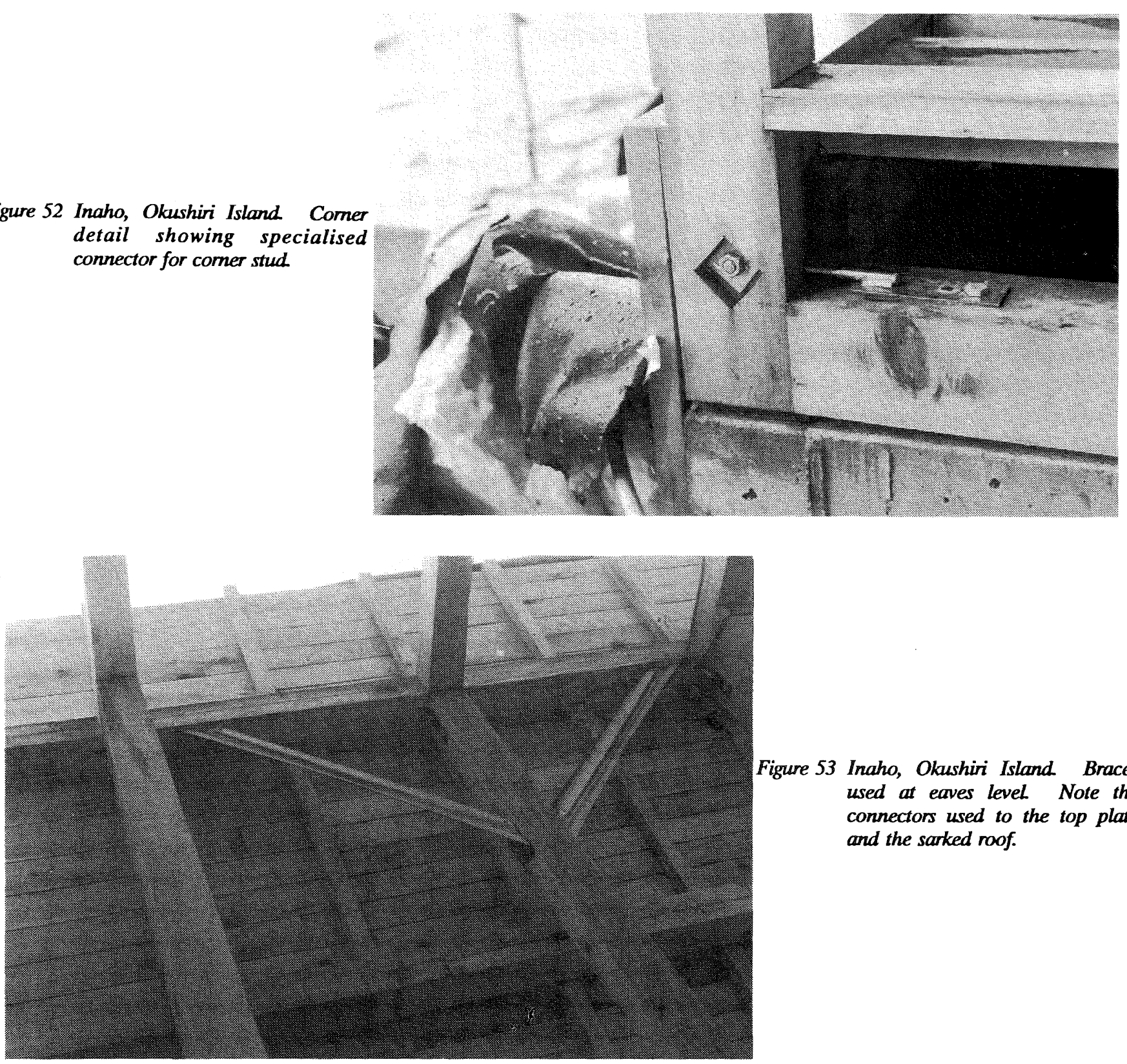

Figure 53 Inaho, Okushiri Island. Braces used at eaves level. Note the connectors used to the top plate and the sarked roof.

Figure 54 Inaho, Okushiri Island Timber framed house which survived the tsunamis which were about $5 \mathrm{~m}$ high. Note the damage to the external cladding due to floating debris.

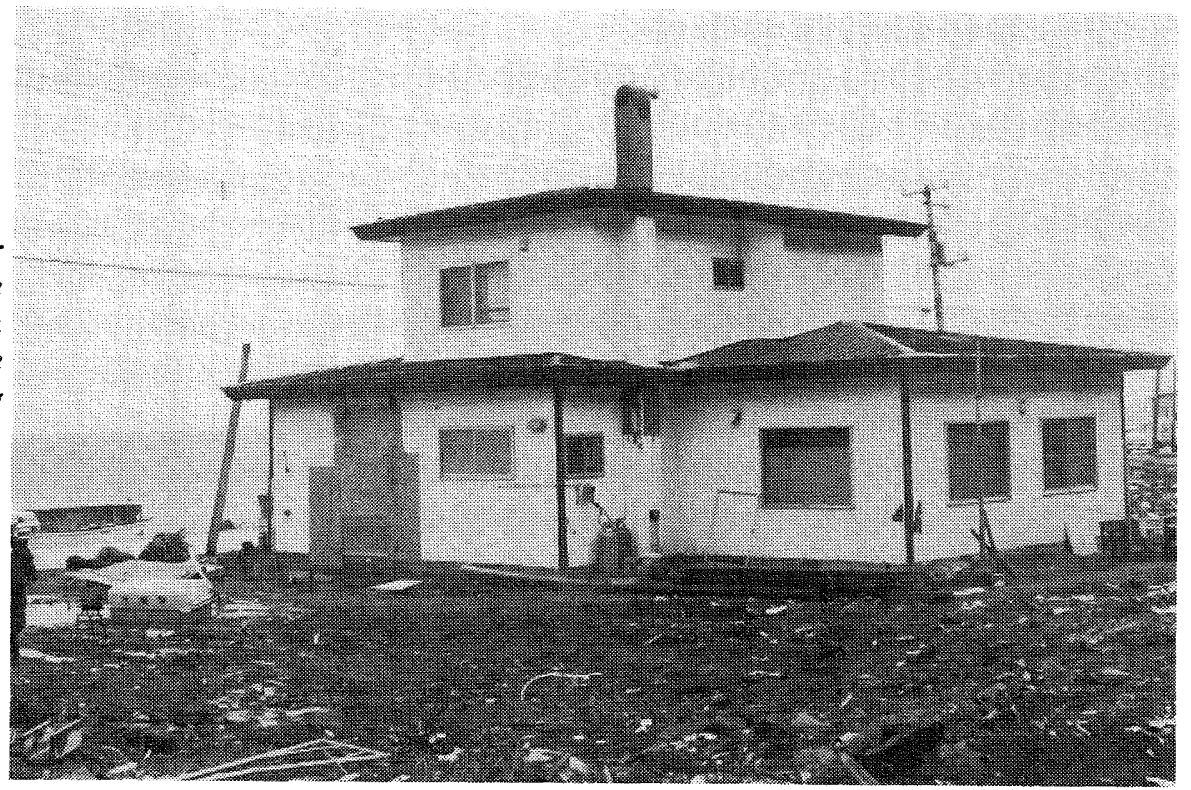




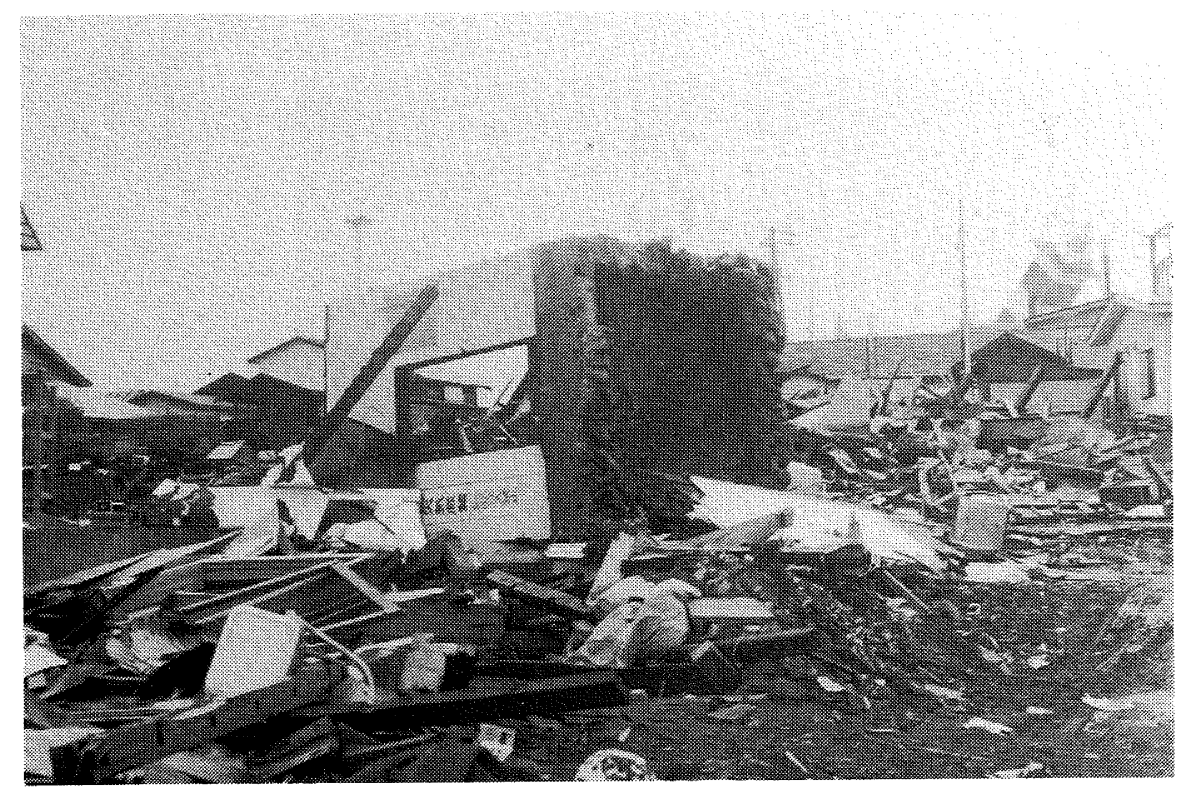

Figure 55 Aonae, Okushiri Island Small soled structure overtumed by the tsunami.
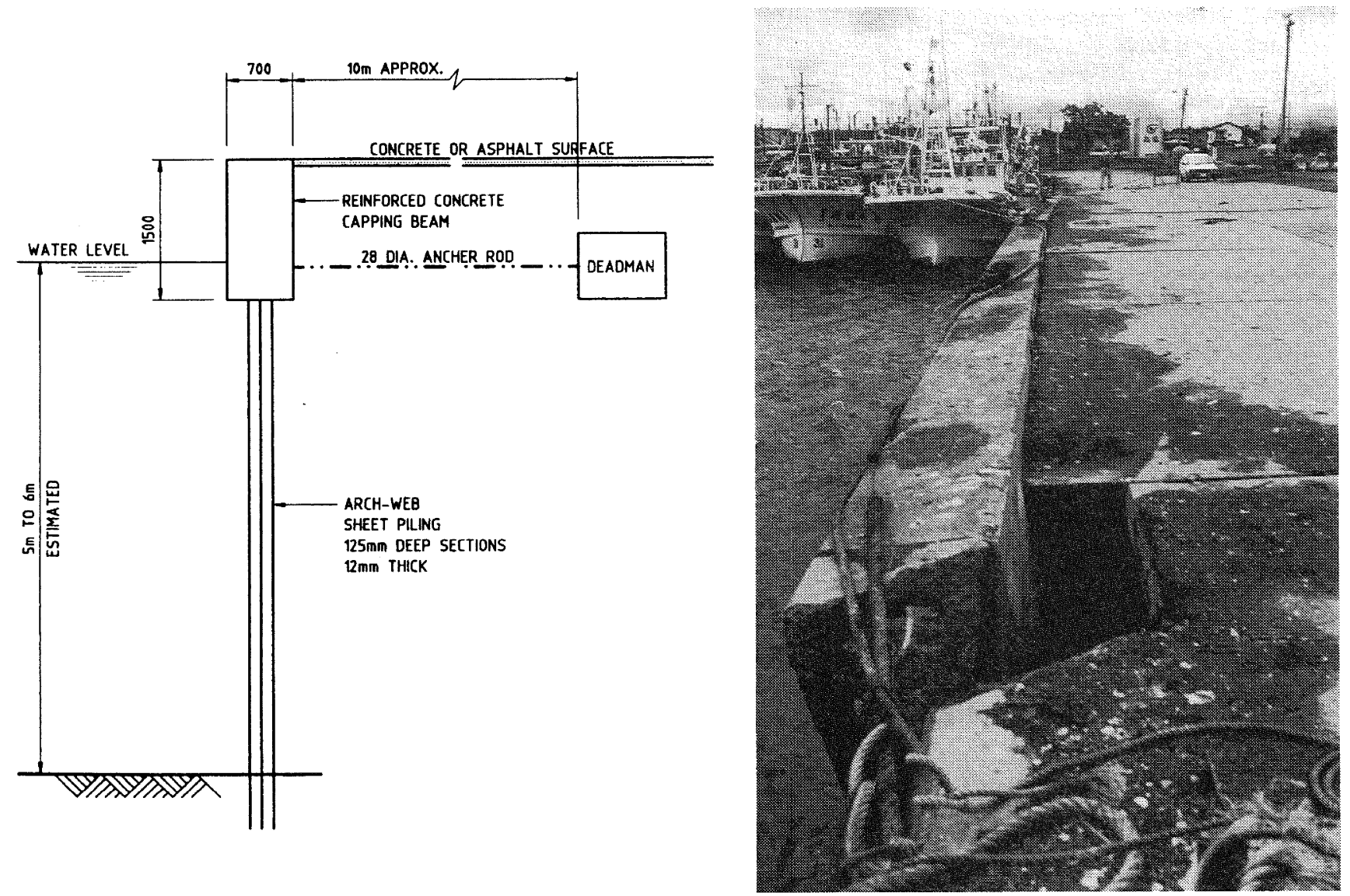

Figure 56 Port Mori. Typical section through breast work wharf.
Figure 57 Port Mori View showing tilting of bulkhead and settlement of pavement slabs. 


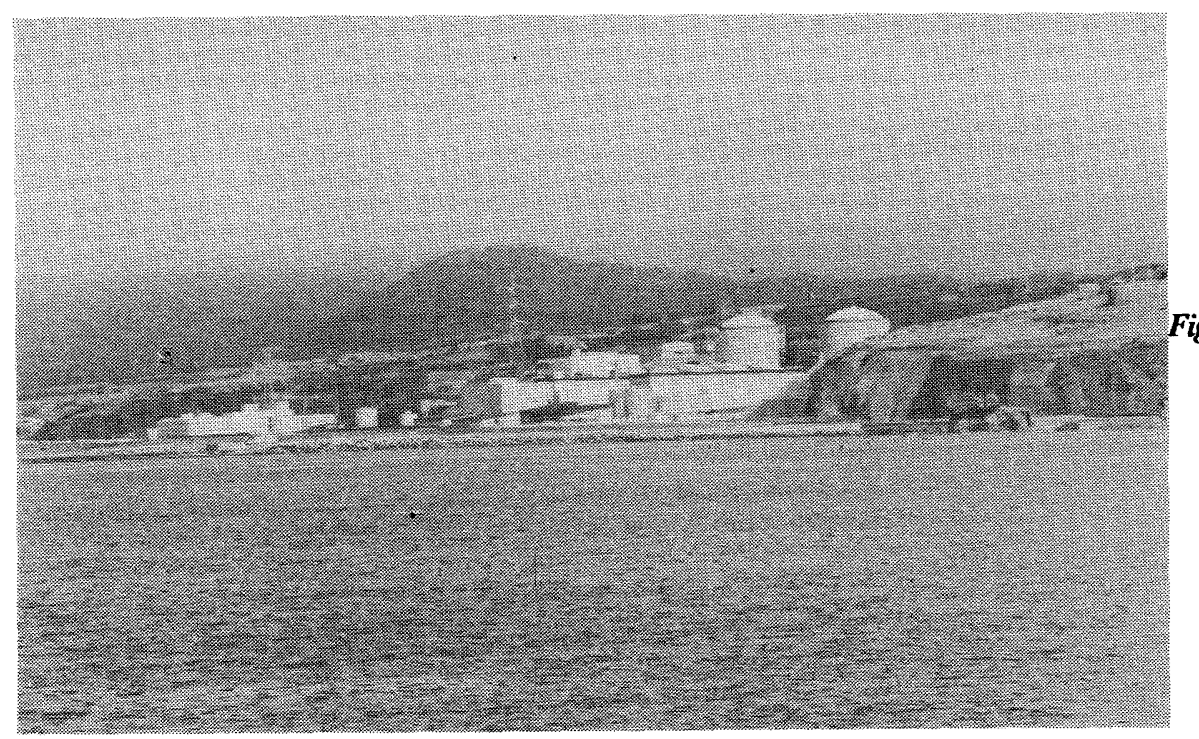

Figure 58 The Nuclear Power Station at Tomari, $90 \mathrm{~km}$ from the epicentre, was reported as undamaged.

Figure 59 Self Defence Forces apartments and barracks at Okishiri-Cho, 60 $\mathrm{km}$ from the epicentre and $25 \mathrm{~km}$ from the rupture zone, were reported as undamaged.
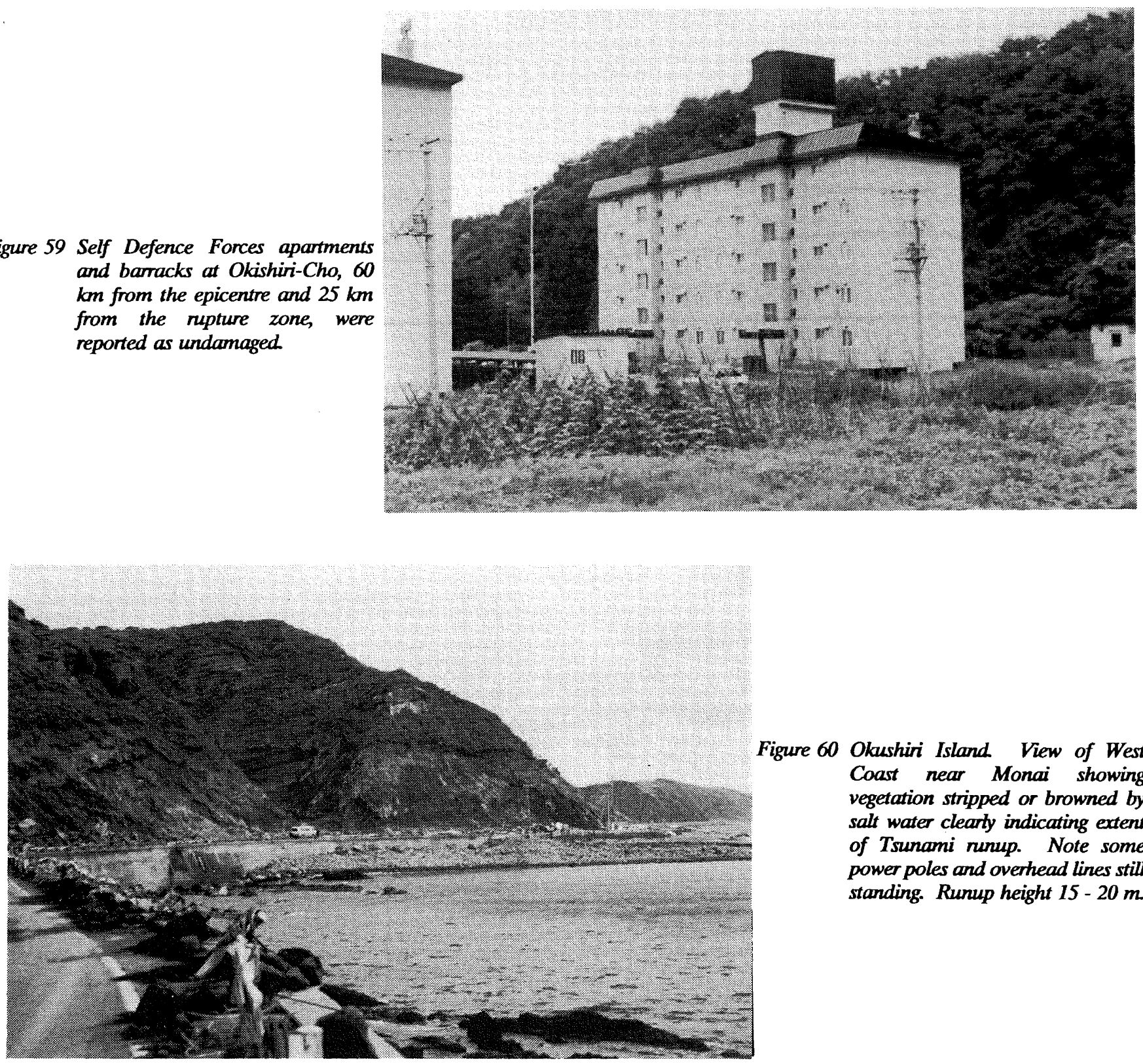

Figure 60 Okushiri Island. View of West Coast near Monai showing vegetation stripped or browned by salt water clearly indicating extent of Tsunami nunup. Note some power poles and overhead lines still standing. Runup height $15-20 \mathrm{~m}$. 


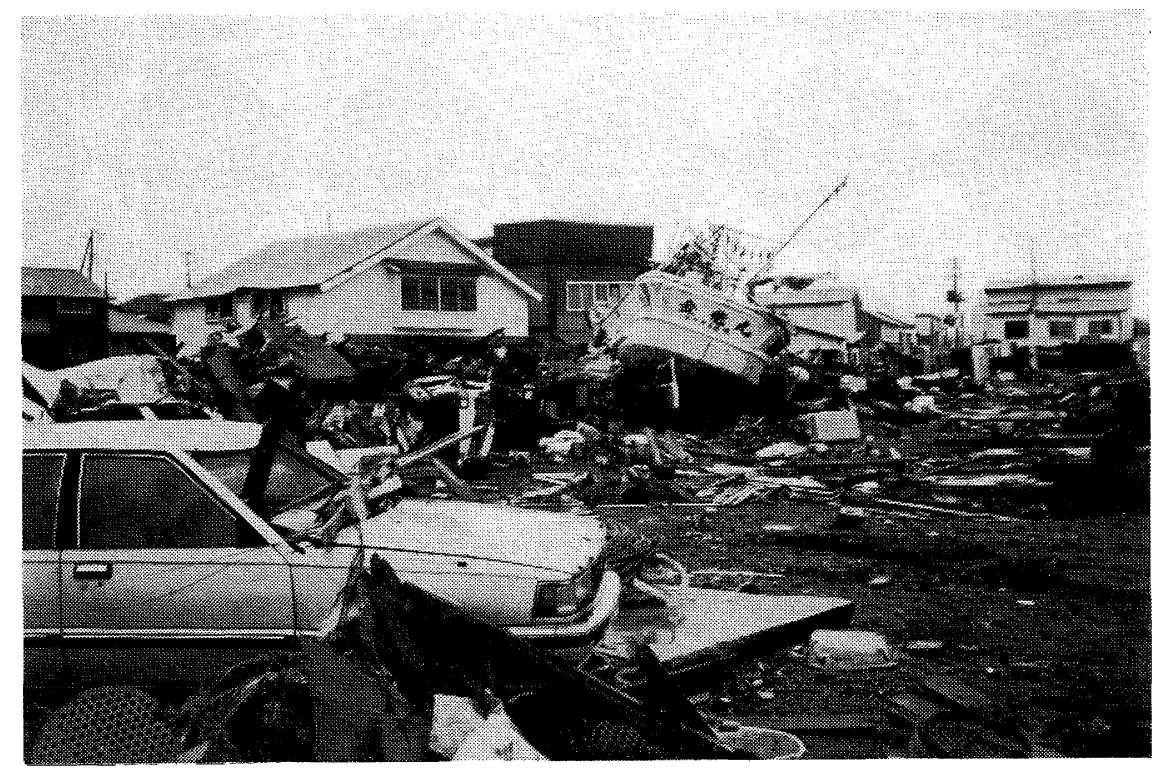

Figure 61 Okushiri Island, Aonae View of tsunami damage in the port area, to houses, boats, and vehicles. Note the fire appliance in the centre of the photograph

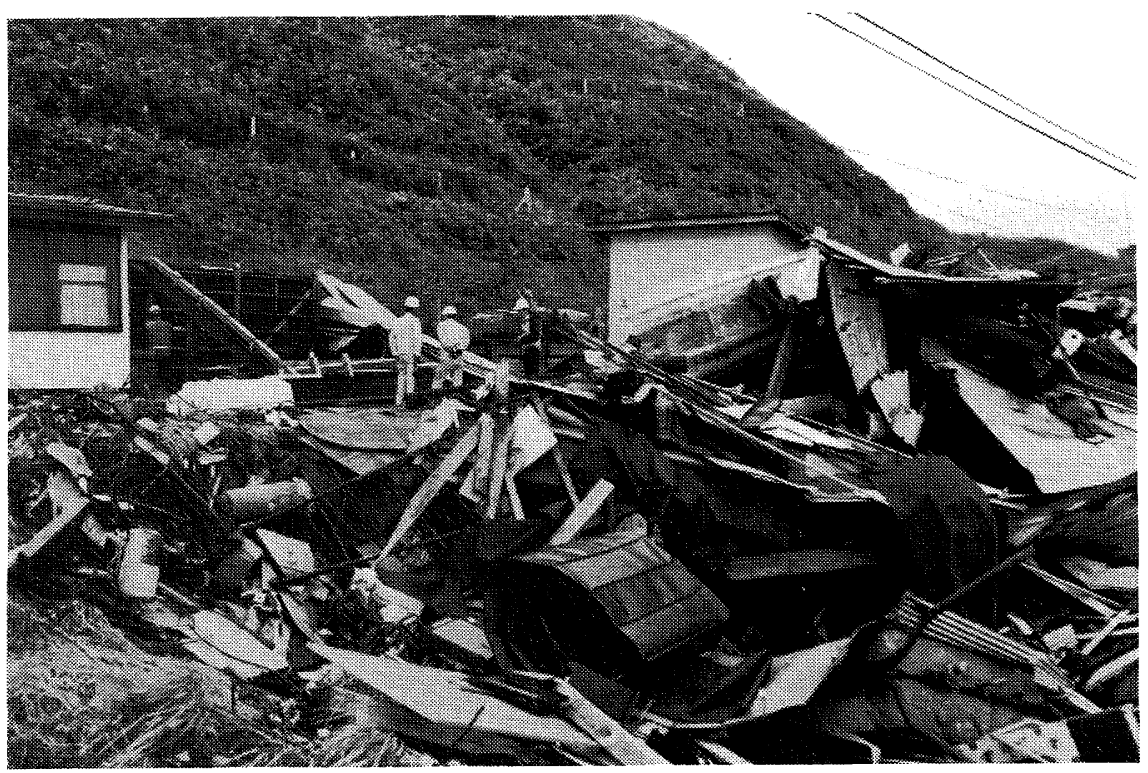

Figure 62 Okushiri Island, Hatsumatsumae View showing house debris from tsunami.

generated a tsunami, which killed 104 people and destroyed 934 buildings when it struck Akita and Aomori prefectures.

Because of the above experience, the Japan Meteorological Agency (JMA) has been making an effort to improve tsunami warning systems. For the Hokkaido-Nansei-Oki earthquake, JMA issued tsunami warnings only 5 minutes after the main shock, a great reduction on the 13 minutes it took for the event of 1983 mentioned above. Unfortunately this was still too late for many people on Okushiri Island.

The JMA has six regional centres for issuing tsunami warnings covering almost the whole of Japan. Each regional centre is responsible for issuing various warnings for its region. In the Hokkaido-Nansei-Oki earthquake, the Sapporo Local Meteorological Centre, Hokkaido, issued tsunami warnings. Tsunami forecasts issued by the JMA have six categories as follows:

* No tsunami: Tsunamis will not be generated

* Tsunami warning: Tsunamis of a few scores of centimetres are likely

* Tsunami alert: Tsunamis of a few scores of centimetres to 2 metres are likely

* Major tsunami alert: Tsunamis of 1 to 3 metres or more are likely

* Cancellation of tsunami warning

* Cancellation of tsunami alert 


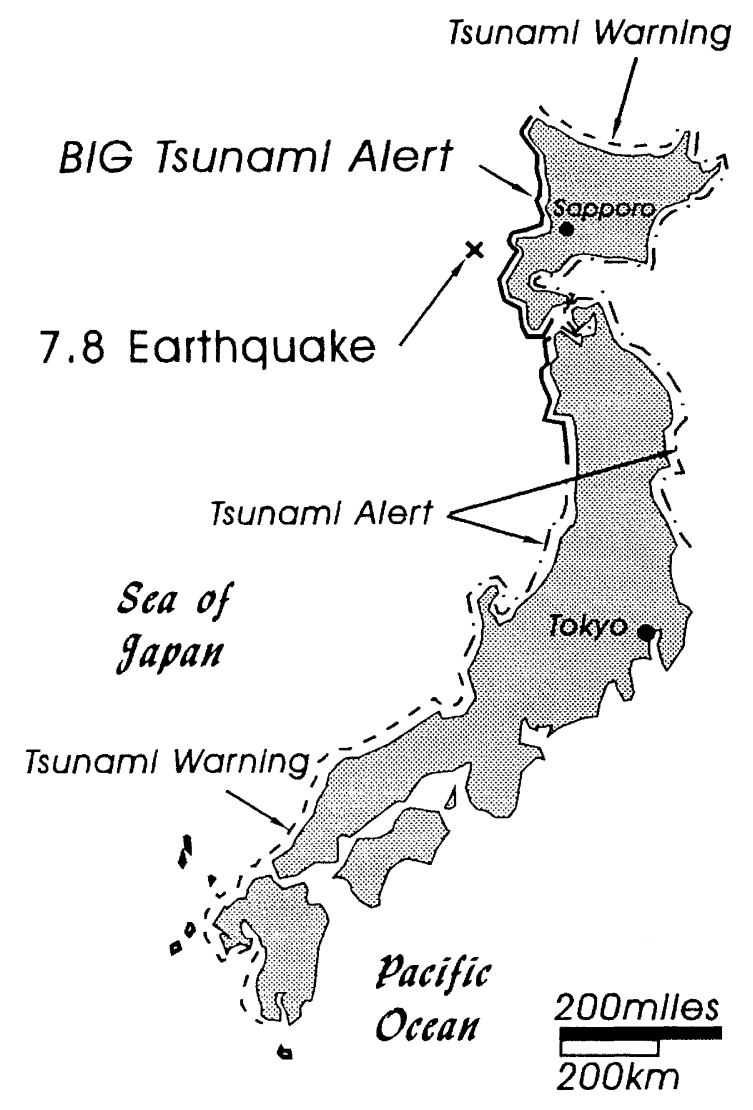

Figure 63 Areas where tsunami alent or warming was given.

Figure 63 shows the areas where a tsunami alert or warning was given. If a tsunami is not going to be generated by the earthquake, the issue of a "no tsunami" forecast is important to prevent panic and the possibility of secondary disaster such as fire. It is noted that if a small fire breaks out in a house after an earthquake and the residents believe that a tsunami is coming, they may evacuate the houses without extinguishing the fire. Possibly in the panic and rush to safely evacuate everyone immediately following the drama of the main earthquake shaking, the occupants of a house at Aonae on Okushiri Island left their house without extinguishing a small fire or turning off their cooking and heating appliances, which could have initiated the big fire which occurred later.

Cancellation of a warning or an alert is also important to advise people that further tsunamis are not expected. It should be remembered that a tsunami may consist of ten or more waves forming a tsunami wave train, with the individual waves following one behind the other between 5 and 90 minutes apart. In the severely damaged areas of Okushiri Island, the first wave flooded houses to about floor level, but the second wave, which arrived ten minutes later, washed houses away, according to Professor Tsuji of Tokyo University.

The popular image of a tsunami wave approaching the shore is that of a nearly vertical wall of water, but in fact most tsunami probably do not form such wave fronts [14]. Instead the water surface is very close to horizontal and it moves up and down, unless a tidal phenomenon known as a bore occurs. This is because the wavelength and period of tsunami waves are normally quite long. In the case of Okushiri
Island, it is believed that bores were not generated because of the topography around the island, according to Professor David L Wilkinson, University of New South Wales.

\subsubsection{Tsunami in New Zealand}

Compared to Japan, New Zealand in historical terms has had little experience of widespread damage and resulting loss of life from tsunami generated by earthquakes. De Lange and Healy [15] have identified 27 tsunamis occurring in New Zealand and generated by local and distant earthquakes in the period 1840 to 1982 . Of these, nine were from distant earthquakes and 18 were from local earthquakes (those occurring within the New Zealand continental shelf). However, the reliability of some of the tsunami reports is low.

The largest reported tsunami occurred on the Waikari River north of Napier during the Napier earthquake of 2 February 1931. This "tsunami" destroyed a woolshed and left fish strewn $15.2 \mathrm{~m}$ vertically above high tide level, although this was believed to be a locally generated wave produced by a large rotational slip on the opposite side of the Waikari Estuary.

The next highest locally generated tsunami was associated with the earthquake on the Wairarapa Fault on 23 January 1855. Eyewitness accounts reported tsunami heights of 9.1 to $10.3 \mathrm{~m}$ at one location on the Palliser Bay coast.

Although the rate of relative plate convergence in New Zealand is about half that of Japan, their locations at a convergent (subducting) plate margin and their tectonic environments are similar. However it is apparent that the New Zealand experience with tsunamis is very much less than Japan. The main reason for this appears to be that in historic times New Zealand has had no large, shallow earthquakes located offshore; all the earthquakes in the New Zealand region that have caused ground rupture during this period, have been located onshore. Whereas during the same period in Japan there have been many large magnitude earthquakes located offshore (Figure 3), a number of which have caused devastating tsunamis. Offshore marine mapping (mainly for oil exploration) along both the east and west coasts of New Zealand, indicates many active fault structures which appear to have the potential to generate tsunamis in the event of their sudden tectonic movement. Thus although large, devastating tsunamis seem to occur less frequently in New Zealand than in Japan, it should be recognised that they could occur. Factors that could affect the run up height of tsunamis in New Zealand include shoaling, the extent and influence of the continental shelf and the Chatham Rise on tsunamis from distant sources such as Chile.

While New Zealand is at risk from tsunami, this should be kept in perspective. Those aspects of the Japanese experience, including that of the Hokkaido-Nansei-Oki earthquake, which are relevant and applicable, can be utilised to improve our tsunami preparedness.

\subsubsection{Speed of Tsunami}

The JMA reported that the speed of the tsunami wave reached $652 \mathrm{~km} /$ hour. The tsunami wave speed, $\mathrm{v}$, is proportional to the square root of the water depth, $d$, and can be approximated as $\mathbf{v}=\sqrt{ }(\mathrm{gd})$, where $\mathrm{g}$ is the acceleration due to gravity. At the epicentre located $60 \mathrm{~km}$ 


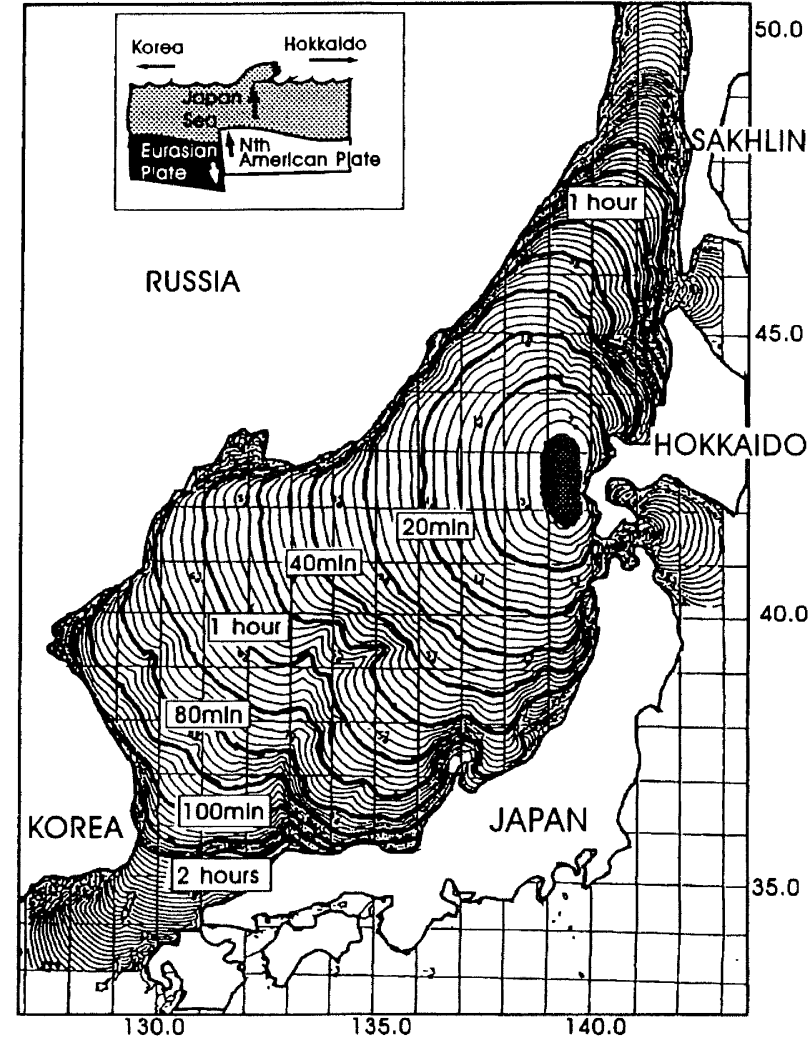

TSUNAMI TRAVEL TIME 12 JULY 1993 JAPAN METEOROLGICAL AGENCY

Figure 64 Tsunami travel times in the Sea of Japan, as calculated by the $J M A$.

north of Okushiri Island, the water depth $\mathrm{d}$ is $3,340 \mathrm{~m}$ which gives $\mathrm{v}=652 \mathrm{~km} /$ hour or $181 \mathrm{~m} / \mathrm{sec}$ from the above equation. Figure 64 shows tsunami travel time determined by the JMA. It can be seen how fast tsunami waves can travel towards the west coast of Japan and the east coast of the Eurasian Continent.

The average depth of water from the epicentre to Okushiri island is about $2,000 \mathrm{~m}$. It is noted that the depth of water near the coast of Okushiri Island is about $1,000 \mathrm{~m}$ and there is little or no shoaling beach around the island. This is the reason why the tsunami reached the island so fast without significant attenuation. Consequently, it took no more than five minutes for the first tsunami to reach Okushiri Island.

By comparison, the Ojima peninsula area on the south-west coast of Hokkaido, is located only $40 \mathrm{~km}$ from the epicentre, and was attacked by the tsunami some time later. This is because the area is surrounded by shoaling beaches with water depths of less than $200 \mathrm{~m}$ and hence the speed of the tsunami wave was attenuated [16]. It is of interest to estimate the average tsunami wave velocity when the waves run up a coast line. Taking the case of the area near Aonae port on Okushiri Island, Professor D L Wilkinson of the University of New South Wales and Dr B Hunt of the University of Canterbury, estimate the maximum velocity of the tsunami wave at the coast line to have been about 2.2 $\mathrm{m} / \mathrm{sec}$, assuming that the tangent of the ground slope is $1 / 30$ and the period of the wave is 10 minutes for the case of a 7 $m$ high wave run up. They derived an equation to estimate the velocity of the wave run up as,

$$
\operatorname{Max} v=h \underline{2 \pi} \cot \theta
$$

where $\mathrm{h}=$ height of wave run up, $\mathrm{T}=$ period of wave and $\theta$ $=$ slope of the ground

The above equation derivation has been based on the so-called "Level Reservoir Approximation" with the following assumptions; (a) The incident angle of the wave is normal to the coast line, (b) The wave surface is almost flat and horizontal compared with the slope of the land because of a long wave length. If the land slope is gentler and the period of the wave is shorter, a higher wave velocity is estimated. However, their estimate seems to be quite reasonable for the reasons discussed below.

According to Bernouilli's theorem, the pressure, $p$, of horizontal steady flow of fluid or gas against an infinite wall standing vertically is expressed basically by,

$$
p=\frac{\gamma}{2 g} v^{2}
$$

where $\gamma=$ density of fluid or gas, $\mathrm{v}=$ velocity of the flow and $\mathrm{g}=$ gravity acceleration.

When it is assumed that a house is submerged under a high tsunami wave with velocity of $2.2 \mathrm{~m} / \mathrm{sec}$, according to the above formula the pressure on the wall of the house is almost equivalent to the wind pressure with a velocity of about 63 $\mathrm{m} / \mathrm{sec}$. Under these conditions, a typical timber house could collapse. Since many of the timber houses near the coast line of Aonae were washed away or collapsed, but some remained, it is reasonable to consider that the velocity of the tsunami wave at the shore line was about $2.2 \mathrm{~m} / \mathrm{sec}$.

Even if the velocity of the tsunami wave is quite small, one or two storey timber houses inadequately connected to their foundations could become buoyant and be washed away. In fact many houses on Okushiri Island and the west coast of Hokkaido were just washed away without collapsing.

\subsubsection{Tsunami Height}

A group dispatched by the JMA, which included local meteorological observatory staff, recorded the heights of the tsunami wave at 59 places along the coast. The results from 49 places where maximum height traces of the tsunami had been clearly found, were recorded as official data and are shown in Figure 65 . The greatest runup height of the tsunami was observed on the west coast of Okushiri island, and reached $22.0 \mathrm{~m}$. The tsunami heights were measured from sea water level at the beach at the time of investigation to the clearly found traces of the Tsunami.

Figure 66 shows the results obtained by a group led by Professor Y Tusji, Tokyo university, where the greatest run up height of the tsunami is recorded as $30.5 \mathrm{~m}$. According to Professor Tsuji [17], the difference in results between the above two groups can be attributed mainly to the difference of the locations selected for measurement.

In south Korea, a tsunami wave of $3 \mathrm{~m}$ height was observed along the east cost and about 60 fishing boats were destroyed. In the Russian Far East, a wave measuring up to $3 \mathrm{~m}$ high struck at Nakhodka, a coastal town near Vladivostok about an hour after the earthquake [18]. 
HEIGHT OF TSUNAMI (m)

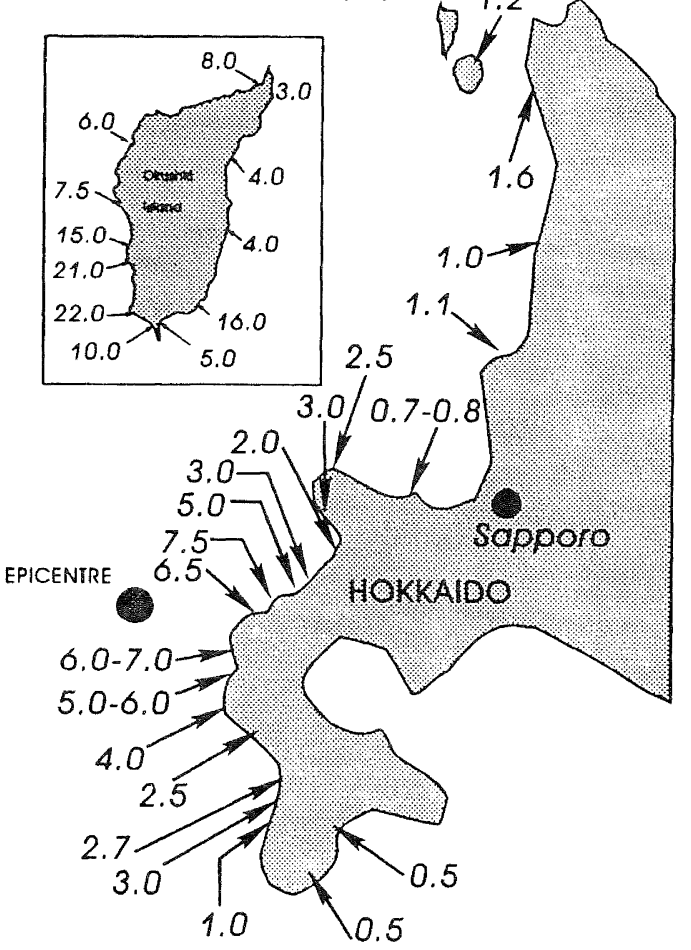

Figure 65 Official tsunami nun up heights measured by the JMA.

\subsubsection{Evacuation}

Many residents in Okushiri island were well aware of the danger of tsunami, as four people were killed and some fishing boats were lost ten years ago due to the tsunami caused by the magnitude 7.7 Nihonkai-Chubu-Oki Earthquake, of 26 May 1983. As a result of this earlier experience, some of the residents escaped to high ground before the Major-tsunami alert was issued. Experience of previous tsunamis has made many people respond quickly and has helped to save lives, not only on Okushiri Island, but also in other areas of Hokkaido and northern Honshu.

The Hokkaido Police carried out autopsies of 55 of 78 bodies recovered and found that the cause of death was mainly due to head injuries and fracture of bones rather than from drowning. Death due to fire was found in only one case. This means that most people died from being hit by floating debris or by being buried under landslides [19]. Based on this report, protection against head injury by wearing a securely fastened safety helmet may be advisable when escaping from a tsunami attack.

Professor Y Tsuji of the University of Tokyo suggests several key points to mitigate disaster due to tsunami as follows:

(1) People should not use a car when they attempt to escape from a tsunami that is likely to arrive in a short time. This is because cars are very vulnerable to tsunami attack, and there is likely to be obstacles on the roads, such as fallen rocks, sagging power lines, fissures and subsidence of roads. In addition, the use of private cars is likely to hinder the operation of vehicles by the emergency services eg. fire, ambulance, police etc.

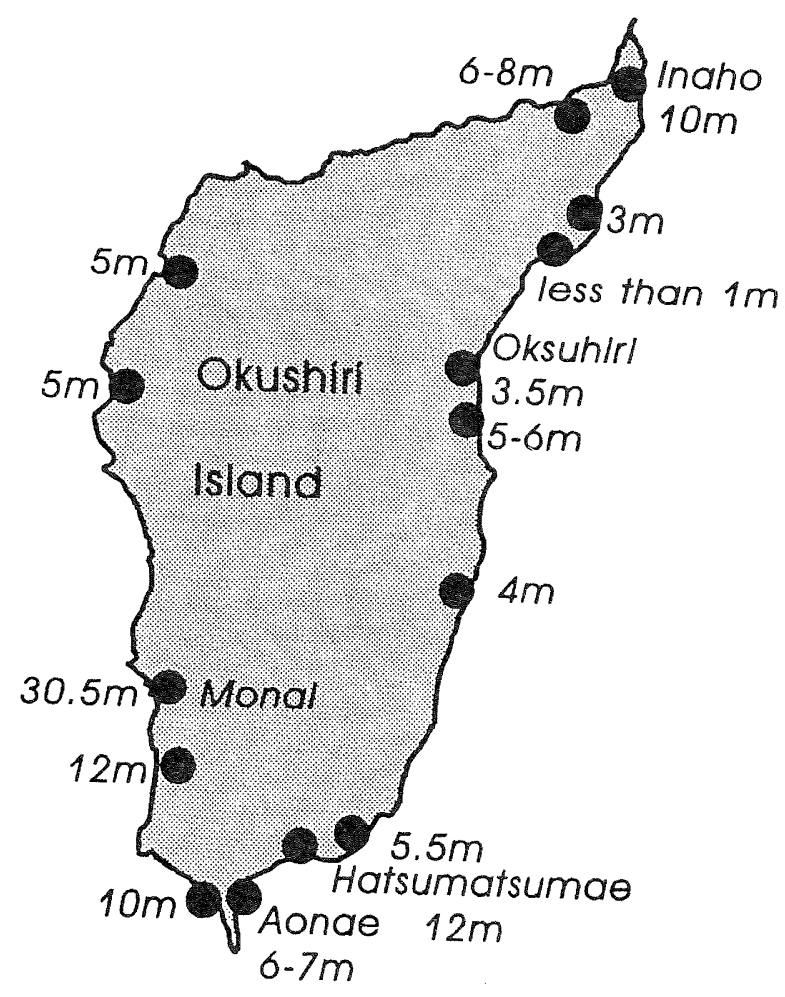

Figure 66 Tsunami run up heights measured by Prof Tsuji, Tokyo University.

(2) Street-lamps which indicate escape routes should have an independent power supply (such as solar batteries).

(3) Timber houses should be firmly connected to their foundations.

(4) It is recommended that reinforced concrete office buildings, warehouses, and domestic residences be constructed in front of timber houses to provide protection. This is because reinforced concrete or masonry buildings are firmly connected to their foundations, and experience shows that they can survive tsunami attack.

It is considered that the item (3) above may be very effective in preventing severe, chain reaction type damage to other timber houses. From interviews with residents it was found that much damage to houses on higher ground was due to impact from houses washed up from lower levels.

Some of the lessons obtained from the field investigation indicate that when tsunami attack is predicted, the local authorities should take the following precautions to alleviate disaster.

(1) Guide residents to adequate pre-planned evacuation assembly areas.

(2) Close roads running along the coasts at risk.

(3) Close railway lines running along coasts at risk and move trains to the nearest station.

(4) Evacuate vessels from harbours and move them offshore. 
and restraining the tanks and cylinders (Figures 69 and 70). It is possible that some of these tanks were overturned by the earthquake, or by the tsunamis, and the contents leaked out.

Some ruptured tanks, and many that were intact but empty were observed amongst the fire debris, indicating that tanks either vented safely or exploded. Diesel fuel on board the many fishing boats swept on shore by the tsunami, as well as petrol and diesel in the large number of cars and other vehicles engulfed by the fire, were additional sources of fuel.

Intervention by the fire service was mainly by conventional means, using water pumped either from water storage tanks or sea water from the harbour. The 38 strong volunteer fire brigade at Aonae was equipped with two appliances while a third, which was in poor condition was parked at the south end of the town, where it was destroyed by the tsunami (Figure 61)[6]. On the other hand, this appliance may have been engulfed while trying to warn residents of the dangers of a tsunami following the earthquake [12]. Interviews with residents at Esashi indicated that the police and the fire service utilised loud hailers mounted on their vehicles to warn the populace of the risk of tsunami following the earthquake.

The fire appliances available at Aonae [6], were equipped with a 2,000 l booster tank, pumps with a capacity 2,600 $1 / \mathrm{min}, 200 \mathrm{~m}$ of $65 \mathrm{~mm}$ hose, and two $4 \mathrm{~m}$ lengths of suction hose. New Zealand rural fire appliances are similarly equipped with a $2,000 \mathrm{l}$ tank, a pump with a capacity of 2,280

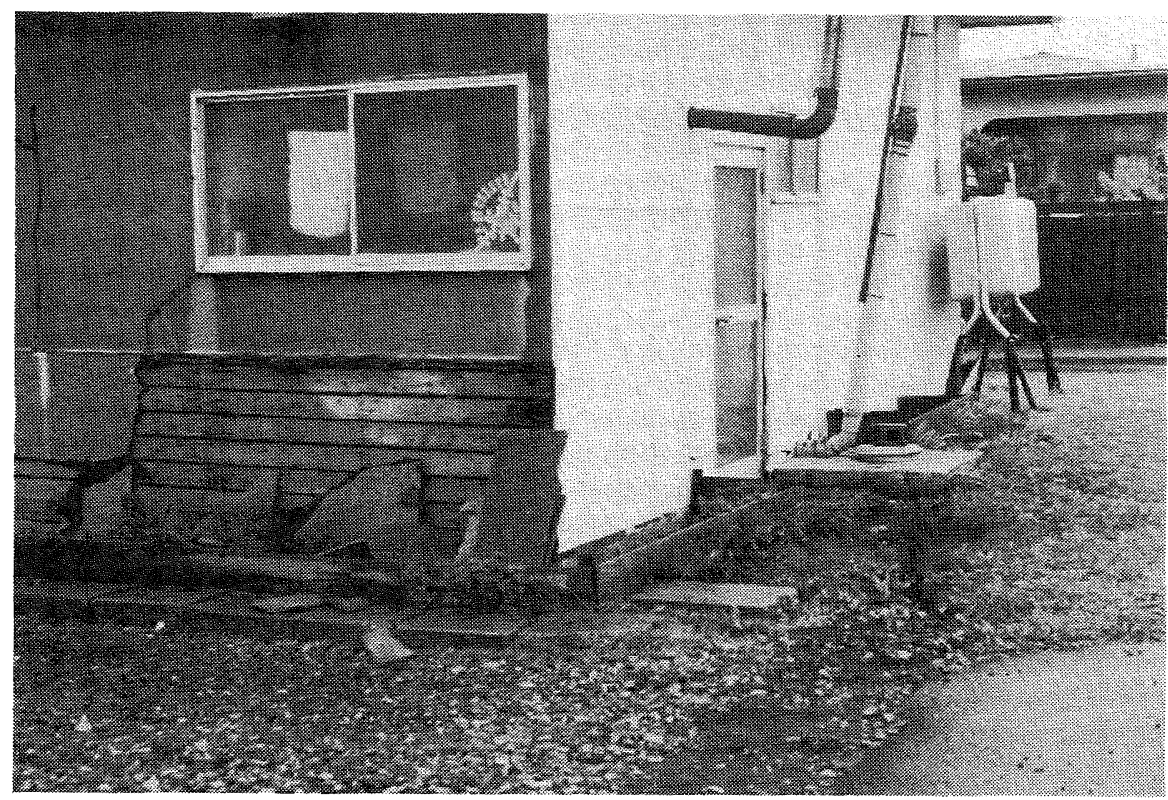

Figure 69 Okushiri Island, Aonae. View of 500 l kerosene storage tank used for heating. Note no special measures used to restrain tank.

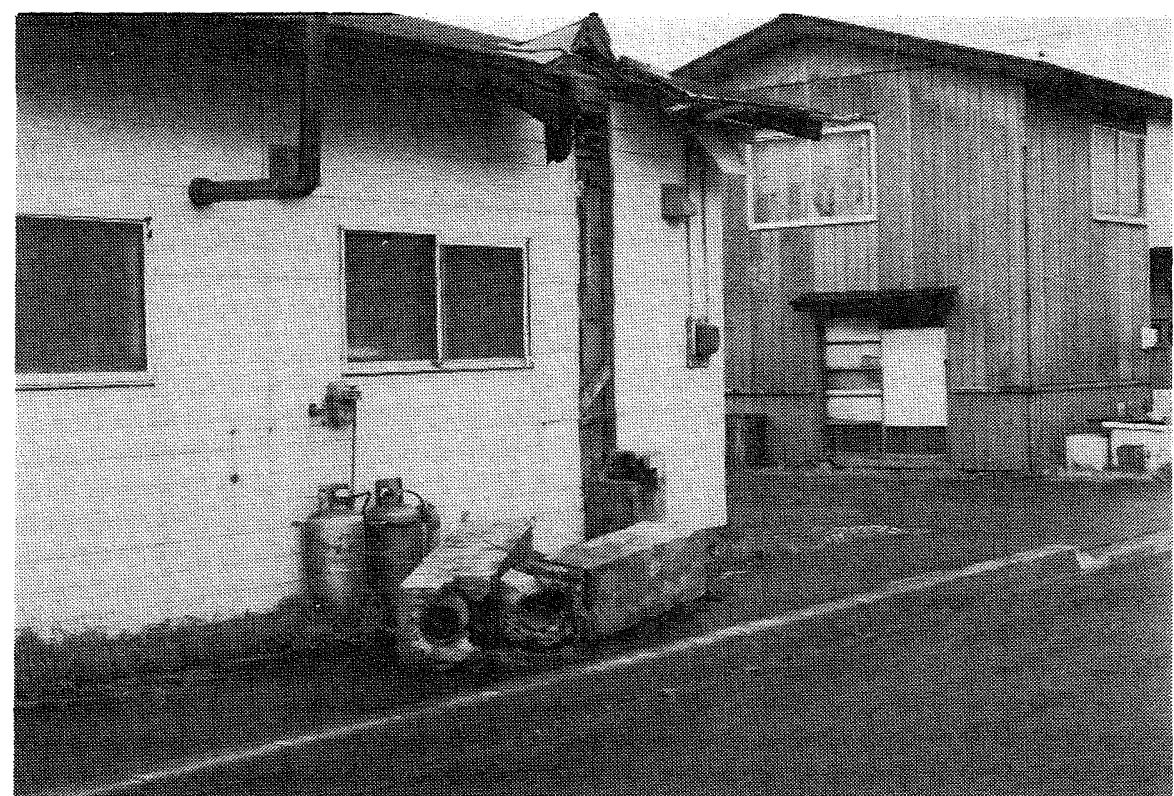

Figure 70 Okushiri Island, Aonae View of LPG cylinder installation 
$1 / \mathrm{min}, 600 \mathrm{~m}$ of 41,45 and $70 \mathrm{~mm}$ hose, a booster hose reel of $90 \mathrm{~mm}$ hose, and four $2.1 \mathrm{~m}$ lengths of suction hose.

Nine fire appliances and personnel were stationed at Okushiri-Cho including five smaller vehicles equipped with pumps. Only two of the smaller vehicles were able to reach Aonae to support the local fire brigade because the road along the coast was blocked in a number of places by landslides, and debris from houses, and boats destroyed or washed ashore by the tsunami. There was no alternative route to Aonae.

The approach to fighting the fire was influenced by:

1. The close proximity of houses and the narrow streets.

2. The amount of debris which restricted road access by conventional fire appliances to the seat of the fire.

3. The lack of back up resources from other fire brigades on the island.

4. The apparent inability to task helicopters with monsoon buckets for fire fighting because of other priorities.

5. The inadequacy of the reticulated water supply [6], and the commitment of resources to pumping from tanks and the harbour.

Fire spread was southward at about $35 \mathrm{~m}$ per hour and some two hours after the fire commenced a second fire ignited south of the fire front [6]. Later, a fire break was created at the southern end near the cold store and fish processing plant (Figure 71). The southward spread of the fire was stopped at 9.00 am on Tuesday morning, some 10 hours after the fire commenced. The fire break saved from destruction almost 40 houses and commercial buildings, which had survived the earthquake and tsunami virtually undamaged. The fire was eventually extinguished by Tuesday evening. According to Dr E Itoigawa, there was no room to stop the spread of fire earlier, due to the large amount of debris and the influence of the strong on-shore wind.

About 200 houses were destroyed by the fire, a number of which had been previously damaged or demolished by the earlier tsunamis. Some reinforced concrete or concrete masonry structures survived the fire without damage, for example, the cold store at Aonae Port (Figure 68). Only two of the 242 lives lost as a result of the earthquake could be attributed to the fire, and although there were many other villages and towns (approximately 30 in all), on Okushiri Island and Hokkaido which suffered similar initial damage to Aonae, no other fires were reported.

\subsection{Lifelines}

Damage to lifelines and restoration of services are discussed in the following sections.

\subsubsection{Roads}

Roads and highways on Okushiri Island and Hokkaido were damaged or blocked at 365 places as a result of the earthquake and the subsequent tsunamis. In most cases the damage was minor and easily repaired. The major damage was the slump which developed on Highway 5 (Figure 72) and the collapse of a section of the Shirato tunnel on Highway 229 (Figure 10). The damage is discussed in 4.1.1 and 4.2.

Most roads were reopened to traffic within a matter of a few hours or at the most 24 hours after the event. Highway 5 however was not opened to traffic for 18 days and Highway 229 was still closed three weeks after the earthquake.

\subsubsection{Bridges}

Five bridges were damaged as a result of the shaking, none seriously. Only one damaged bridge was closed to traffic and this was the Motoei bridge across the Assabu river (Section 4.2.6). Damage to this bridge and the nearby Yanagizaki bridge is discussed in 4.1 and 4.2.7. The most widespread minor damage to bridges was caused by the settlement of the approaches to bridge abutments (Figure 73). Repairs using asphalt smoothing coats to allow traffic free access to bridges was still being undertaken 3 weeks after the event (Figure 74).

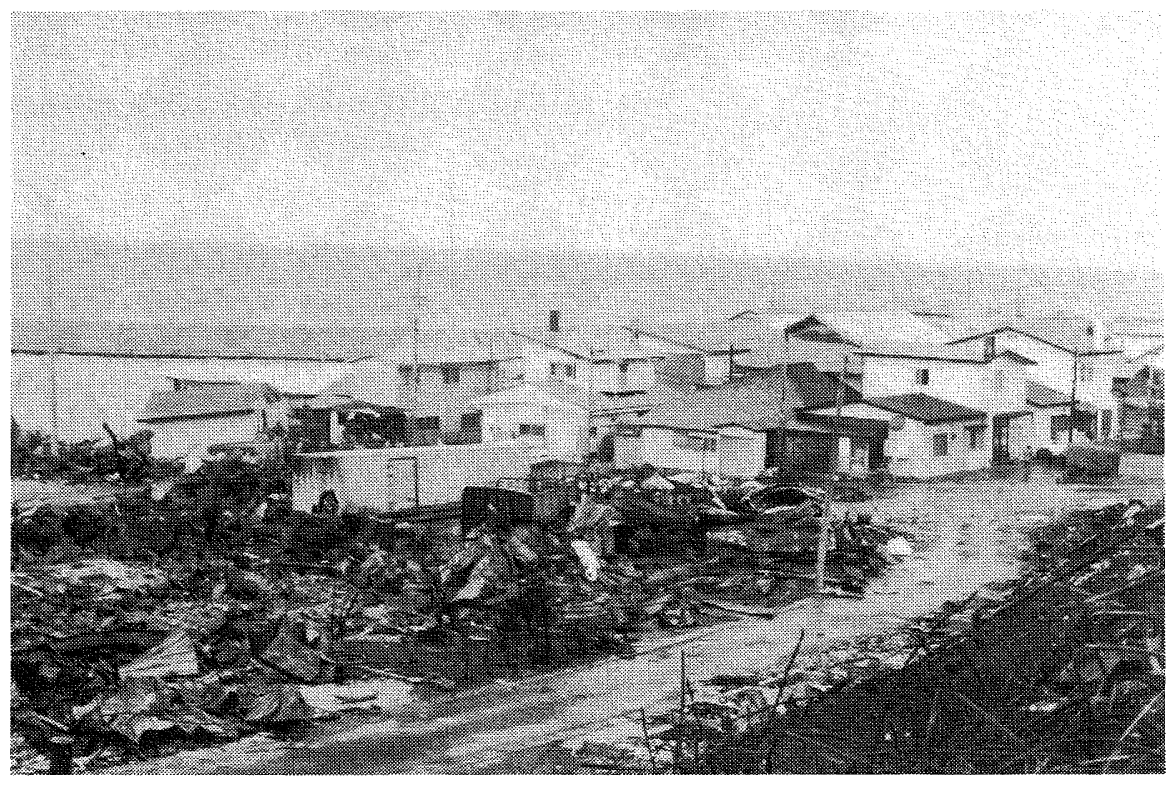

Figure 71 Okushiri Island, Aonae Firebreak at southern end. The cold store is to the left of the photograph. 


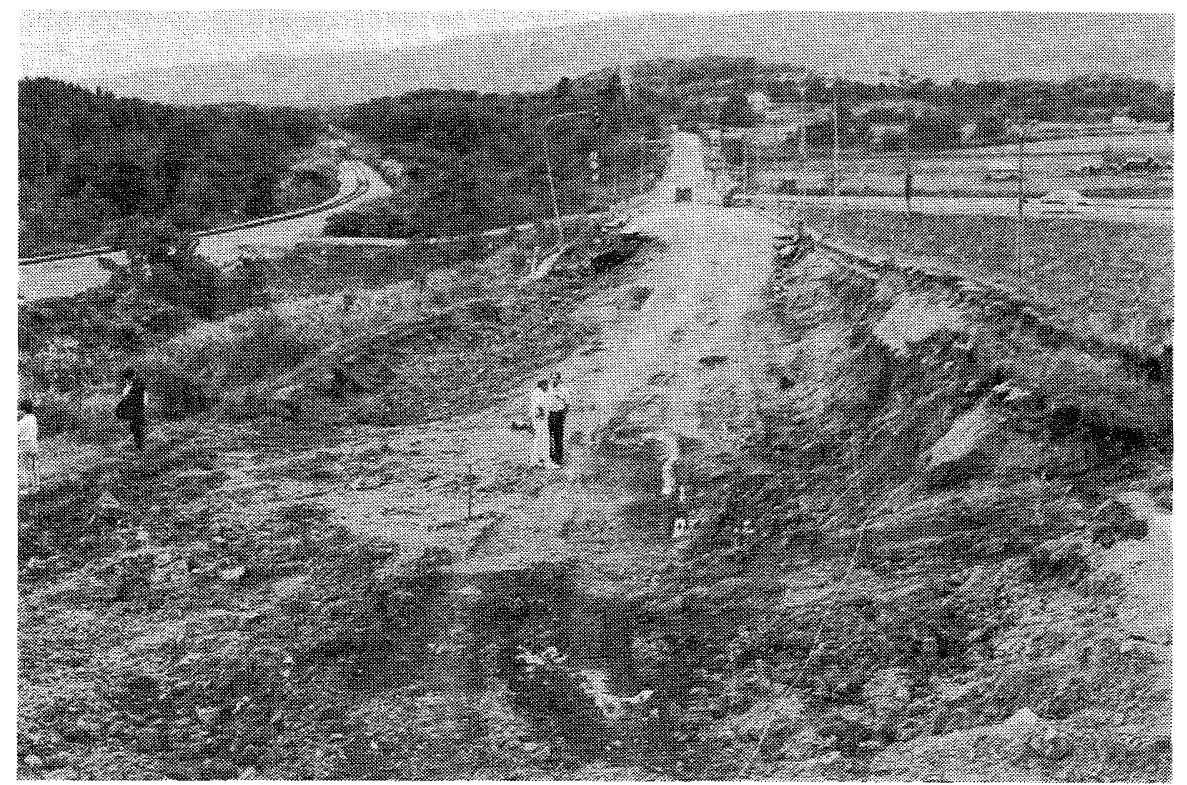

Figure 72 Slump on Highway 5 showing reinstated railway on the left and road deviation on the right.

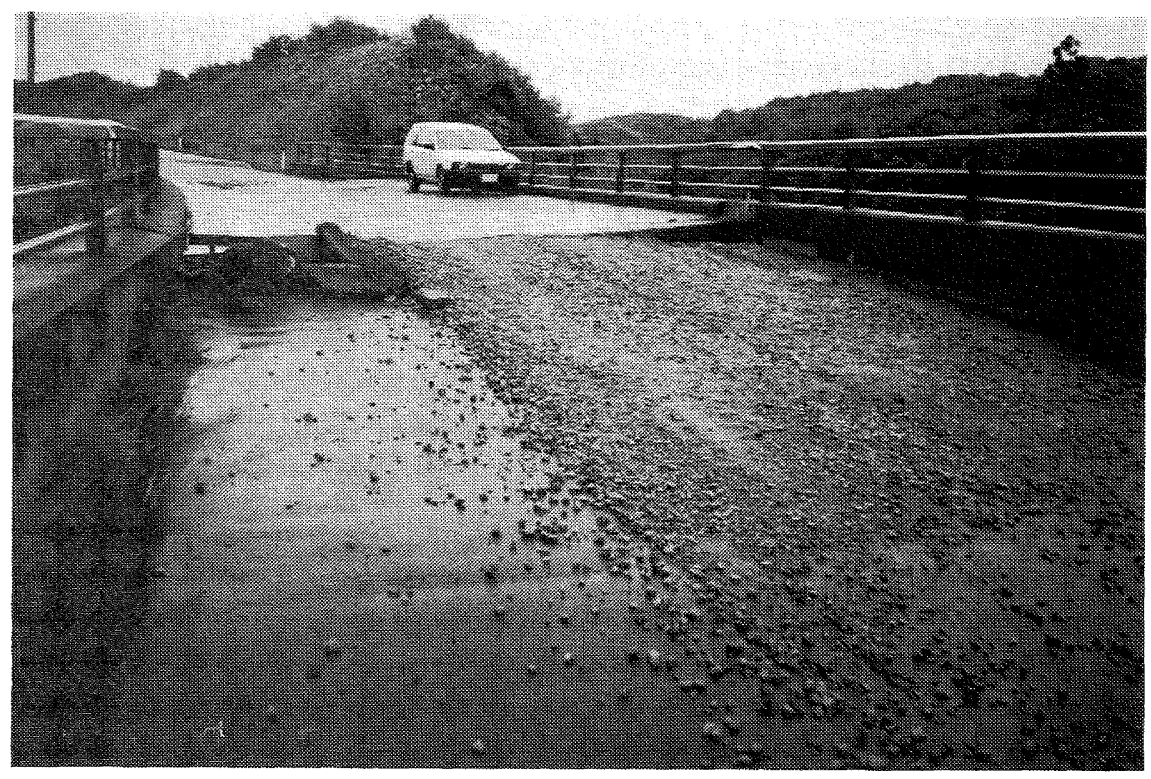

Figure 73 Okushiri Island Settlement of bridge approach and temporary repairs.

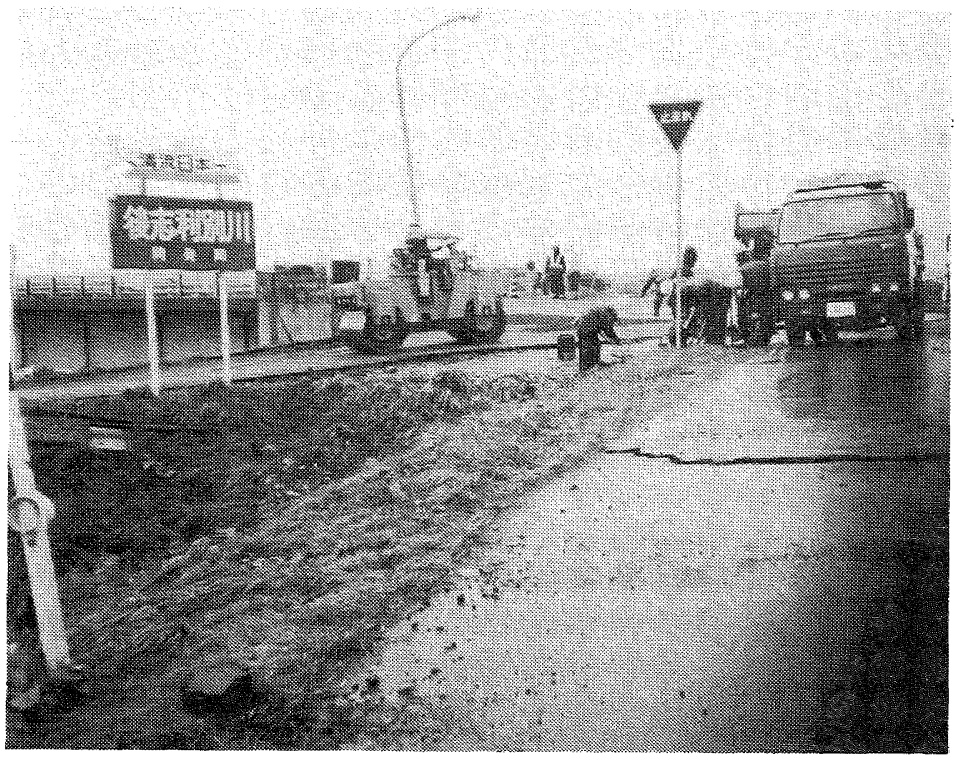

Figure 74 Shiribeshi-Toshibetsu River. Asphalt smoothing coat being applied to rectify settlement at bridge approach. 


\subsubsection{Railways}

Railway trackwork was damaged at 124 places but repairs were made quickly and services restored within a few days. This included the section of track adjacent to Highway 5 which was damaged by a rotational failure and is discussed in 4.1.

\subsubsection{Airports}

There are normally two daily flights by Air-Nippon between Okushiri and Hakodate. When the earthquake occurred, a $20 \mathrm{~m}$ section of the runway of the Okushiri Airport cracked and suffered relative displacement. Flights were cancelled for four days from 13 to 16 July until repairs were made. However the Airport was used by helicopters for emergency services from 13 July.

The airports at Hakodate and other cities in southern Hokkaido were not damaged.

\subsubsection{Ports}

The ports of Hakodate and Mori suffered liquefaction and settlement due to the earthquake which resulted in severe damage to pavements, services, breastwork wharves and the graving docks. The graving docks which were large enough to permit the construction of $350,000 \mathrm{t}$ ships were no longer in use at the time of the earthquake and are unlikely to be repaired. The breastwork walls tilted outwards more than 1 $\mathrm{m}$ in Hokodate and up to $600 \mathrm{~mm}$ at Mori.

The medium sized ports of Okushiri-Cho, Aonae, Esashi, and Setena and the minor fishing ports on Okushiri Island and the south west coast of Hokkaido, were attacked by the tsunamis with varying levels of damage.

One of the main reasons for the delay in restoring the ferry services between the Hokkaido west coast ports and Okushiri-cho on Okushiri Island was the number of cars, motorcycles and other debris swept into the harbour by the tsunamis. These had become obstructions in the shipping berths. At Esashi port for instance, 20 cars, had to be cleared from the ferry berth before services could be commenced. It is estimated that at Esashi a total of 30 cars and motorcycles were swept into the harbour. A similar number of cars had to be removed from the ferry berth at Okushiri.

Major protection works for the ports and harbours generally performed adequately although many were overtopped by the tsunami waves. These were in varying degrees of completion at the time of the earthquake with some of the walls in the second or third stage of extension or being raised. Armouring by variously shaped precast units had also been placed in front of the walls and out to sea, in areas of high risk from wave attack. The armouring systems are generally considered to have worked well, although some breakwaters consisting of large concrete gravity units suffered damage or displacement of units at a number of ports. At Okushiri ferry port the tsunami waves displaced a number of large ( 6 by 3 by $3 \mathrm{~m}$ ) concrete breakwater sections (Figure 75). A number of gravity sections of sea wall were overturned seaward by the retreating water loading the inside exposed face of the walls.

\subsubsection{Water Supply}

The number of households with disruptions to their water supply was initially 14,600 [12]. The disruptions were due to damage to mains, reticulation and connections and loss of power to pumps. In most areas full supplies were restored within a few hours, or during the following day.

At Aonae a welded steel water main was broken, presumably by the tsunami, where it crossed a stream below a bridge [6]. As a result of this, together with damage to the reticulation and house connections due to the tsunami and subsequent fire, full water supply was not restored until about two weeks later. During this period emergency supplies were trucked in by tankers of the Ground Self Defence Forces.

At Oshamanbe the water main was damaged in a number of places by ground movements and was replaced by a temporary $150 \mathrm{~mm}$ diameter PVC pipe laid on the ground surface (Figure 76). The Nakanosawa primary school at Oshomanbe however was still without water 20 days after the event.

At Iwanai-Cho there was no disruption to the water supply.

The result of encasing an underground pipe in concrete so that rotations or movement due to ground damage are localised is clearly shown in the example of damage to a ductile steel water main at Hakodate Port (Figure 77).

\subsubsection{Television and Radio}

It is understood that the television and radio stations were functioning during and after the earthquake. Japan Broadcasting Corporation (NHK) televised the emergency news at 22:24, 7 minutes after the earthquake. However, due to the power cut in Okushiri television was not an effective media to send emergency messages to the damaged area. Instead, people received news on the emergency through portable radios. According to the Hokkaido newspaper on 13 July, the people who were evacuated to the schools etc. had been listening to the radio to obtain information about tsunami during the night of the event. According to the Mainichi newspaper of 14 July [13], a woman in Okushiri-cho drove her car to higher ground car immediately after the earthquake to avoid the tsunami, following instructions given through a cable radio broadcast.

\subsubsection{Telecommunications}

No serious damage to the telephone system was reported except on Okushiri island where overhead lines were brought down by the tsunami. A large parabolic antenna was installed by the Nippon Telegraph and Telephone Co (NTT) on 15 July and services to Okushiri island were fully restored. The main problem the telecommunication system faced was the severe overloading of the services for a period of two to three days after the earthquake, resulting in long delays in obtaining outside lines.

According to the EERI Newsletter [6], two Remote Control Switches (RCS) are present on Okushiri Island; one in Okushiri-Cho and the other in Aonae. The Okushiri-Cho RCS is located in a two-story reinforced concrete building on firm soils. Atop the building is a $40 \mathrm{~m}$ high free standing steel truss microwave tower. No damage or problems were reported for the tower, microwave, telecom, electrical or 

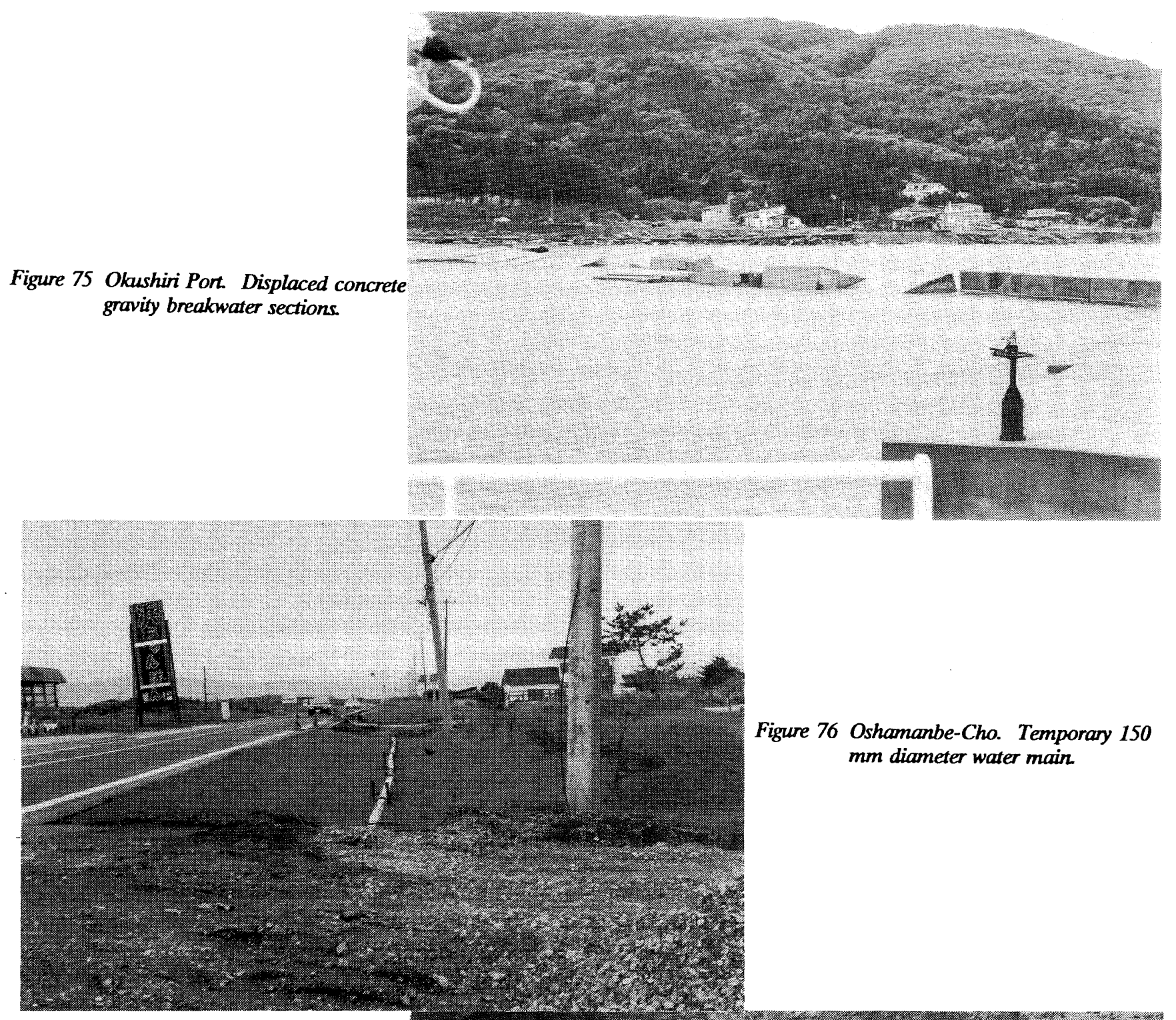

Figure 76 Oshamanbe-Cho. Temporary 150 mm diameter water main

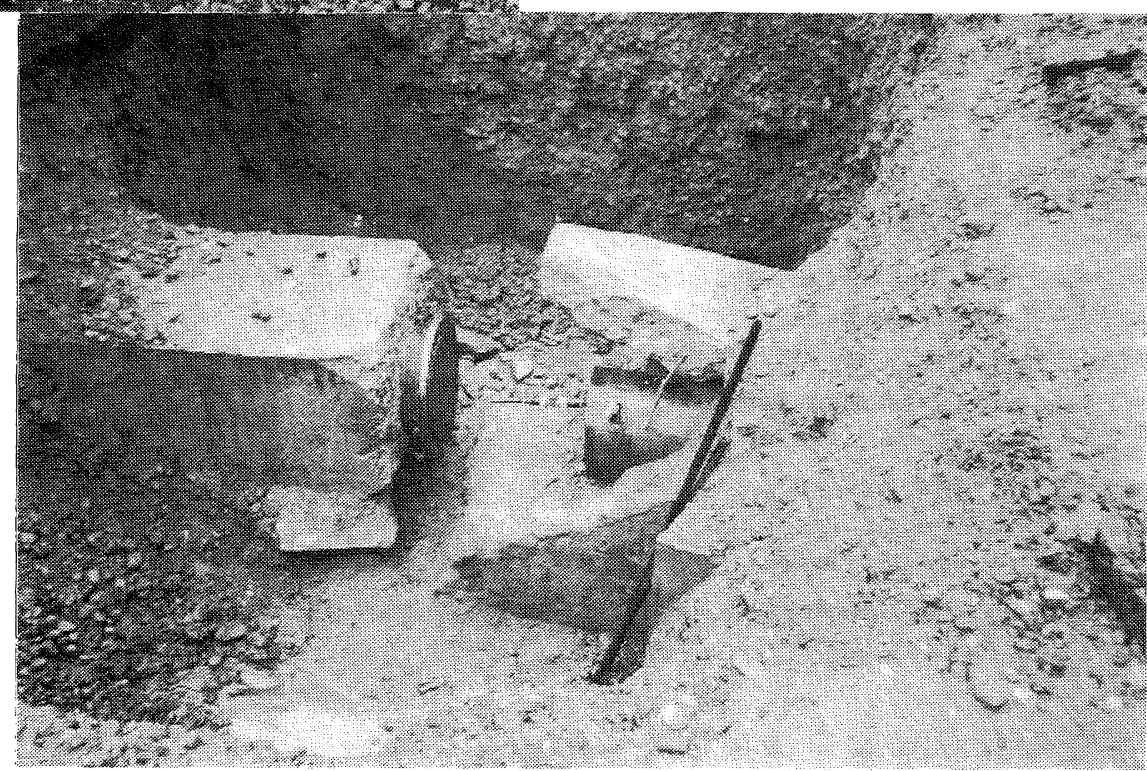

Figure 77 Hakodate Port. Damage to $300 \mathrm{~mm}$ diameter steel water main encased in concrete. The buckled section has been cut out ready for welding in a new section of pipe. Note the displacement of the encased sections of pipe and the splitting of the concrete where buckling occurred. 
other equipment in the building, nor for the building itself. Backup diesel generators functioned well following the quake.

\subsubsection{Newspapers}

A valuable feature of Japanese newspapers, including the English language papers, is the extensive publication of detailed technical articles and current reports on events such as the Hokkaido-Nansei-Oki earthquake. Articles of human interest are also well covered. Some of the information presented at the briefing for the team came from such sources.

New Zealand newspapers on the other hand in the same circumstances appear to concentrate only on the human interest aspects and the response of the emergency services.

\subsection{Response of Emergency Services}

The emergency services at local, prefecture and national government level responded rapidly and efficiently to the emergency. Overall control was exercised through the Prime Ministers Office, where an emergency headquarters was set up under the control of a cabinet minister, in accordance with the Disaster Relief Law. Similar headquarters were set up by the Hokkaido Prefectural Government under the Governor and at levels controlled by the mayors.

Under these various emergency headquarters, financial assistance was provided to localities designated as disaster areas in terms of the Disaster Relief Law for help in reconstructing the infrastructure. Also, affected farmers and small to medium businesses were eligible for low interest loans. In addition, families were eligible to receive compensation for the loss of the head of the household (5 million yen; NZ\$85,000), and for the loss of a family member (2.5 million yen; NZ\$42,000) [12]. Temporary houses (Figure 78) were built in the Aonae district on Okushiri Island following the earthquake and it is planned that these will eventually total 300 [12].

The achievement of issuing tsunami alerts and warnings for significant stretches of the coastlines of Hokkaido and
Honshu Islands five minutes after the event was remarkable and an impressive improvement on the time taken for previous earthquakes. Unfortunately on this occasion it was not early enough to precede the first tsunami wave at Okushiri Island.

The deployment of the Japan Self-Defence Forces and specialised police units into the disaster area was extremely rapid. They played a vital role in the emergency services response following the earthquake. The Self-Defence Forces provided: medical nursing and rescue services; food and medical supplies; and together with the police, provided helicopter support; all within the first few hours. They also provided ships and dive teams for search and rescue and for the recovery of bodies. The Ground Self-Defence Forces provided emergency water supplies and construction teams for the erection of temporary housing.

Some indication of the extent of emergency services provided immediately after the earthquake can be seen from Appendix 2: "The Sequence of the Events and Response of Emergency Services". Early in the morning of 13 July, 8,500 meals, 1,300 blankets, 1,200 items of clothing and $164 \mathrm{~kg}$ of medicines were sent to the Okushiri Island by a transport ship and an escort ship of the Maritime Self Defence Force. 50,000 l of drinking water was sent by a fishing boat from Otobe-Cho, a town located at the west coast of Hokkaido. More food, blankets, milk, diapers, etc were also sent by ships of the Maritime Safety Agency, the JMA and helicopters of the Ground Self Defence Force.

A typical example of the emergency response measures taken by a municipal government is that at Iwanai-Cho. Iwanai-Cho is located on the west coast of Hokkaido and has an area of $70.6 \mathrm{~km}^{2}$. As of 31 December 1992, the population was 19,116. The town suffered from the Hokkaido-Nansei-Oki earthquake and the following tsunamis. As a result, 67 houses and 5 public facilities were damaged. Typical damage was failure of chimneys, spalling of plaster on walls, etc. Damage to roads, river banks, and port facilities was found in four, one and 14 places, respectively. Three fishing boats and three cars were damaged by the tsunami. The organisation of the disaster relief and the

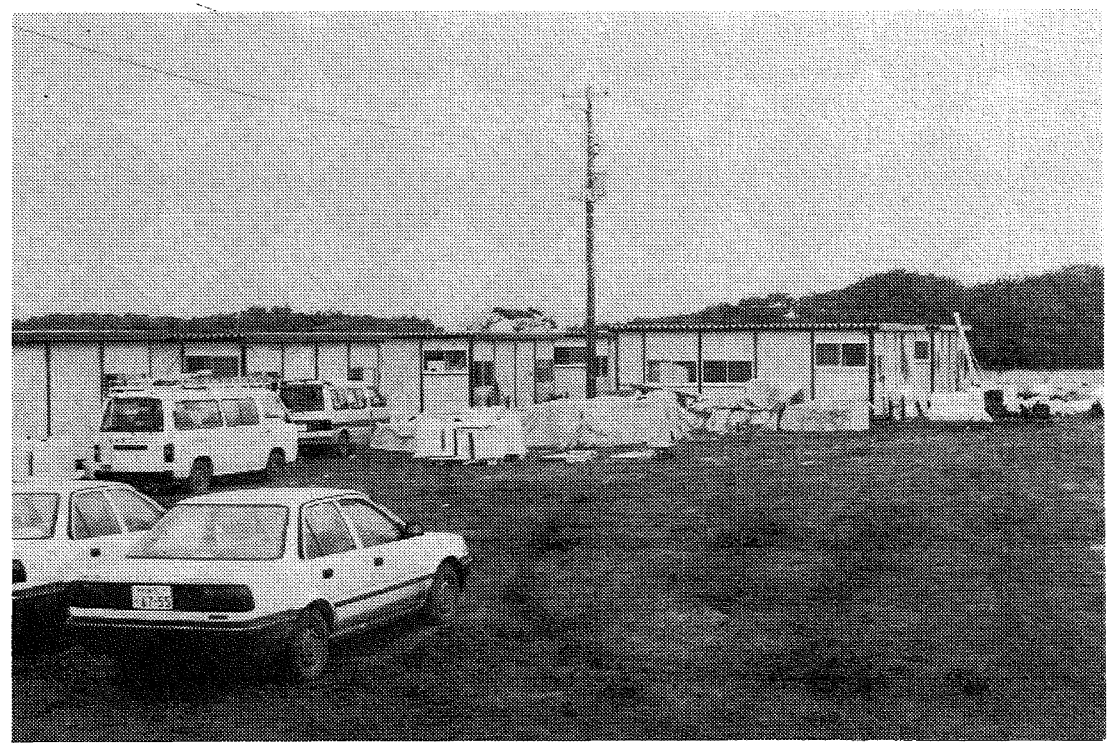

Figure 78 Aonae, Okushiri Island. Temporary housing erected for those made homeless by the tsunamis and fire. 
avallable emergency services are shown in Appendix 2 , from where it can be seen that preparations for the supply of emergency water and food received high priority.

The Hokkaido Development Bureau (HDB) is a large planning, design, and construction organisation of the National Government with responsibility for the construction of lifelines such as roads, bridges, ports, and river protection works as part of the infrastructural development of Hokkaido Prefecture. The nearest New Zealand equivalent would have been the now defunct Ministry of Works. As an essential part of the emergency services response immediately after the earthquake, the HDB carried out surveys of these lifelines and organised temporary repairs and initial reinstatement. The HDB also prepared more detaled assessments, cost estimates, and data for submission to Government for financial approval of the permanent repairs to damaged lifelines during the recovery phase.

\section{EARTMQUAKE ENGINEERING PRACTICE IN JAPAN}

\section{\$.1 Geotechnical}

As is the case elsewhere, it is apparent that geotechnical practices used in Japan are continuing to evolve, and in addition to adopting new practices, work is being progressively undertaken to upgrade existing structures. The latter provides the greatest challenge, as many existing facilities are constructed on natural or man made fills on weak soils that are susceptible to softening under seismic loading. The response time to plan and initiate remedial works after the earthquake was impressive, as are the resources and equipment that can be mobilised.

\subsection{Crvil Engineering and Buildings}

In Japan, buildings are designed by architectural engineers who graduate from schools of architecture and architectural engineering. Structures and facilities other than buildings, such as bridges, roads, flood protection works, dams, etc. are designed by civil engineers who graduate from civil engineering schools. Also, architectural engineers and civil engineers use different loading and materials codes and specifications. Hence it is not simple to describe the situation in Japan. However, their basic seismic design concept will be almost the same as that as the SEAOC Recommendations in California [21]. That is, the hndamental seismic performance criteria required for structures are to:

1. Resist minor earthquakes without damage.

2. Resist moderate earthquakes without structural damage, but with some non structural damage.

3. Resist major earthquakes without collapse, but with some structural as well as non structural damage, except for extremely important structures like nuclear power plants.

\subsection{Japanese Building Code}

In the Japanese building code [22], [23] \& [24], the so-called two phase method is used for the design of bulldings. The first phase of design is for moderate earthquakes which are interpreted as those which generate an elastic response of
$0.2 \mathrm{~g}$ at the base of low-rise buildings in the zones of the highest seismic intensity factor. This value corresponds to the maximum efective horizontal ground acceleration of 0.08 to $0.1 \mathrm{~g}$. For this level of earthquake, a first step elastic structural analysis is conducted using trial member sections. The member sections are determined based on the derived member actions, using allowable stress design. In the case of design of reinforced concrete buildings, the allowable compressive and tensile stresses for longitudinal reinforcing steel are the specified yield strength, and the allowable compressive stress for concrete is two-thirds of the specified compressive strength. The inter-storey drifts are required not to exceed $0.5 \%$ at this step. The above seismic design load level determination was based on the experience that old buildings, which had been designed using a base shear coefficient of $0.2 \mathrm{~g}$, seldom suffered structural damage during moderate earthquakes.

In the second phase design, the ultimate strength of each structural element designed in the previous phase is calculated. The ultimate lateral load carrying capacity of each storey is then calculated by any method including incremental non linear analysis, limit analysis and other simplified methods. Finally, the ulimate lateral load carrying capacity of each storey is checked to see whether it is sufficient against each corresponding lateral storey shear due to a major earthquake calculated from the code specifications. If the result of this check was not satisfactory, the designed sections are modified and return to the second phase design. Major earthquakes in the zones of the highest seismic intensity factor are interpreted as those which cause the maximum effective ground acceleration of 0.3 to $0.4 \mathrm{~g}$, similar to the great Kanto earthquake of 1923.

If a low-rise building with the natural period of vibration of less than about $0.4 \mathrm{~s}$ responds elastically to such earthquakes, a base shear coefficient of $1.0 \mathrm{~g}$ or more is required to be used. For ductile frame buildings, $0.25 \mathrm{~g}$ for steel structures and $0.3 \mathrm{~g}$ for reinforced concrete structures are used as the minimum base shear coefficients. These values may be increased, depending on the ductility level and the vertical and horizontal irregularities of the structure.

The above design procedures are compulsory for buildings which are 31 to $60 \mathrm{~m}$ in height, except when an equivalent or more sophisticated design method, approved by the Ministry of Construction, is used. Buildings which are more than 60 m high must be designed by a special study, usually incorporating time-history non-linear response analysis, and again the design method must be approved by the Ministry of Construction.

In the case of buildings up to $31 \mathrm{~m}$ in herght, the check of the ultimate lateral load carrying capacities of each story can be omitted if the building design for moderate earthquakes satisfies several requirements. Those requirements relate to the horizontal eccentricity of rigidity of each storey, the vertical distribution of storey rigidity, the ductility and the surplus of strength.

The above design methods using wo levels of earthquakes may help to give practitioners a more thorough understanding of structural behaviour under elastic and inelastic conditions during earthquake motions, and possibly leads to a higher protection of buildings. However, a problem with this approach is that there exists the possibility of the formation of a soft storey if the practitioners' efforts are just directed to 
meet the inter-storey drift limits and the lateral load carrying capacities required. Because of this point, the New Zealand Capacity Design method, which is explicitly aimed at the formation of beam hinge mechanism under major earthquakes, has been recommended in the "Design Guideline for Earthquake Resistant Reinforced Concrete Buildings Based on Ultimate Strength Concept [25]. In this design guide line, the inter-storey drifts are recommended not to exceed $1.0 \%$ during the major earthquake.

In general, Japanese buildings are conservatively designed and most of the modern buildings would normally suffer only minor damage even as a result of major earthquakes.

\section{COMPARISONS WITH PREVIOUS EARTHQUAKES}

\subsection{The Kushiro-Oki Earthquake}

Six months before the Hokkaido-Nansei-Oki earthquake another big earthquake with a magnitude of 7.8 occurred in the Pacific Ocean off the south-east coast of Hokkaido. This earthquake was named the Kushiro-Oki earthquake. A maximum horizontal acceleration of $0.94 \mathrm{~g}$, (NS component) was recorded in the Kushiro Local Meterological Observatory building located $14 \mathrm{~km}$ north of the epicentre. In Kushiro city itself, an intensity of JMA 6 (which corresponds to MM 9 to 11) was felt. It is of note that the area of damage due to this earthquake was also relatively small, although Kushiro is a medium size city with a population of about 211,000 . The details of the Kushiro-Oki earthquake have been reported in Kenchiku Bohsai (Building Disaster Prevention, in Japanese), the Japan Building Disaster Prevention Association, June 1993. A brief comparison of the two earthquakes follows.

The Kushiro-Oki earthquake occurred at 2006 hours on Friday 15 January 1993 . The epicentre was located at $42^{\circ} 51^{\prime}$ $\mathrm{N}$ and $144^{\circ} 23^{\prime} \mathrm{E}$. The focal depth was much deeper than that of the Hokkaido-Nansei-Oki earthquake at an estimated $107 \mathrm{~km}$. A tsunami was not generated by the Kushiro-Oki earthquake because the hypocentre was so deep. Figure 79 shows the two horizontal components and the vertical component recorded at ground level by the Kushiro Local Meteorological Observatory. The duration of strong motion is significantly shorter than that for the Hokkaido-Nansei-Oki earthquake, but the maximum acceleration recorded is much higher. Seismologists have already pointed out that the duration of strong motion normally becomes shorter as the hypocentre becomes deeper. Another aspect of this type of earthquake is that the acceleration rapidly reduces as the natural period of vibration exceeds $0.3 \mathrm{~s}$, as can be seen from the acceleration response spectra (Figure 80 ). These may be the main reasons why the damage due to the Kushiro-Oki earthquake was less severe than expected.

During the Kushiro-Oki earthquake, two people were killed by a falling chandelier, (surprisingly not due to the collapse of a house or a building), while 932 people were injured, according to the Hokkaido headquarters for emergency countermeasures, on 11 February 1993. Twelve houses collapsed, 72 houses were severely damaged, and about 3,400 houses suffered minor damage. With respect to reinforced concrete buildings, two buildings were severely damaged, another moderately damaged, and eight slightly damaged. Most of these buildings were designed according to the old seismic design code of Japan and constructed before 1974.
It is notable that two buildings designed according to the current Japanese seismic design code and enforced from 1981, were only slightly damaged. Hence it may be argued that the current seismic design code of Japan is more than adequate, and possibly rather conservative in ensuring the adequate performance of concrete buildings against severe earthquake attacks.

Destruction by fire in the Kushiro-Oki earthquake was not so severe as in the Hokkaido-Nansei-Oki earthquake. In Kushiro-City, only one house was completely burnt down, while two houses were partially destroyed and six houses damaged by fire. It is believed that most people turned off their stoves immediately the earthquake occurred, and this could have prevented the occurrence of fire. Also emergency services responded quickly because no traffic jams were reported that night.

In the Kushiro-Oki earthquake, some damage due to liquefication occurred in the port facilities and in the sewer systems constructed on the alluvium of Kushiro plain area. However, this damage was not as severe or as extensive as in the Hokkaido-Nansei-Oki earthquake. Ground damage affecting houses and buildings was usually light. The reason is not clear, but it may be because the surface soil in Kushiro area was frozen when the earthquake occurred. It may also be attributed to the comparatively deep foundations which are commonly provided for buildings in this area to prevent damage due to frost heave during winter. Roads were cut in several places due to landslides or subsidence, but no severe damage occurred to bridges. Hence there was no significant disruption of road traffic. The railway was cut in two places due to deformation of rails and the displacement of a bridge girder. The traffic between cities was maintained by long distance buses and by airlines. Since Kushiro airport was undamaged, there was no cancellation of services.

Power supply was cut to 8,200 houses in Kushiro city but restored to 5,900 houses by 2240 hours on 15 January and completely restored by 0405 hours on 16 January. The water supply was cut to 265 houses. In severely damaged areas, water was supplied by four road tankers of the Kushiro city and 10 road tankers of the Ground Self Defence Force until 20 January. The gas supply was cut to 9,390 houses due to leakage from damaged pipes but was restored completely by 6 February. Telecommunication services were maintained, although one optical fibre cable was cut due to landslide.

In conclusion, it can be said that while lifelines in Hokkaido have been disrupted in some areas due to severe earthquakes, they have been restored very quickly. The ability of the people and local government of Hokkaido to cope with natural disaster and their preparedness seems to be of a very high order.

The losses due to the Kushiro-Oki earthquake were estimated at 36,1 billion yen in Kushiro city and 4.63 billion yen in the remainder of the Hokkaido area, in total about NZ\$ 772 million.

\subsection{The 1983 Nipponkai - Chubu Earthquake}

On May 26, 1983 an earthquake of magnitude 7.7 hit off Akita prefecture in northern Honshu. The epicentre was located about $120 \mathrm{~km}$ northwest of Akita city in the Sea of Japan, a little to the south of the Hokkaido-Nansei-Oki earthquake rupture zone. These two earthquakes are both 


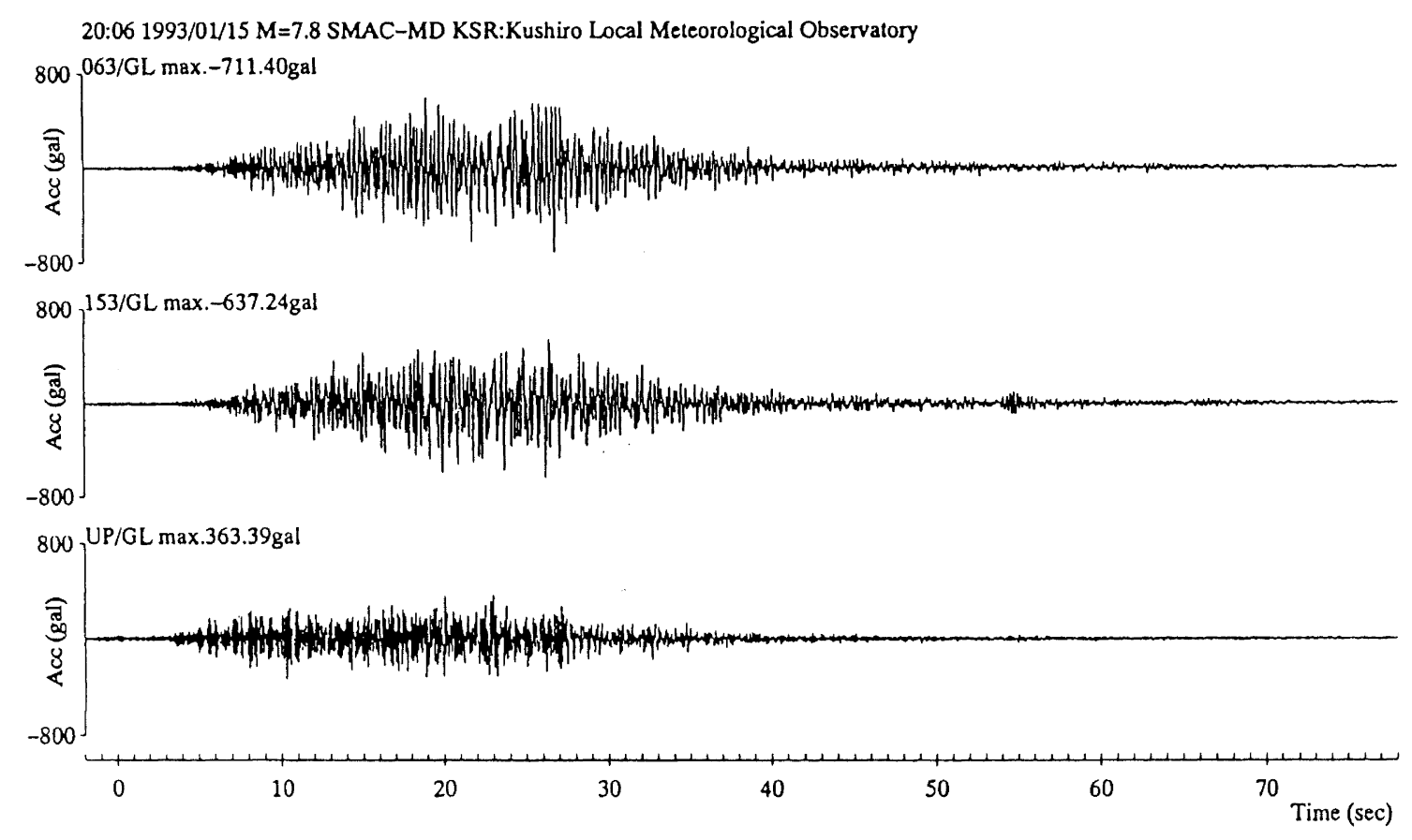

Figure 79 Kushiro-Oki Earthquake. Strong motion records from the Kushiro Local Meteological Obsenvatory produced by SMAC-MD recorder set on the ground. The epicentral distance was $14 \mathrm{~km}$.
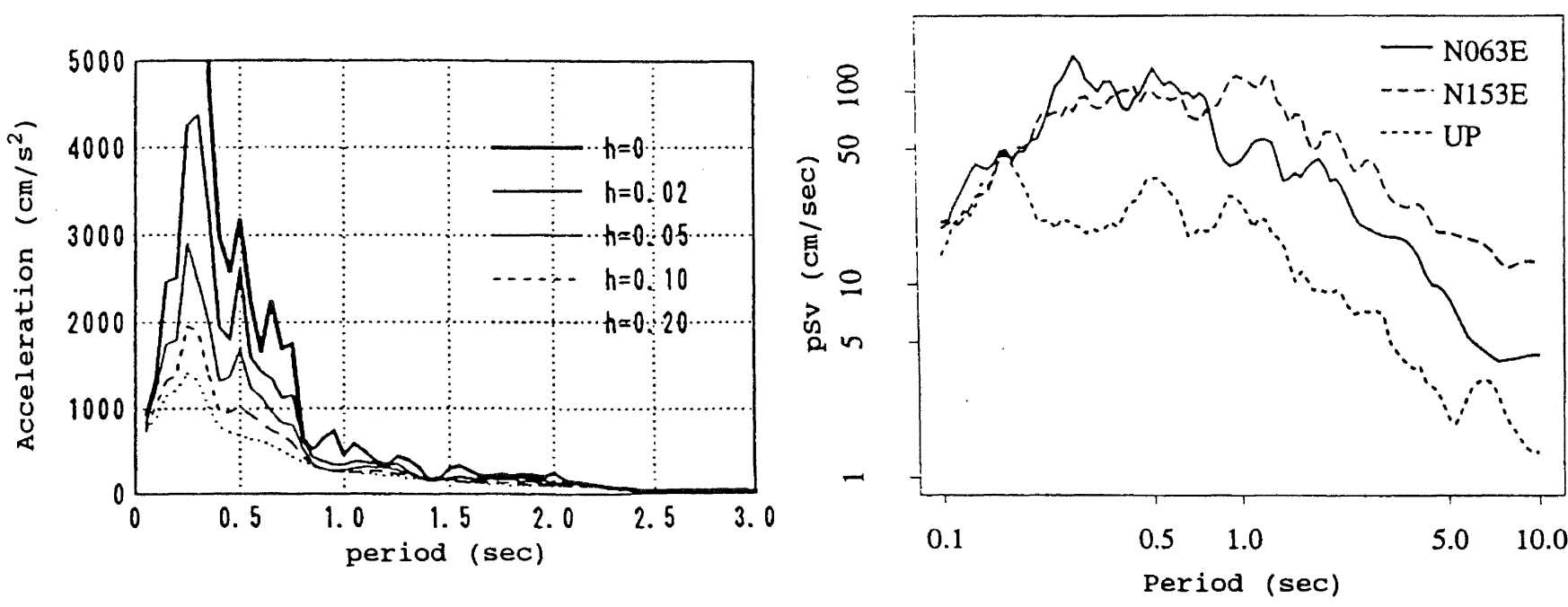

Figure 80 Kushiro-Oki Earthquake Response spectra for (left) acceleration and (right) velocity at 5\% damping based on the strong motion record obtained at the Kushiro Local Meteorological Observatory.

located on the plate boundary and nascent subduction zone situated off the east coast of northern Japan, a plate boundary which has been unexpectedly active during the last ivo years (Figure 4).

The Nipponkai-Chubu and the Hokkaido-Nansei-Oki earthquakes are very similar in many respects; they have a similar magnitude and mechanism, both generated large, destructive tsunamis, the extent of their areas of strong shaking are very similar with both earthquakes generating a maximum intensity of JMA 5 on the mainland (Figure 81), peak horizontal ground accelerations of about $0.2 \mathrm{~g}$, and similar levels of damage. The Nipponkai-Chubu earthquake caused US\$ 48 million of damage to port facilities alone.

It is of interest to note that the Nipponkai-Chubu earthquake caused no damage to Hakodate Port located some $220 \mathrm{~km}$ from the epicentre, where an intensity of JMA 3 was felt (MM intensity 5 to 6), whereas during the Hokkaido-NanseiOki earthquake an intensity of JMA 4 (MM 6 to 7 - most probably MM 7) caused extensive liquefaction damage to the port facilities at an epicentral distance of $170 \mathrm{~km}$. In New 


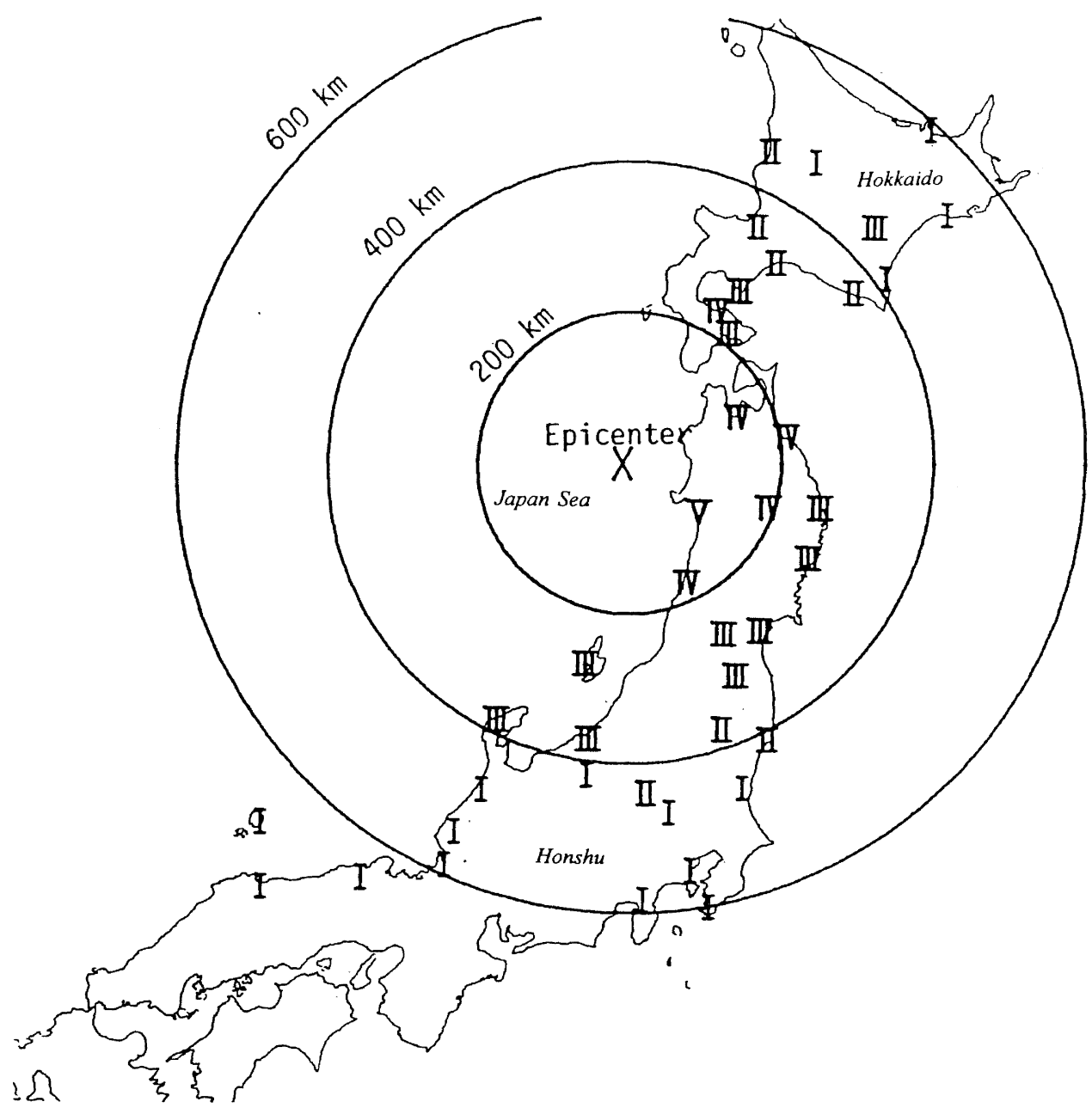

Figure 81 JMA intensities for the 1983 Nipponkai-Chubu earthquake.

Zealand MM 7 is regarded as the minimum felt intensity for the onset of liquefaction in the most susceptible soils.

\section{CONCLUSIONS}

1 Only a small number of structures were damaged or destroyed directly by ground shaking. Most of the damage to structures occurred as a result of ground damage resulting from the shaking. This includes landslides, liquefication, and subsidence. Substantial damage and destruction to port facilities at Hakodate and at other ports resulted from extensive liquefication and settlement of soft sediments and reclaimed areas.

2 The earthquake was of international importance and produced information and lessons which will be of value to all communities in their efforts to achieve greater seismic awareness and preparedness. The information and lessons include:

Information which will enable a better understanding of plate boundaries and the plate tectonics of the region.
- Tsunami generation, tsunami warning systems, and the means of advising the populace.

- $\quad$ The risk of fire following tsunami, fuel sources, fire response priorities versus rescue and casualty recovery, and alternative methods of fire service intervention.

3 The Japanese have undertaken extensive protection works for the coastal roading systems with major works to prevent damage or loss of life from falling debris. The protection works are generally constructed for protection against small, isolated rock falls due to high intensity rainfall during typhoons and winter freeze-thaw conditions. Resources in New Zealand may preclude the use of such high cost measures and the team note that there is some doubts about the effectiveness of some of the measures for earthquakes. The high hazards in constructing the systems may offset the advantages to road users, and difficulties with reinstatement also need to be considered.

4 The upgrading of the flood stopbank protection works, etc., has been progressing as funds permit. The difficulties in obtaining funding approval are probably less onerous than in New Zealand where flood protection systems are regionally and often District funded. The safety review systems applied 
in establishing the condition and risks to flood protection works are similar to those required by the Resource Management Act for work being undertaken in New Zealand.

5 One of the most interesting observations is that damage to ground can be equally as disruptive as damage to structures. Hakodate Port is severely damaged and the graving docks in particular made effectively inoperable. The cost of reinstatement, should the facility be reopened, will be very high. Ground damage at Oshamanbe destroyed a service station, severely damaged the foundations of buildings and will require shape correction works to be carried out on roading. Rehabilitation works will also be required to the approach roading to the bridge at Horonai. This may significantly delay the opening of the new coastal road. By contrast, damage to services due to the earthquake shaking was not extensive. This is because the ground damage occurred remote from more developed areas.

6 It was interesting to observe that in many of the areas where there had been ground damage affecting structures, small drilling rigs were carrying out investigation core drilling with regular SPT testing.

7 The deployment of elements of the Japan Self-Defence Forces and specialised police units into the disaster area was extremely rapid and effective. Their combined available resources are large, and their medical, rescue, communications, supplies, and clean-up teams played an essential part in the effectiveness of the emergency services response to the earthquake. The response of the Hokkaido Development Board, local Government and transport departments to the emergency was also impressive, with some major repair works completed and many more planned and in the process of construction.

8 The Hokkaido earthquake showed that devastating tsunamis can strike very quickly after an earthquake and cause enormous damage and loss of life, even in Japan where people are highly aware of the tsunami danger. However there is good evidence that local awareness and experience with tsunamis led to the immediate evacuation of some tsunami prone villages and helped to avoid greater loss of life.

\section{LESSONS FOR NEW ZEALAND}

1 The damage to the stop banks and flood protection works in the Shiribetsu and Shiribeshi-Toshibetsu River valleys of Hokkaido is an example of the likely effect that ground shaking could cause in a number of flood prone areas in New Zealand. In the Wellington region, studies have identified liquefication susceptible soils in urban developed areas on which stop banks and flood protection works are founded and which could be damaged as a result of ground shaking [26]. There are also a number of rural areas where similar risks exist. Depending upon the assessed risks of flooding, the requirements and the construction time involved for permanent repairs, different approaches to temporary repairs or protection works could apply to urban areas as compared to rural areas. Temporary protection solutions could range from the driving of steel sheet piling, which is costly but was used extensively in Hokkaido, down to the cheaper option of levelling of stop banks to avoid catastrophic failure during floods.
2 In Japan there have been a number of large offshore earthquakes this century (Figure 3), many of which have generated tsunamis. In the same period in New Zealand there have been no large (magnitude $\geq 7.4$ ) offshore earthquakes. However this does not mean that large offshore earthquakes cannot occur in New Zealand (the tectonic environment is similar to that of Japan) but it does indicate that the incidence of tsunamis in New Zealand is significantly less. Further studies are required to quantify the tsunami hazard in New Zealand and to identify areas at risk.

3 In general, the stock of light timber framed housing in New Zealand is likely to perform as well to strong shaking and to tsunami attack as did the Japanese houses in the Hokkaido earthquake. The amount of debris, the difficulty of access, and the lack of water for conventional urban firefighting was highlighted by the fire that followed the tsunami at Aonae. As a realistic model to illustrate tsunami damage, and for the development of a more effective means of fire intervention, the Aonae district should be studied by the New Zealand Civil Defence and Fire Service, and the lessons applied to those areas of New Zealand identified as being at risk from tsunami.

4 In Japan, the generally older and less well compacted fills (bridge approaches at abutments, road and rail embankments, stopbanks, and harbour reclamations) settled and spread during the earthquake shaking stronger than MM Intensity 7. Similar ground damage is likely to occur in New Zealand where many old fills and stopbanks were constructed by end tipping and harbour reclamations constructed by hydraulic fill methods. Although there is a general awareness of this in New Zealand, more needs to be done to identify places at risk from earthquake induced ground damage, the nature and extent of repairs that may be required following an earthquake, and the remedial works that might be appropriate.

5 Expectations in a modern society are high and where temporary housing is provided for homeless families, the temptation to transfer people to these before the units are fully complete should be avoided. Otherwise loss of morale and wellbeing can occur rapidly. Full completion includes all services, footpaths, drainage and roading.

6 Well funded and supported seismic and strong motion instrument networks are vital for recording basic earthquake data in seismically active countries. Such data is essential, together with supporting research and funding, for determining realistic seismic and tectonic models of the country.

7 A feature of the Hokkaido earthquake was the important role of the Japan Self Defence Forces and the Hokkaido Development Bureau in the response phase and the HDB in the recovery phase. The resources available in New Zealand from the Defence Forces for a similar event are likely to be very much smaller. This will place a greater load on Civil Defence at all levels, and will require more self-help by those who become the victims of the event. With the changes that have occurred to Government Departments in the last decade, and the demise of the Ministry of Works, there is now uncertainty as to their ability to be able to respond in such an emergency. It is unlikely that a Regional Council in an affected area would have the resources to take over the role of the former Government Departments such as the MOW in the response and recovery phases of a large 
earthquake. In Hokkaido this role was effectively carried out by the HDB. Methods for the management of consultants, construction organisations, and builders for damage evaluation, planning, design, costing, emergency repairs, permanent repairs, and reconstruction need to be discussed with the construction and insurance industries. The systems agreed on should cover all the phases following the earthquake.

8 The level of seismic awareness and preparedness of both the public and local authorities appeared to be much higher in Japan than in New Zealand (even when allowance is made for the effect of the Hokkaido earthquake just two weeks before the arrival of the reconnaissance team. Professional bodies need to work more closely with the Ministry of Civil Defence, the emergency services, and the media to raise public awareness of the earthquake hazard in New Zealand, and to identify the precautions that can be taken to reduce the impact on the individual, the family, and the community.

\section{ACKNOWLEDGEMENTS}

The New Zealand Earthquake Reconnaissance Team wishes to thank most sincerely the following people for their kind assistance before and during the visit to Hokkaido.

Immediately after the event, first hand information on the earthquake and the accompanying tsunami was provided by Professors S Otani, K Ishihara and T Katayama, of the University of Tokyo, Professor $\mathrm{O}$ Joh, of Hokkaido University, Dr $\mathrm{K}$ Sakai, of the Hokkaido Development Bureau, and Dr M Nishiyama, of Kyoto University. Based on this information, the New Zealand National Society for Earthquake Engineering decided to send a field team to Tokyo and Hokkaido to collect more detailed information.

During the visit to the University of Tokyo, Professors $S$ Otani, K Ishihara, Y Tsuji, Dr A Tasai, and Mr Lee Sangho provided invaluable information and some detailed analyses on the earthquake and the tsunami.

In Hokkaido, Professors O Joh, S Toki, and Dr Yamashita, of Hokkaido University, provided invaluable information and also accompanied the team to several sites where earthquake damage occurred. Very detailed information on the damage to roads, river protection works and port facilities was provided by Messrs K Fukuda, H Seki, T Jonishi, A Shimohata, and Y Shimoyama, of the Hokkaido Development Bureau.

The details on the organisation for disaster prevention and emergency services in the case of a small town, was obtained from Mr Y Yamamoto, of the Iwanai town office.

Special thanks are due to Dr K Sakai, Messrs A Shimohata, and Y Shimoyama, of the Hokkaido Development Bureau, who made special arrangements to allow the team to enter the restricted areas on Okushiri Island and in Hakodate.

The assistance of the Earthquake Commission in providing funds for the teams travel costs is gratefully acknowledged.

\section{REFERENCES}

1. Yoshikawa, T., Kaizuka, S., Ota, Y., (1981), "The Landforms of Japan", University of Tokyo Press, Tokyo.

2. Satake, K., (1985), "The mechanism of the 1983 Japan Sea earthquake as inferred from long-period surface waves and tsunami's", Physics of the Earth Planet Interiors, 37, 249-260.

3. Satake, K., (1986), "Re-examination of the 1940 Shakotan-oki earthquake and the fault parameters of the earthquakes along the eastern margin of the Japan Sea", Physics of the Earth Planet Interiors, 43, 137-147.

4. Sangawa, A., Kinugasa, Y., Kakimi, T., (1984), 1:500,000 Neotectonic Map, Sheet 4, Sapporo, Geological Survey of Japan.

5. Ota, Y., Matsushima, Y., Unutsu, M., Kanawa, T., (1987), "Middle Holocene Shoreline Map of Japan, 1:2,000,000", Yokahama National University.

6. EERI Newsletter, Special Earthquake Report, (1993), "Special Edition - The July 12, 1993, Hokkaido-NanseiOki earthquake", August.

7. Seismological Society of Japan, Programme and Abstracts, (1993), No. 2.

8. Research Group for Active Faults of Japan, (1991), 1:3,000,000 Quaternary Tectonic map.

9. Tanioka, Y., Ruff, L., (1993), "Mechanism of the 1993 S W Hokkaido earthquake", Seismological Society of Japan, programme and abstracts.

10. Campbell, K.W., (1981), "Near source attenuation of peak horizontal acceleration", Bulletin of the Seismological Society of America, 71(6): 2039-2065.

11. Franks, C.A.M., Beetham, R.D., Salt, G.A., (1989), "Ground damage and seismic response resulting from the 1987 Edgecumbe earthquake, New Zealand", New Zealand Journal of Geology and Geophysics, 32, 135144.

12. Yamazaki, F., Meguro, K., Katayania, T., (1993), "A Quick Look Report on the Hokkaido-Nansei-Oki Earthquake, 12 July 1993", Incede Newsletter, Institute of Industrial Science, The University of Tokyo.

13. Manichi Newspaper, 14 July 1993.

14. Walter C. Dudley and Min Lee, (1988), "Tsunami", University of Hawaii Press.

15. De Lange, W.P., Healy, T.R., (1986), "New Zealand tsunamis 1840 - 1982", New Zealand Journal of Geology and Geophysics, 29, 115-134.

16. Daily Asahi, 14 July 1993.

17. Daily Hokkaido, 28 July 1993.

18. Daily Yoniuri, 14 July 1993. 
19. Daily Asahi, 15 July 1993.

20. Asahi Evening News, 13 July 1993.

21. Seismology Committee, Structural Engineers Association of California, (1975), "Commentary on the Fourth Edition of the Recommended Lateral Force Requirements", pp. 84.

22. The Ministry of Construction, Housing Bureau and Building Research Institute, (1980), "Commentary on the Structural Calculation based on the Revised Enforcement Order", the Building Standard Law (in Japanese)", Building Centre of Japan, November, pp173.

23. Umemura, H. (coordinating editor), (1979), "New Earthquake Resistant Design (in Japanese)", Building Centre of Japan, May.

24. Aoyama, H., (1981), "Outline of Earthquake provisions in the Recently Revised Japanese Building Code", Bulletin of The New Zealand National Society of Earthquake Engineering, 14(2), 63-80.

25. Architectural Institute of Japan, (1988), "Design Guideline for Earthquake Resistant Reinforced Concrete Buildings Based on Ultimate Strength Concept".

26. Van Dissen, R.J., (1991), "Ground shaking hazard map for Lower Hutt and Porirua areas: a summary report", DSIR Contract Report No. 1991/42 - prepared for the Wellington Regional Council, pp. 41. 


\section{APPENDIX 1}

Details and Timings of the Reconnaissance

Date Time Event

July 1993

25 am

1. The team assembled for initial briefing and allocation of tasks and responsibilities at Auckland Airport. Travel to Japan.

pm 2. Arrived at Tokyo - Narita Airport.

$\mathrm{am} / \mathrm{pm}$ 3. Briefings at University of Tokyo.

pm 4. Team flew to Sapporo - Hokkaido.

am 5. Briefings on damage to roads ports and river protection, Hokkaido Development Bureau (HDB).

pm 6. Briefings on Earthquake damage University of Hokkaido - Sapporo.

am/pm 7. Hired rental car and accompanied reconnaissance groups from Universities of Tokyo and Hokkaido and local geotechnical consultants inspecting ground damage and damage to lifelines. Visited Lake Toya, Oshamanbe, Esashi, Shiribetsu River.

am

8. Stayed overnight at Esashi. Inspected damage to bridges Motoei, Yanagizaki, and ground damage. Also damage to lifelines and flood protection with HDB area officer. Inspected temple at Esashi and overturned tombstones.

am/pm 9. Travelled to Okushiri Island by ferry with rental car.

pm 10. Met HDB area officer and travelled to Aonae at the south end of Okushiri Island and off the west coast of the island.

am 11. Stayed overnight in the HDB offices and returned to Aonae for a more detailed inspection of damage to structures, fire and tsunami as well as ground damage. Team divided into two groups.

am 12. Travelled to the north end of Okushiri Island to inspect damage to housing and smaller buildings from tsunami and ground damage. Team working in two groups.

13. Travelled back to Setana Hokkaido by ferry.

pm 14. Visited damaged tunnel and talus shelters on Highway 229 north of Setana with the geotechnical group from University of Hokkaido.

pm 15. Travelled by road to Hakodate.

$\mathrm{am} / \mathrm{pm}$ 16. Inspected damage to the port facilities at Hakodate.

August

1

am/pm 17. Stayed overnight in Hakodate and travelled north to inspect damage at Port Mori, Oshamanbe, Shiribetsu River, and Iwanai-Cho.

2

In Summary

Period being briefed

Period in the field

Period travelling

Total

am

$\mathrm{am} / \mathrm{pm} 19$

$\mathrm{pm}$

am/pm 21. Arrived back in New Zealand

Stayed overnight in Hotel Kato at Iwanai. Inspected damage to Town Hall and fire station at Iwanai and to the Higashi-Nihon ferry terminal. Unable to visit nuclear power station at Tomari-Mura.

Travelled by road back to Sapporo and flew to Tokyo - Narita Airport.

. Travel from Narita Airport to New Zealand.

\section{Days}

6

2

$\underline{10}$

\section{APPENDIX 2}

The Sequence of Events and Response of Emergency Services

12 July

22:17

A major earthquake of magnitude 7.8 occurs.

22:20 An evacuation order is issued to Tanohata-mura (village), Iwate Prefecture, north-east coast of Honshu.

22:21-22 The first tsunami wave arrives at Okushiri and floods houses at about floor level. This was not as significant as the second tsunami attack about ten minutes later.

22:22 A Major-tsunami alert is issued for the coast of Hokkaido facing the Japan Sea, a tsunami alert is issued for the coast of Hokkaido facing the Pacific Ocean and to the coast of the northern part of Honshu facing the Japan Sea by the Sapporo Meteorological Observatory. Tsunami warnings are also issued for the regions shown in Figure 37.

An evacuation order or recommendation is also given for these regions.

A special office for earthquake policing is established in the Hokkaido Police Headquarters. A disaster relief headquarters is also established in the Hokkaido Prefectural Government Office.

22:30-33 The second tsunami wave washes houses away on Okushiri Island.

The Hokkaido Prefectural Government gives instructions on precautions to be taken in the 14 provinces of Hokkaido, based on the first report from the Sapporo Meteorological Observatory. 
22:40 Observations of the tsunami are reported from several areas.

23:00 A fire breaks out at Aonae area in Okushiri Island. At Esashi port, on the west coast of Hokkaido, a 2,500 tonne floating dock with three people on board is washed away by the tsunami. A patrol boat of the Hakodate Maritime Safety Agency is dispatched to rescue it. 200 people are evacuated in Hachimori-cho, Akita prefecture, north-west of Honshu, where 10 people died due to the Nihonkai-chubu-oki Earthquake of 26 May 1983.

23:05 On Tobishima Island 40km off Sakata-shi, Yamagata prefecture, north west of Honshu, fishing boats are ordered to leave the harbour and move to the open sea. By 23:10, 40 to 50 boats have departed.

23:18 To avoid tsunami attack, three night trains with sleeping cars and three ordinary trains evacuate to nearest stations between Akita and Sakata, north west coast of Honshu.

23:19 The first tsunami observation at Hukaura in Aomori prefecture, the northern extremity of Honshu, is reported.

13 July

00:00 The Hokkaido Police Headquarters is informed that houses on Okushiri Island have been destroyed by the tsunami and subsequent fire.

00:30 -Helicopters of the Hokkaido Police Headquarters are dispatched to investigate the disaster areas.

-The Hokkaido Prefectural Government decides to apply the Disaster Relief Act to the town of Okushiri.

00:45 The disaster relief emergency headquarters of the Hokkaido Prefectural Government, is informed that the Yoh-yoh-so Hotel on Okushiri Island has been totally engulfed by a landslide and 20 to 30 people have been buried alive.

01:32 The police branch office at Aonae, Okushiri Island, reports that about a third of the 680 houses in the area have been destroyed by the tsunami and about 340 houses are on fire, but the details of damage have yet to be fully investigated.

02:00 In the city of Niigata, north-western Honshu, 7 schools are opened as evacuation centres.

03:50 The tsunami alert and warning given to the coast areas facing the Pacific Ocean is cancelled.

04:45 A transport ship, Nemuro, belonging to the Maritime Self Defence Force, is dispatched from Aomori at the northern extremity of Honshu to Okushiri Island, carrying medical supplies and 8,500 meals.
05:16 Seven doctors and 23 nurses arrive at Okushiri Island from Sapporo by helicopters belonging to the Ground Self Defence Force.

05:37 Twenty one rescuers arrive at Okushiri-Island from the Kucchan Base of Ground Self Defence Force, western Hokkaido.

06:00 The Hokkaido Prefectural Government decides to apply the Disaster Relief Act to the town of Taisei located on the west coast of Hokkaido.

07:00 -The Meteorological Agency names the earthquake as the Hokkaido-Nansei-Oki Earthquake.

-The Tsunami alert and warning given to the coast areas facing the Japan Sea is cancelled. -The prefectural governor of Hokkaido, Mr T Yokomichi, is appointed as the head of the earthquake disaster relief emergency organisation established by the Hokkaido Prefecture Government.

11:00 The Japanese Government establishes a disaster relief headquarters The head is $\mathrm{Mr} \mathrm{T}$ Inoue, Minister of the National Land Agency. Some members of the National Land Agency, the Meteorological Agency and the Hokkaido Development Bureau are summoned, and the first meeting is held.

11:30 The National Police Agency establishes a policing headquarters for the Nansei-Oki Earthquake. The head is the director of the Security Bureau of the National Police Agency.

Afternoon: The Hokkaido Prefectural Government decides to apply the Disaster Relief Act to the town of Setana and the village of Shimamaki located on the west coast of Hokkaido.

Evening: The fire in Aonae is extinguished.

14 July

Morning: The Hokkaido Prefectural Government decides to apply the Disaster Relief Act to the town of Kita-Hiyama located on the west coast of Hokkaido.

Afternoon: The National Government confirms the provision of compensation funds to those who lost family members or who were injured.

15 July

Afternoon: - The ferry service between Setana and Okushiri-island is re-opened. A shipping service to transport medicines and food is established. - The Meteorological Agency reports that the velocity of the tsunami was $652 \mathrm{~km}$ per hour and the successive tsunami waves attacked about every ten minutes, based on reports from the branch offices.

Evening: Electric power supply is restored in the Aonae area, Okushiri-Island, where damage was most severe. 


\section{APPENDIX 3}

\section{Outline Disaster Response and Recovery Plan of the Municipal Government of Iwanai-Cho}

When a disaster occurs or is predicted, the following organisation is established based on the manual entitled "Guidelines for Disaster Prevention Planning and Flood Prevention Planning of Iwanai-Cho".

Head: Mayor

(1) General Affairs Division

- (a) General Affairs Section

(i) Establishment and management of the Emergency Headquarters

(ii) Security of power supply and communication system

(iii) Urgent requests of help to the Self Defence Force

(iv) Reports to the Hokkaido Prefectural Government and the National Government

(v) Others which will not be dealt by other divisions

(2) Planning and Adjustment Division

- (a) Planning Section

(i) Collection and distribution of information on the disaster and weather forecasts

(ii) Security of communication and transportation with disaster area

(iii) Countermeasure planning etc.

- (b) Public Information Section

(i) Issue of emergency warning, evacuation recommendation and order, and issue of an all clear, etc

(3) Investigation Division

- (a) Investigation Section

(i) Collection of damage investigation reports, etc

(4) Treasury Division

- (a) Financial Management Section

(i) Establishment of recovering funds, etc

- (b) Transportation Section

(i) Transportation of relief parties, goods, evacuees, etc

(5) Division of Relief and Protection of the Sufferers

- (a) Relief and Protection Section

(6) Commodities Division

- (a) Goods Section

(i) Delivery of emergency foods, boiled rice, etc

- (b) Water Supply Section

- (c) Agriculture, Forest and Fishery Section

(i) Regulation of product prices

(ii) Protection of tourists, etc
(7) Construction Division

- (a) Management Section

(i) Planning for delivery of emergency goods, etc

(ii) Planning for recovery work etc

- (b) Facilities Section

(i) Restoration of roads, bridges, port facilities, community centres

(ii) Disposal of debris etc

(8) Education Division

- (a) School Section

(i) Evacuation of school pupils

(ii) Supply of school meals and stationery, etc

-(b) Facilities Section

(i) Establishment of evacuation centres

(ii) Restoration of education facilities

(iii) Protection of the cultural properties, etc

Note: (1) Number of facilities able to provide emergency boiled rice is 13 and 4,910 meals can be prepared at one time.

(2) Four water treatment units are available and four water supply sets (filtration capacity 120 litre/minute/set) will be provided by the Self Defence Force in an emergency. Maximum water supply capacity 144,000 litre/set/day. Number of water supply tankers 3 number.

(3) Stock of port protection materials for oil spillage.

- Oil boom, $200 \mathrm{~m}$, oil absorbing materials $400 \mathrm{~kg}$

- Oil dispersal chemical agent 504,000 litre

(4) High risk areas susceptible to flooding: Area $=1.9$ ha, number of houses with high risk 33 number. Length of coast line with a high risk from tsunami or high tide:

District $1=3,308 \mathrm{~m}$

District $2=4,683 \mathrm{~m}$

District $3=13,917 \mathrm{~m}$

District $4=1,705 \mathrm{~m}$

(5) Places which can be used as emergency landing areas for helicopters - 11 places $220,259 \mathrm{~m}^{2}$ 


\section{APPENDIX 4}

Comparison of the JMA and MM Intensity scales

\begin{tabular}{|c|c|c|c|c|c|c|c|c|c|c|c|}
\hline JMA & 0 & 1 & & 2 & 3 & & 4 & 5 & 6 & 7 & 8 \\
\hline ODIFIED MERCALLI & 1 & II & III & IV & v & VI & VIIIV & IIII 11 & $x$ & $X I$ & XII \\
\hline ROSSI-FOREL & 1 & 11 & III & $\mathrm{N}$ & v & vi $\mathrm{V}$ & VIII VIII & IX & $x$ & & \\
\hline
\end{tabular}

The Japan Meteorological Agency Intensity Scale (JMA)

Summary

$0=$ No feeling: Registered by seismographs only

1 = Slight: felt by some individuals at rest

2 = Weak: felt by most people

3 = Rather strong: shaking of houses and buildings

4 = Strong: strong shaking of houses and buildings and unstable objects fall over

5 = Very strong: cracking of plaster walls, heavy objects such as tombstones and stone lanterns fall over, and damage to masonry chimneys and mud-plastered warehouses

6 = Disastrous: collapse of up to $30 \%$ of wooden houses, numerous landslides and embankment failures, fissures on flat ground

7 = Very disastrous: collapse of more than $30 \%$ of wooden houses, falling of objects wavy deformation observed in horizon

Source of the Approximate Comparison of Earthquake Intensity Scales;

M.D. Trifunac and A.G. Brady. "One the correlation of seismic intensity scales with the peaks of recorded strong ground motion, "Bulletin of Seismological Society of America, Vol. 65, 1975. 